\title{
AVALIAÇÃO DOS OSSOS MAXILARES E DE LESÕES PERIAPICAIS INDUZIDAS EM RATAS OVARIECTOMIZADAS SUBMETIDAS OU NÃO AO TRATAMENTO COM BISFOSFONATO OU COM INIBIDOR DA CATEPSINA K
}

Tese de Doutorado apresentada à Faculdade de Odontologia de Ribeirão Preto da Universidade de São Paulo para a obtenção do título de Doutor em Ciências. Programa: Odontopediatria.

Área de Concentração: Odontopediatria.

Orientador: Prof. Dr. Paulo Nelson Filho

Co-orientadora: Profa. Dra. Raquel Assed Bezerra SEGATO 


\section{AUtORIZAÇÃo PARA RePROdUÇÃo}

Autorizo a reprodução e divulgação total ou parcial deste trabalho, por qualquer meio convencional ou eletrônico para fins de estudo e pesquisa, desde que citada a fonte.

\section{Priscilla COUTINHo Romualdo}

\section{Ficha Catalográfica}

Romualdo, Priscilla Coutinho

Avaliação dos ossos maxilares e de lesões periapicais induzidas em ratas ovariectomizadas submetidas ou não ao tratamento com bisfosfonato ou com inibidor da catepsina K. Ribeirão Preto, 2017.

127p. : il. ; $30 \mathrm{~cm}$

Tese de Doutorado apresentada à Faculdade de Odontologia de Ribeirão Preto da Universidade de São Paulo (FORP-USP) - Área de concentração: Odontopediatria.

Orientador: Prof. Dr. Paulo Nelson Filho

Co-orientadora: Profa. Dra. Raquel Assed Bezerra Segato

1. Ovariectomia 2. Osteoporose 3. Lesão periapical 4. Bisfosfonato 5. Alendronato 6. Odanacatib 


\section{FOLHA DE APROVAÇÃo}

Romualdo PC. Avaliação dos ossos maxilares e de lesões periapicais induzidas em ratas ovariectomizadas submetidas ou não ao tratamento com bisfosfonato ou com inibidor da catepsina $\mathrm{K}$.

Tese de Doutorado apresentada à Faculdade de Odontologia de Ribeirão Preto da Universidade de São Paulo para a obtenção do título de Doutor em Ciências Programa: Odontopediatria.

Área de Concentração: Odontopediatria.

Data da defesa:

\section{BANCA EXAMINADORA}

Prof(a). Dr(a): :

Julgamento: Assinatura:

Prof(a). Dr(a).:

Julgamento: Assinatura:

Prof(a). Dr(a).:

Julgamento: Assinatura:

Prof(a). Dr(a).:

Julgamento: Assinatura:

Prof(a). Dr(a).:

Julgamento: Assinatura: 



\section{Priscilla Coutinho Romualdo}

Dados CurRiculares

Nascimento 03 de janeiro de 1989 - Ipuã/SP.

Filiação Itamar Romualdo.

Rosângela Coutinho.

2007-2010 Curso de Graduação em Odontologia.

Faculdade de Odontologia de Ribeirão Preto - FORP/USP.

2009-2010 Iniciação Científica - Projeto de pesquisa intitulado "Utilização do localizador eletrônico foraminal iPex para odontometria - Estudo ex vivo em molares decíduos" (bolsa CNPq). Orientador: Prof. Dr. Paulo Nelson-Filho.

2011-2013 Curso de Especialização em Odontopediatria.

Associação Odontológica de Ribeirão Preto - AORP - Monografia intitulada "Eficácia in vivo do curativo de demora à base de hidróxido de cálcio, associado ou não ao digluconato de clorexidina, em dentes humanos decíduos com necrose pulpar e lesão periapical". Orientadora: Profa. Dra. Léa Assed Bezerra da Silva; Co-orientador: Prof. Dr. Paulo Nelson Filho.

2011-2013 Curso de Pós-Graduação em Odontopediatria, nível Mestrado. Faculdade de Odontologia de Ribeirão Preto - FORP/USP - Dissertação intitulada "Sistemas de irrigação de canais radiculares: Avaliação radiográfica, histopatológica, histomicrobiológica e histoenzimológica, em dentes de cães com lesão periapical" (bolsa CAPES). Orientador: Prof. Dr. Paulo Nelson-Filho.

2015-2017 Curso de Especialização em Acupuntura.

Fundação Odontológica de Ribeirão Preto - FUNORP - Monografia intitulada "A acupuntura no tratamento da neuralgia do nervo trigêmeo". Orientadora: Profa. Dra. Maria Cristina Borsatto. 

Trabalho desenvolvido nos Laboratórios de Histologia, Biologia Molecular e Cultura de Células do Departamento de Clínica Infantil da Faculdade de Odontologia de Ribeirão Preto - Universidade de São Paulo, no Laboratório de Bioengenharia da Faculdade de Medicina de Ribeirão Preto - Universidade de São Paulo e no Laboratório de Microbiologia, Imunologia e Biologia Molecular - Universidade de Guarulhos, sob a orientação do Prof. Dr. Paulo Nelson Filho, com apoio financeiro da Fundação de Amparo à Pesquisa do Estado de São Paulo (Processos FAPESP no 2013/18231-9 - Auxilio Regular e 2014/13238-8 - Bolsa de Doutorado). 



\section{Dedicatória}

\section{A Deus...}

Pela graça da vida.

Por me guiar pelos melhores caminhos.

Pela presença e conforto constantes.

Por me presentear com pessoas maravilhosas.

Pela oportunidade de mais uma conquista!

"Tornaste o meu pranto em folguedo

Desataste o meu pano de saco, e me cingiste de alegria

para que a minha glória a ti cante louvores, e não se cale

Senhor, meu Deus, eu te louvarei para sempre"

\section{Salmos 30:11,12.}

\section{Ao meu orientador Prof. Dr. Paulo Nelson-Filho...}

Porque foi o meu grande parceiro nessa jornada e sei que está tão feliz quanto eu ao ver os frutos do nosso trabalho.

Obrigada pela paciência e pela grande dedicação.

Obrigada por todos os ensinamentos.

Obrigada por sempre ter acreditado em mim e me incentivado, mesmo quando eu escolhi seguir por caminhos diferentes.

Professor, eu tenho muito orgulho de ser sua aluna e da relação de respeito e confiança que construímos ao longo desses anos.

Serei sempre grata a Deus por ter te colocado no meu caminho e grata a você pela forma gentil e generosa que sempre me orientou! 



\section{Agradecimentos Especials}

Aos meus amados pais...

\section{Rosângela Coutinho e Itamar Romualdo}

Pelo apoio e amor incondicionais. Por sempre me proporcionarem condições para realizar os meus sonhos. Por serem meus exemplos de vida e minha inspiração e serem tão fortes e guerreiros. A minha admiração e o meu amor são tão grandes quanto a gratidão que eu sinto por ser filha de vocês!

Aos meus amados irmãos e sobrinhos...

Carlos Henrique Romualdo, Flaveline C. Romualdo de Andrade, Itamar Romualdo Jr., Carolina M. Romualdo, Carlos Henrique Romualdo Jr. e Matheus Romualdo de Andrade Por todo apoio e amizade. Pela imensa alegria que me proporcionam todos os finais de semana. Por serem minhas fontes de motivação. Amo muito vocês!

Ao meu noivo...

\section{Raphael Felipe Matos dos Santos}

Por sempre me dar força e me apoiar em todos os momentos. Pela motivação e paciência diárias. Pela alegria de viver que contagia todos a sua volta. Por sempre trazer luz e otimismo para minha vida. Obrigada por fazer parte da minha vida de uma forma tão presente, meu amor!

A todos os meus familiares e amigos...

Que sempre torceram por mim e que também fazem parte dessa conquista. Agradeço a Deus todos os dias por ter colocado vocês na minha vida. Eu me sinto muito abençoada $e$ grata por ter tantas pessoas maravilhosas ao meu redor!

"A minha familia é benção do Senhor Me ensina a tratar minha familia com amor

Edifica minha casa para o teu louvor A minha familia é um presente do senhor Te agradeço pela minha familia

e por tua presença no meu lar Te agradeço pelo pão de cada dia que o senhor nunca deixou faltar" 


\section{Agradecimentos Especials}

\section{À minha co-orientadora Profa. Dra. Raquel Assed Bezerra Segato,}

Por sempre estar presente e de portas abertas nos momentos que precisei. Muito obrigada pela disponibilidade e por sempre me receber com tanta generosidade e carinho. Você transmite muito otimismo e alegria, motivando a mim e a todos ao seu redor!

\section{À Profa. Dra. Léa Assed Bezerra da Silva,}

Por todas as oportunidades a mim oferecidas e pela grande contribuição na minha formação acadêmica. Obrigada por todos os ensinamentos. É uma honra poder contar com a sua ajuda e experiência. Você é um exemplo de amor e respeito à profissão!

\section{Ao Dr. Francisco Wanderley Garcia de Paula e Silva,}

Por todas as contribuições sempre tão pertinentes, neste e em outros trabalhos. Você é um exemplo de profissional completo e generoso, sempre disposto a ajudar e a ensinar. Aprendi muito com você durante a Pós-Graduação. Obrigada por tudo!

\section{À amiga Marîlia Pacífico Lucisano,}

Porque eu não conheço pessoa mais doce, delicada e gentil. Você sempre foi minha "madrinha" em todo o meu trajeto na Pós-Graduação. Obrigada por toda ajuda, sempre com tanta generosidade e carinho. Desejo sempre estar ao seu lado para continuarmos aprendendo juntas e compartilhando momentos tão agradáveis! 


\section{Agradecimentos}

À Universidade de São Paulo, na pessoa do atual Reitor, Prof. Dr. Marco Antônio Zago, e do Vice-Reitor, Prof. Dr. Vahan Agopyan.

À Faculdade de Odontologia de Ribeirão Preto da Universidade de São Paulo, na pessoa da atual Diretora, Profa. Dra. Léa Assed Bezerra da Silva e do Vice-Diretor, Prof. Dr. Arthur Belêm Novaes Jūnior.

À Fundação de Amparo à Pesquisa do Estado de São Paulo (FAPESP), pela bolsa de doutorado (Processo FAPESP no 2013/18231-9) e pelo auxilio à pesquisa (Processo FAPESP no 2014/13238-8) concedidos.

À Coordenação do Curso de Pós-Graduação em Odontopediatria da Faculdade de Odontologia de Ribeirão Preto da Universidade de São Paulo, na pessoa da Coordenadora, Profa. Dra. Raquel Assed Bezerra Segato e da Vice-Coordenadora Profa. Dra. Léa Assed Bezerra da Silva.

Aos professores da disciplina de Odontopediatria da Faculdade de Odontologia de Ribeirão Preto da Universidade de São Paulo:

Profa. Dra. Aldevina Campos de Freitas, exemplo de amor e dedicação à Odontopediatria. Obrigada pela simpatia e por todos os ensinamentos transmitidos.

Profa. Dra. Alexandra Mussolino de Queiroz, por todo apoio a mim oferecido desde a graduação, por todos os ensinamentos clínicos e pela forma generosa e alegre que sempre me recebe.

Profa. Dra. Andiara De Rossi Daldegan, por ser sempre tão receptiva e carinhosa todas as vezes que conversamos.

Prof. Dr. Fabrício Kitazono de Carvalho, por estar sempre disposto a ajudar, com alegria e generosidade.

Profa. Dra. Maria Cristina Borsatto, pela alegria que contagia todos ao seu redor e pela convivência tão agradável. Obrigada por todos os ensinamentos e pelas palavras de incentivo e motivação.

Profa. Dra. Kranya Victoria Díaz Serrano, pelo carinho e atenção. Obrigada por todo o apoio e por ser sempre tão receptiva e agradável. 
Profa. Dra. Maria da Conceição Pereira Saraiva, professora da Disciplina de Epidemiologia. Muito obrigada pelo apoio e incentivo desde a graduação. Nunca esquecerei todas as suas palavras de motivação para que eu continuasse na Odontologia e que me inspiraram a seguir pela vida acadêmica. Obrigada, professora, por sempre ter me recebido com tanto carinho e atenção.

Ao Prof. Dr. Alberto Consolaro, por todos os ensinamentos transmitidos durante o período em que eu estive na Pós-Graduação e pela contribuição na análise histopatológica deste trabalho, com tanta dedicação e generosidade.

À amiga Profa. Dra. Érika Calvano Küchler, pelo apoio, pela confiança e por todas as oportunidades a mim concedidas. Muito obrigada por estar sempre presente e disposta a me ajudar. Você é um exemplo de profissional dedicada e competente.

Aos professores da disciplina de Ortodontia da Faculdade de Odontologia de Ribeirão Preto da Universidade de São Paulo: Prof. Dr. Fábio Lourenço Romano, Prof. Dr. José Tarcísio Lima Ferreira, Prof. Dr. Adilson Thomazinho, Profa Dra. Mírian Aiko Nakane Matsumoto e Profa. Dra. Maria Bernadete Sasso Stuani, pela convivência agradável no mesmo Departamento e por todos os ensinamentos transmitidos.

Aos Funcionários do Departamento de Clínica Infantil da Faculdade de Odontologia de Ribeirão Preto:

Marco Antônio dos Santos, por toda a ajuda nas atividades laboratoriais deste trabalho, pela disponibilidade e pelos momentos de convivência agradável que compartilhamos.

Nilza Letícia Magalhães, pela grande simpatia, dedicação e paciência. Eu admiro muito a forma leve que você conduz o seu trabalho e que transmite tanto otimismo e alegria a todos ao seu redor. Obrigada por toda a ajuda e pelos momentos de alegria e de cumplicidade!

Fátima Aparecida Jacinto Daniel, pela ajuda nas atividades laboratoriais e pelo carinho durante todo esse período de convivência.

Matheus Morelli Zanela e Filomena Leli Placciti, por toda a atenção e paciência, pela disponibilidade e, principalmente, pela convivência agradável. A dedicação e a ajuda de vocês foram de grande importância durante o período que eu estive na Pós-Graduação. 
Micheli Cristina Leite Rovanholo, por toda a ajuda e pela imensurável paciência. Mi, você me incentivou tanto, sempre com palavras de carinho e de motivação. Muito obrigada por tudo!

Aos funcionários, José Aparecido Neves do Nascimento, Vera do Nascimento Scandelai, Fătima Aparecida Rizoli e Karina Dadalt Quaglio, pela simpatia, pela convivência agradăvel e pelo apoio nas atividades clínicas.

Aos funcionários, Aline Aparecida Ferraresi Tiballi, Antônio Massaro e Antônio Sérgio Aparecido Mesca, por serem sempre tão generosos e atenciosos comigo no período que estive no biotério. Muito obrigada pela ajuda, disponibilidade e paciência!

À Profa. Dra. Janete Aparecida Anselmo Franci e ao especialista de laboratório Ruither de Oliveira Carolino, por terem me recebido com tanto carinho no laboratório de Neuroendocrinologia da Reprodução, da Faculdade de Odontologia de Ribeirão Preto. Muito obrigada por todos os ensinamentos que foram fundamentais para o desenvolvimento deste trabalho!

Ao Prof. Dr. Manoel Damião de Sousa Neto e à Dra. Graziela Bianchi Leoni, por me receberem tão bem no Laboratório de Pesquisa em Endodontia da Faculdade de Odontologia de Ribeirão Preto. Muito obrigada pela ajuda no desenvolvimento deste trabalho e pela disponibilidade.

Ao Prof. Dr. José Batista Volpon e à especiąlista de laboratório Dra. Ariane Zamarioli, por abrirem as portas do Laboratório de Bioengenharia da Faculdade de Medicina de Ribeirão Preto e me recebem sempre com atenção e gentileza.

À Profa. Dra. Magda Feres e à técnica de laboratório Izilvania Maroly Quinderé Barreto, por toda ajuda e disponibilidade durante as análises realizadas no Laboratório de Microbiologia, Imunologia e Biologia Molecular da Universidade de Guarulhos.

À família de Ribeirão Preto, Katharina Morant Holanda de Oliveira, Mariana Alencar Nemezio e Rachel Fernanda Matos dos Santos, pelos anos de convivência regados à amizade, 
cumplicidade e alegrias. Obrigada por toda ajuda, paciência e pelos momentos maravilhosos que compartilhamos!

Às amigas, Ana Caroline Fumes e Daniele Lucca Longo: vocês foram fundamentais durante esses anos, principalmente nesta reta final. É imensurável meu carinho por vocês! Foram presentes de Deus na minha vida. Sou muito grata por todos os momentos incriveis que vivemos. Muito obrigada por tudo e por tanto!

Às amigas da Pós-Graduação, Carolina Maschietto Pucinelli, Daniela Silva Barroso de Oliveira, Driely Barreiros, Francine Lorencetti da Silva, Juliana Arid, Karla Orfelina Carpio Horta dos Reis, Fernanda Vicioni Marques, Larissa Nogueira Soares Ribeiro e Marjorie Ayumi Omori, pelos momentos de alegria e cumplicidade que compartilhamos. Obrigada pela confiança, pelo carinho e por todo apoio.

A todos os alunos do Programa de Pós-Graduação em Odontopediatria da Faculdade de Odontologia de Ribeirão Preto, pela convivência agradável e por todas as experiências, dificuldades e alegrias compartilhadas.

À amiga Keila Dayane Bariotto dos Santos, doutoranda pelo Programa de Neurociências da Faculdade de Medicina de Ribeirão Preto, pelos ensinamentos que contribuíram para o desenvolvimento deste trabalho e também para o meu crescimento e evolução pessoal. Você me recebeu tão docemente e me ensinou a lidar com os animais, esbanjando generosidade e carinho. Foi o meu exemplo de como tratar os animais com amor e respeito. Muito obrigada!

Aos Animais que fizeram parte desta pesquisa, que antes de tudo são seres vivos e cumprem a nobre função de nos proporcionar os primeiros resultados da pesquisa antes de aplicála aos seres humanos. A pesquisa com animais é uma etapa fundamental no avanço do conhecimento e é imprescindível, principalmente na área da saúde. Entretanto, não é uma tarefa fácil, talvez tenha sido a mais difícil da Pós-Graduação. Foram meses de dedicação, cuidado e convivência diária. Por isso, um dia eu prometi aos meus nobres animais que eu faria o trabalho mais lindo que eu pudesse e que todo o nosso esforço não seria em vão. Sou grata pelos resultados que me proporcionaram! 
"Não é sobre ter Todas as pessoas do mundo pra si Esobre saber que em algum lugar Alguém zela por ti Esobre cantar e poder escutar Mais do que a própria voz Ésobre dançar na chuva de vida Que cai sobre nós

Esaber se sentir infinito Num universo tão vasto e bonito Esaber sonhar E, então, fazer valer a pena cada verso Daquele poema sobre acreditar

Não é sobre chegar no topo do mundo Esaber que venceu Esobre escalar e sentir Que o caminho te fortaleceu Esobre ser abrigo E também ter morada em outros coracões Eassim ter amigos contigo Em todas as situações

A gente não pode ter tudo Qual seria a graça do mundo se fosse assim? Por isso, eu prefiro sorrisos E os presentes que a vida trouxe Pra perto de mim"

Ana Vilela

(Trem Bala) 

SUMÁRIO

RESUMO

ABSTRACT

INTRODUÇÃO

PROPOSIÇÃO

MATERIAL E MÉTODOS

RESULTADOS

DISCUSSÃO

$\begin{array}{ll}\text { CONCLUSÃO } & 105\end{array}$

REFERÊNCIAS

$\begin{array}{ll}\text { ANEXO } & 121\end{array}$

APÊNDICE 



\section{RESUMO}

Romualdo, PC. Avaliação dos ossos maxilares e de lesões periapicais induzidas em ratas ovariectomizadas submetidas ou não ao tratamento com bisfosfonato ou com inibidor da catepsina K. Ribeirão Preto, 2017. 127p. Tese [doutorado]. Faculdade de Odontologia de Ribeirão Preto, Universidade de São Paulo.

O objetivo do presente estudo foi avaliar ossos maxilares e lesões periapicais induzidas em ratas ovariectomizadas submetidas ou não ao tratamento com bisfosfonato (Alendronato ALD) ou com inibidor da catepsina K (Odanacatib - ODN). Foram utilizadas 45 ratas, divididas em 6 grupos: I - sham (cirurgia de ovariectomia fictícia); II - sham e lesão periapical (LP); III - ovariectomia (OVX) sem LP; IV - OVX e LP; V - OVX, LP e ALD; e Grupo VI - OVX, LP e ODN. Um dia após a realização da OVX ou da cirurgia fictícia, os animais dos grupos $\mathrm{V}$ e VI começaram a receber ALD ou ODN, via gavagem. Decorridas 9 semanas da realização da OVX, os primeiros molares dos grupos II, IV, V e VI foram submetidos à indução de LP por 3 semanas. Decorrido este período, foi realizada colheita microbiológica dos canais radiculares para a quantificação de micro-organismos e os animais foram submetidos à eutanásia. Fêmures foram analisados por meio de densitômetro, para registro da densidade mineral óssea (BMD). As maxilas foram analisadas por meio de microtomografia computadorizada (micro-CT) para avaliação da microarquitetura e BMD do osso interradicular e as mandíbulas para avaliação do volume das LP. Os primeiros molares inferiores foram submetidos ao processamento histotécnico, sendo os cortes corados com hematoxilina e eosina (HE) e analisados em microscopia convencional. Paralelamente, foi realizada a análise morfométrica da área das lesões periapicais, em microscopia de fluorescência e histoenzimologia para a atividade da TRAP. Os primeiros molares superiores foram submetidos à detecção da expressão gênica de citocinas, marcadores da osteoclastogênese e de metaloproteinases da matriz. Os resultados obtidos foram submetidos à análise estatística apropriada, com nível de significância de 5\%. A OVX afetou a BMD do fêmur e da maxila e a microarquitetura apenas do fêmur. O ALD recuperou a BMD dos ossos avaliados. A OVX não foi capaz de influenciar nos níveis de contaminação microbiana do canal radicular. As LP dos animais do grupo IV apresentaram expressão aumentada de RANK, RANKL, IL-1 $\beta$, IL-6, TNF-a, MMP-8 e 13, enquanto o tratamento com ALD (grupo V) foi capaz de reduzir a expressão de IL-6 e MMP-8, ao mesmo nível que nas LP do grupo II. Além disso, as LP do grupo IV foram maiores (área e volume), em comparação às dos grupos II e V. O ODN, na dose e frequência de administração aplicada, não foi capaz de promover alterações significantes. A OVX e os tratamentos antirreabsortivos não influenciaram no número de osteoclastos ao redor da LP. Assim, concluiu-se que a condição hipoestrogênica induzida pela OVX foi capaz de diminuir a BMD do fêmur e da maxila e alterou a microarquitetura do fêmur. Apenas o ALD foi capaz de recuperar o fenótipo da BMD, ou seja, retorno aos níveis observados nos animais saudáveis. Ainda, a OVX agravou o processo de reabsorção, a inflamação e a expressão de MMPs, provocando lesões periapicais maiores. O ALD e o ODN proporcionaram uma melhora da resposta periapical. Entretanto, apenas o tratamento com ALD recuperou o fenótipo, fazendo com que as lesões periapicais fossem similares às lesões dos animais saudáveis.

Palavras-chave: Ovariectomia. Osteoporose. Lesão periapical. Bisfosfonato. Alendronato. Odanacatib. 



\section{ABSTRACT}

Romualdo, PC. Evaluation of maxillary bones and apical periodontitis induced in ovariectomized rats subjected or not to treatment with bisphosphonate or cathepsin K inhibitor. Ribeirão Preto, 2017. 127p. Tese [doutorado]. Faculdade de Odontologia de Ribeirão Preto, Universidade de São Paulo.

The aim of this study was to evaluate maxillary bones and apical periodontitis induced in ovariectomized rats treated or not with bisphosphonate (Alendronate - ALD) or cathepsin K inhibitor (Odanacatib - ODN). Forty-five female rats were divided into 6 groups: I - sham surgery; II - sham and apical periodontitis (AP); III - ovariectomy (OVX) without AP; IV OVX and AP; V - OVX, AP and ALD; and Group VI - OVX, AP and ODN. One day after OVX or sham surgery, the animals in groups $\mathrm{V}$ and $\mathrm{VI}$ started receiving ALD or ODN, by gavage. After 9 weeks, the first molars of the rats in groups II, IV, V and VI were subjected to induction of AP for 3 weeks. Microbiological root canal sampling was collected for quantification of microorganisms and the animals were euthanized. Bone mineral density (BMD) of the femurs was analyzed by bone densitometry. The maxillas were analyzed by microcomputed tomography (micro-CT) to determine the microarchitecture and BMD of the interradicular bone while the mandibles were analyzed to determined AP volume. The mandibular first molars were subjected to histotechnical processing and hematoxylin and eosin-stained histological sections were examined with conventional microscopy. In addition, a morphometric analysis of AP area was performed using fluorescence microscopy and tartrate-resistant acid phosphatase (TRAP) histoenzymology. The maxillary first molars were used to evaluate the gene expression of cytokines, osteoclastogenesis markers and matrix metalloproteinases (MMP) using RT-PCR. The results were subjected to appropriate statistical analysis with 5\% significance level. OVX affected femoral and maxillary BMD and femoral microarchitecture. ALD recovered the BMD of both types of bones. OVX was not able to influence the microbial levels of the root canal. In group IV, AP showed increased expression of RANK, RANKL, IL-1 $\beta$, IL- 6 , TNF- $\alpha$, MMP-8 and MMP-13, while ALD treatment (group $\mathrm{V}$ ) reduced IL-6 and MMP-8 expression to the same level as the AP in group II. In group IV, AP area and volume were larger than in groups II and V. ODN, in the dosage and frequency of administration applied, was not able to promote significant changes. OVX and antiresorptive treatments did not influence the number of osteoclasts around the AP region. In conclusion, the hypoestrogenic condition induced by OVX was able to decrease the BMD of femur and maxilla and only the microarchitecture of the femur. ALD was able to recover the BMD phenotype, i.e., return to the levels observed in healthy animals. Furthermore, OVX exacerbated resorption, inflammation and MMP expression, inducing larger lesions. Treatment with ALD and ODN resulted in an improvement of the periapical response. However, only ALD recovered the phenotype, with AP similar to that of healthy animals.

Key words: Ovariectomy. Osteoporosis. Apical periodontitis. Bisphosphonate. Alendronate. Odanacatib. 

Introdução 



\section{INTRODUÇÃO}

O tecido ósseo e o sistema imunológico são funcionalmente interligados (Zupan et al., 2013). A osteoimunologia é responsável pelo estudo dessa ligação, analisando sua interdependência em diferentes níveis, com ênfase no conhecimento dos receptores e das moléculas de sinalização que regulam esse processo (Arboleya e Castaneda, 2013).

Nos últimos 20 anos, avanços nas pesquisas básicas e clínicas, no conhecimento da genética de roedores e de humanos e no diagnóstico por imagem permitiram uma mudança considerável no conhecimento relativo à biologia óssea e da relação entre hormônios sexuais e a fisiologia e patologia do metabolismo ósseo (Almeida et al., 2017).

As células ósseas possuem receptores para estrógeno e este hormônio pode atuar diretamente sobre o tecido ósseo, por meio de funções protetoras que, quando encontram-se em disfunção, são determinantes na patogenicidade de diversas alterações como, por exemplo, a osteoporose. A deficiência de estrógeno pósmenopausa desempenha um papel importante nas alterações do volume do osso trabecular, que conduzem às formas precoce e tardia da osteoporose, em mulheres (Riggs et al., 1998).

Além disso, o estrógeno exerce ações indiretas por meio da regulação da produção de citocinas pelas próprias células ósseas e por linfócitos $T$ e $B$, provocando alterações no processo de remodelação (Arboleya e Castaneda, 2013). Dentre essas citocinas, encontram-se a Interleucina-1 (IL-1), a Interleucina-6 (IL-6), o Fator de Necrose Tumoral a (TNF-a), o Fator Estimulador de Colônias de Macrófagos (GMCSF) e a Prostaglandina E2 (PGE2), as quais influenciam o recrutamento de osteoblastos, osteoclastos e células $\mathrm{T}$, afetando o metabolismo ósseo. Estes fatores induzem a reabsorção óssea, principalmente por meio do recrutamento de préosteoclastos da medula óssea que, por sua vez, são reduzidos na presença de estrógeno (Pacifici, 1996; Manolagas, 2000).

Especificamente na Odontologia, o estrógeno pode regular a proliferação e promover a diferenciação de células mesenquimais dentárias, por meio da via de sinalização mediada pelos receptores de estrógeno. Ainda, pode potencializar a 
osteogênese e a dentinogênese em células mesenquimais dentárias, indicando que este hormônio pode ter implicações clínicas na regeneração do tecido dentário, assim como na reconstrução do osso alveolar (Lu et al., 2016).

Em roedores, os efeitos da deficiência de estrógeno podem ser modulados experimentalmente pela ovariectomia $(\mathrm{OVX})$, procedimento que provoca deficiência hormonal semelhante à da menopausa, estimulando a reabsorção óssea por meio do aumento da formação de células osteoclásticas (Weitzmann e Pacifici, 2006) e do aumento da vida útil dessas células (Krum et al., 2008; Martin-Millan et al., 2010), induzindo osteopenia. Em ratas, a privação de estrógeno parece mimetizar os padrões de perda da massa óssea observados em humanos (Frost e Jee, 1992). A rata ovariectomizada é um modelo animal bem estabelecido e comumente utilizado na área da saúde para investigar os efeitos da osteoporose, bem como das terapias antirreabsortivas (Kalu, 1991; Peng et al., 1997; Kim et al., 2015; Mathavan et al., 2015).

Paralelamente, sabe-se que a osteoporose é uma doença óssea metabólica que tem como característica a diminuição da densidade mineral óssea, resultando na diminuição da resistência do esqueleto. Tais características levam à fragilidade óssea e ao aumento do risco de fraturas (Dennison et al., 2013). É considerada um problema notável de saúde pública, devido à sua associação com fraturas relacionadas ao avanço da idade. Estima-se que 10 milhões de indivíduos com mais de 50 anos têm osteoporose no quadril, nos Estados Unidos, com aproximadamente 1,5 milhões de fraturas por ano. Na Europa, estima-se que 27,6 milhões de pessoas têm a doença relacionada ao avanço da idade e mais de 3,5 milhões de fraturas são detectadas por ano. O custo para o tratamento econômico dessas fraturas é imenso, ultrapassando bilhões de dólares (Hernlund et al., 2013). De acordo com a Organização Mundial da Saúde, a osteoporose é estabelecida quando atinge-se uma densidade mineral óssea (BMD) com 2,5 desvios padrões ou mais, abaixo do pico médio de massa óssea de adultos jovens (T-score), saudáveis, conforme medido pelo exame de densitometria óssea. Para o diagnóstico, os ossos utilizados são, preferencialmente, quadril e fêmur (Eastell et al., 2016).

O efeito da osteoporose na microarquitetura e na densidade mineral dos ossos maxilares tem sido estudado, porém os resultados são controversos (Ejiri et 
al., 2008; Dai et al., 2014). Em geral, os ossos longos e a coluna vertebral são mais sensíveis à deficiência de estrógeno que ocorre após a OVX, em comparação aos ossos maxilares (Tanaka et al., 2002; Liu et al., 2015). Alguns estudos evidenciaram que os ossos maxilares são pouco afetados pela OVX (Ishihara et al., 1999; Patullo et al., 2009; Liu et al., 2015), enquanto outros demonstraram grandes alterações na porosidade do osso alveolar, com diminuição da BMD em mandíbulas de ratas ovariectomizadas (Tanaka et al., 2002; Dai et al., 2014). Portanto, o efeito da osteoporose nos ossos maxilares continua um assunto controverso e mais estudos com essa abordagem são necessários.

Especificamente na Endodontia, pouco se conhece sobre os efeitos da redução dos níveis de estrógeno no desenvolvimento de lesões periapicais. A relação entre lesões periapicais e BMD foi avaliada em um estudo transversal com mulheres na pós-menopausa, onde foi demonstrada uma significante associação entre a presença de áreas radiolúcidas periapicais e a baixa densidade mineral óssea (LopezLopez et al., 2015). Adicionalmente, a ovariectomia poderia levar a um aumento significante da perda óssea em lesões periapicais induzidas, em ratas (Xiong et al., 2007; Wayama et al., 2015).

Atualmente, a osteoporose está sendo cada vez mais diagnosticada em crianças, devido ao aumento da prevalência de distúrbios associados à perda óssea nestes pacientes. As crianças com osteoporose e fraturas decorrentes da maior fragilidade óssea necessitam de uma avaliação precisa para descartar uma causa secundária, pois uma BMD reduzida pode ser, frequentemente, consequência de uma doença crônica ou do seu tratamento. Até o presente momento, os bisfosfonatos (BFs) são considerados o principal tratamento para a osteoporose pediátrica (Saraff e Hogler, 2015; Marrani et al., 2017).

Os BFs são medicamentos utilizados para o tratamento de pacientes com doenças ósseas metabólicas, tais como mieloma múltiplo, doença de Paget e osteoporose. Esses medicamentos podem afetar a reabsorção óssea de várias maneiras, incluindo efeitos no recrutamento, diferenciação e atividade reabsortiva dos osteoclastos, podendo também induzir apoptose destas células (Russell, 2007). No entanto, segundo Halasy-Nagy et al. (2001), a inibição da reabsorção óssea pelos $\mathrm{BFs}$, particularmente o Alendronato, não requer a apoptose de osteoclastos. 
Além dos BFs, existem diversos medicamentos usados para o tratamento da osteoporose, tais como Denosumab, Teriparatida, moduladores seletivos do receptor de estrógeno, compostos à base de vitamina $D$, calcitonina, inibidores da catepsina $\mathrm{K}$, entre outros. Entretanto, os BFs são as drogas mais comumente usadas para o tratamento da osteoporose, administrados tanto por via oral quanto por via intravenosa. São divididos em duas classes: os que não contêm nitrogênio e os que contêm nitrogênio. Estas duas classes têm alvos intracelulares distintos e mecanismos moleculares de ação que levam à inibição da reabsorção óssea mediada pelos osteoclastos (Rogers et al., 2011; Das e Crockett, 2013; Tabatabaei-Malazy et al., 2017).

A prevenção da perda óssea após a menopausa ou em crianças com osteoporose é de extrema importância para a manutenção da integridade óssea, prevenindo possíveis fraturas (Seedor et al., 1991; Saraff e Hogler, 2015). O Alendronato (ALD), um BF que contém nitrogênio, é considerado um medicamento capaz de prevenir a perda óssea induzida pela deficiência de estrógeno (Seedor et al., 1991; Chen, G. X. et al., 2014) e está associado com o aumento da densidade mineral óssea e com a redução do risco de fratura (Black et al., 2000; Muschitz et al., 2014).

Devido às suas propriedades antirreabsortivas, estudos também têm investigado a aplicação dos BFs na Odontologia, usando diferentes modelos experimentais (Gao et al., 2009; Tanoue et al., 2015; Wayama et al., 2015). O ALD tem se mostrado eficaz na prevenção da perda óssea alveolar na doença periodontal induzida (Duarte et al., 2004; Goes et al., 2014), melhora o resultado da terapia periodontal não-cirúrgica, podendo ser um tratamento adjuvante para evitar a perda óssea periodontal (Lane et al., 2005) e aumenta a densidade mineral óssea sendo incorporado, inclusive, nas estruturas dentais mineralizadas (Nelson-Filho et al., 2012; Lucisano et al., 2013). Além disso, o ALD não interfere na densidade óssea alveolar (Santamaria et al., 2010) e mantém suas características estruturais, possibilitando o planejamento de movimentação ortodôntica em pacientes que fazem uso deste medicamento (Consolaro, 2014).

Sabe-se que a terapia com ALD poderia desempenhar um papel protetor contra a perda óssea periapical (Xiong et al., 2007; Xiong et al., 2010). Uma forte 
relação foi observada entre a duração do tratamento com BFs e o sucesso endodôntico (Dereci et al., 2016). No entanto, uma condição inflamatória préexistente, como a lesão periapical, pode ser um fator predisponente que pode exacerbar o desenvolvimento da osteonecrose dos maxilares relacionada ao uso de BFs, após a extração dentária. Recomenda-se que a lesão periapical seja controlada antes de executar a extração dentária em pacientes que fazem o uso de BPs, a fim de reduzir o risco de desenvolver osteonecrose dos maxilares (Song et al., 2016).

Como já salientado, embora os BFs sejam amplamente prescritos no tratamento da osteoporose, outros fármacos antirreabsortivos têm sido desenvolvidos com o objetivo de proporcionar uma redução substancial de fraturas osteoporóticas em todos os locais do esqueleto (Reginster et al., 2014). O Odanacatib (ODN) é um medicamento que atua como inibidor altamente seletivo e reversível da catepsina $\mathrm{K}$, colagenase secretada por osteoclastos, e atualmente está sendo testado clinicamente no tratamento da osteoporose pós-menopausa (Brixen et al., 2013). Este medicamento apresenta a capacidade de reduzir a reabsorção óssea sem diminuir o número de osteoclastos, mantendo a formação óssea concomitantemente (Masarachia et al., 2012; Brixen et al., 2013). O ODN inibe seletivamente a proteólise da matriz pela catepsina $\mathrm{K}$, sem afetar outras atividades ou a viabilidade dos osteoclastos, com inibição simultânea da inflamação. Isto, por sua vez, diminui a ativação e diferenciação dos osteoclastos, o que mostra ser um método terapêutico promissor para as lesões periapicais (Bahuguna et al., 2016). Além disso, estudos recentes têm demonstrado que o ODN aumenta a densidade mineral óssea, aumentando a resistência óssea do quadril, da coluna vertebral (Brixen et al., 2013), do rádio e da tíbia (Cheung et al., 2014).

Embora os inibidores da catepsina $\mathrm{K}$ tenham a capacidade de suprimir a perda óssea induzida pela ovariectomia em ratas (Kim et al., 2006; Ochi et al., 2014), as informações existentes na literatura sobre os seus efeitos na área da Endodontia são limitadas. A administração de um inibidor da catepsina K (NC-2300) foi capaz de reduzir a expansão da lesão periapical e a síntese de citocinas próinflamatórias, sugerindo que este pode ser um medicamento eficaz no tratamento da lesão periapical (Suzuki et al., 2015). Com relação ao ODN, apenas um estudo avaliou seu efeito em lesões periapicais de roedores (Hao et al., 2015), 
demonstrando que este medicamento promoveu um efeito protetor, uma vez que inibiu o desenvolvimento das lesões periapicais, a reabsorção óssea e a resposta imune do animal. Entretanto, os animais utilizados no estudo de Hao et al., (2015) não foram submetidos à ovariectomia e, portanto, não há na literatura estudos avaliando o efeito do ODN em lesões periapicais de animais ovariectomizados, tratados ou não.

A supressão da catepsina $\mathrm{K}$ tende a afetar a resposta imune, tendo em vista que os pré-osteoclastos são ativados por RANKL produzido por osteoblastos, células T e B. Estas células podem ser ativadas por citocinas pró-inflamatórias e quimiocinas tais como IL-1, IL-6 e TNF-a (Cochran, 2008). Na lesão periapical, a imunidade inata resulta em macrófagos ativados que, por meio de citocinas, resultam em reabsorção óssea. A inibição da catepsina $\mathrm{K}$ afeta a resposta imune adaptativa ao diminuir o número de células T. O número de osteoblastos também diminui, o que resulta em menor produção de citocinas pró-inflamatórias, levando a uma menor ativação e diferenciação dos osteoclastos (Bahuguna et al., 2016).

As lesões periapicais são resultado da infecção bacteriana da polpa dentária e do sistema de canais radiculares, envolvem o recrutamento de células inflamatórias, citocinas e enzimas, além da ativação de osteoclastos, promovendo o desenvolvimento de reabsorção óssea alveolar. Tendo em vista o efeito do estrógeno no processo de reabsorção óssea, uma deficiência estrogênica poderia ser um fator agravante no desenvolvimento da lesão periapical (Xiong et al., 2007).

Sabe-se que as alterações nos níveis hormonais ocasionadas pela ovariectomia promovem alterações ósseas morfológicas e diminuição da densidade mineral óssea (Boyd et al., 2006) que, teoricamente, poderia favorecer a disseminação de micro-organismos oriundos do canal radicular para a região periapical. Adicionalmente, tem sido evidenciado na área da Periodontia que essas alterações hormonais podem apresentar repercussões na cavidade bucal, incluindo o aumento dos níveis de patógenos periodontais (Hernandez-Vigueras et al., 2016). Pelo exposto, pode-se hipotetizar que a deficiência estrogênica teria influência, também, nos níveis de contaminação microbiana da cavidade bucal e, consequentemente, do canal radicular. 
Adicionalmente, sabe-se que as citocinas desempenham um papel importante na modulação da resposta imune e inflamatória no microambiente periapical e, consequentemente, podem determinar o desenvolvimento das lesões periapicais (Silva et al., 2007; Graves et al., 2011), modulando o equilíbrio da osteoclastogênese (Fukada et al., 2009).

A ocorrência de reabsorção óssea nas lesões periapicais envolve uma interação entre a resposta imune do hospedeiro e as bactérias patogênicas presentes no sistema de canais radiculares (Kakehashi et al., 1965; Stashenko et al., 1992; Silva et al., 2012). O processo inflamatório é iniciado e mantido pela liberação de um grande número de citocinas pró-inflamatórias, tais como TNF-a, IL-1 $1 \beta$ e IL-6 (Seymour e Gemmell, 2001). Estas moléculas atuam como citocinas próinflamatórias, estimulando a diferenciação osteoclástica e a reabsorção óssea nas lesões periapicais.

O TNF-a estimula a produção de colagenase, prostaglandina E2, quimiocinas, citocinas, moléculas de adesão celular e fatores relacionados à reabsorção óssea (Wajant et al., 1998; Boyce et al., 2005). A expressão aumentada de TNF-a contribui para a formação da lesão periapical (Nair, 2004; Hao et al., 2015). A IL-1ß e o TNFa também têm sido detectados nos tecidos periapicais e no exsudato de canais radiculares na presença de lesões periapicais. Altas concentrações de IL-1 $\beta$ e IL-6 têm sido detectadas em dentes portadores de sintomatologia e de extensas áreas de radioluscência, correspondentes à reabsorção óssea (Ataoglu et al., 2002; Jakovljevic et al., 2015).

Paralelamente, sabe-se que a tríade molecular composta de RANK/RANKL/OPG é descrita como um sistema-chave para o controle da diferenciação e da função dos osteoclastos (Kearns et al., 2008). O RANKL é necessário para a ativação e para a diferenciação dos osteoclastos, desempenhando um papel importante na reabsorção óssea que leva ao desenvolvimento de lesões periapicais. A Osteoprotegerina (OPG) é um ligante antagônico natural para o RANKL. Portanto, o equilíbrio entre OPG e RANKL regula a diferenciação dos osteoclastos (Hofbauer e Heufelder, 2001). Há evidências que confirmam a potente ação antirreabsortiva do estrógeno e que parte dessa ação está relacionada ao sistema RANK/RANKL/OPG (Eghbali-Fatourechi et al., 2003; Dempster et al., 2012). 
No entanto, ainda não é esclarecido se esse envolvimento é direto ou indireto, podendo envolver outras citocinas. Ainda nesse contexto, as metaloproteinases da matriz (MMPs), as quais se constituem em um grupo de enzimas responsáveis pela degradação dos componentes da matriz extracelular (Bonnans et al., 2014), são produzidas por células ósseas e parecem desempenhar um papel importante em vários estágios do processo de reabsorção. Há relatos de que os bisfosfonatos podem inibir a expressão de MMPs (Llavaneras et al., 2001; Buduneli et al., 2007; Fernandez-Gonzalez et al., 2016).

Tendo em vista que a osteoporose é uma doença que afeta mundialmente a qualidade de vida de muitos pacientes, estudos adicionais enfocando esses aspectos são necessários. Do ponto de vista clínico, o conhecimento desses mecanismos pode embasar futuras pesquisas envolvendo diferentes formas de tratamento de lesões periapicais, em pacientes osteoporóticos.

Apesar desses conhecimentos, até o momento há pouca informação disponível na literatura específica sobre o impacto da osteoporose e da administração de medicamentos antirreabsortivos nos ossos maxilares e no desenvolvimento de lesões periapicais, incluindo a possível influência nos níveis de citocinas próinflamatórias, no sistema RANK/RANKL/OPG e nas MMPs. 
Proposição 



\section{Proposição}

O objetivo geral do presente estudo foi avaliar ossos maxilares e lesões periapicais induzidas em ratas ovariectomizadas, submetidas ou não ao tratamento com Alendronato ou com Odanacatib.

Objetivos específicos:

- Avaliação da densidade mineral óssea (BMD) dos fêmures, por meio de densitômetro de absorbância de raios-X de energia dual (DXA).

- Avaliação da microarquitetura e BMD dos fêmures e maxilas, por meio de microtomografia computadorizada (micro-CT).

- Quantificação de 40 espécies de micro-organismos nos canais radiculares, por meio da técnica de biologia molecular Checkerboard DNA-DNA Hybridization.

- Deteç̧ão da expressão gênica de citocinas pró-inflamatórias (II-13, Il-6, Il-10 e Tnf-a), de marcadores da osteoclastogênese (Rank, Rankl e Opg) e de metaloproteinases da matriz (Mmp-1, Mmp-8 e Mmp-13) nos dentes com ou sem lesão periapical, por meio da reação em cadeia da polimerase em tempo real (RT-PCR).

- Descrição das características das regiões apical e periapical em cortes histopatológicos, avaliados por meio de microscopia de luz convencional (coloração de hematoxilina e eosina).

- Identificação e contagem de osteoclastos na região periapical ao redor do ligamento periodontal ou das lesões periapicais induzidas, por meio da histoenzimologia para a atividade da fosfatase ácida resistente ao tartarato (TRAP).

- Comparação entre a mensuração da área e do volume das lesões periapicais e do espaço do ligamento periodontal na região periapical, em microscopia de fluorescência e em micro-CT, respectivamente. 

Material e Métodos 

Material e Métodos

O presente projeto de Pesquisa foi submetido à apreciação pela Comissão de Ética no Uso de Animais da Faculdade de Odontologia de Ribeirão Preto Universidade de São Paulo (Protocolo no 2013.1.1404.58.4 - Anexo A), tendo sido aprovado.

\section{Obtenção dos animais}

Para experimentação, foram utilizadas 45 ratas da linhagem Wistar, de aproximadamente 12 semanas de idade, adquiridas do Biotério Central da Universidade de São Paulo (USP) - Campus de Ribeirão Preto. Todos os animais foram mantidos no Biotério II da Faculdade de Odontologia de Ribeirão Preto - USP com livre acesso à ração e água filtrada.

Os animais foram divididos aleatoriamente em 6 grupos (Tabela 1).

Tabela 1. Distribuição dos grupos experimentais e controles

\begin{tabular}{ccc} 
Grupos & Procedimento & $\mathbf{n}$ \\
\hline I & Sham (controle) & 5 animais \\
\hline II & Sham + LP (controle) & 5 animais \\
\hline III & OVX (controle) & 5 animais \\
\hline IV & OVX + LP & 10 animais \\
\hline V & OVX + LP + ALD & 10 animais \\
\hline VI & OVX + LP + ODN & 10 animais \\
\hline OVX = Ovariectomia; Sham = Cirurgia de ovariectomia fictícia; LP = Lesão periapical; ALD = Alendronato; ODN = Odanacatib.
\end{tabular}

\section{Ovariectomia}

Para a obtenção dos animais ovariectomizados (OVX), as ratas foram anestesiadas por meio de injeção intramuscular com Ketamina (Ketamina 10\% Agener União Química Farmacêutica Nacional S/A, Embu-Guaçu, SP), na dosagem de $55 \mathrm{mg} / \mathrm{Kg}$ de peso corporal e Xilazina (Xilazina 2\% - Dopaser, Laboratórios Calier, AS, Barcelona, Espanha), na dosagem de $10 \mathrm{mg} / \mathrm{Kg}$ de peso. Ovariectomias bilaterais foram realizadas nos animais dos grupos III a VI. Os animais dos grupos I e II foram submetidos a cirurgias de ovariectomia fictícias (sham), nas quais os ovários foram 
apenas movimentados e devolvidos intactos à posição original, como descrito previamente (Orrico et al., 2005).

\section{Administração dos medicamentos}

A administração dos medicamentos foi iniciada um dia após a realização da OVX. Os animais do grupo $\mathrm{V}$ receberam duas doses semanais de $1 \mathrm{mg} / \mathrm{Kg}$ de Alendronato de Sódio (Alendronato Monossódico Triidratado, Galena Química e Farmecêutica Ltda, Índia) quimicamente puro, diluído em água destilada, via gavagem (sonda inserida via bucal). A administração do medicamento foi mantida por 12 semanas (Sugimoto et al., 2013; Chen, G. X. et al., 2014), totalizando 24 doses durante o período experimental.

Os animais do grupo VI receberam um total de 7 doses de $2,12 \mathrm{mg} / \mathrm{kg}$ de Odanacatib (Santa Cruz Biotechnology Inc, Santa Cruz, CA, USA), a cada 12 dias. Este medicamento foi diluído em PEG (Polietilenoglicol) $400(2,5 \mathrm{mg} / \mathrm{mL})$. A administração do medicamento foi também realizada por meio de gavagem e mantida por 12 semanas. Esta dose e frequência foram calculadas por meio de extrapolação alométrica de camundongos para ratos, com base nos dados apresentados por Hao et al. (2015).

Para a administração das drogas via gavagem, os animais foram contidos manualmente e mantidos em jejum por duas horas. Foi utilizada uma agulha de aço inox curva, específica para a realização de gavagem em ratos (Ciencor Scientific Ltda. São Paulo - SP), com cânula de diâmetro de $1,2 \mathrm{~mm}$, esfera de $2,25 \mathrm{~mm}$ e $38 \mathrm{~mm}$ de comprimento, para que a solução fosse injetada diretamente no trato gastrointestinal.

Após a administração dos medicamentos, os animais foram mantidos por alguns minutos na posição vertical para evitar a ocorrência de refluxo e/ou irritação gastroesofágica e para garantir a total ingestão do volume administrado. Massagens abdominais também foram realizadas para maior conforto do animal.

Semanalmente, os animais foram pesados (Balança eletrônica modelo 3400, ${ }^{\odot}$ Toledo do Brasil) para controle do peso corpóreo e para que novas soluções de 
Alendronato e Odanacatib fossem preparadas com a concentração adequada, ajustando a dose de medicamento ao peso dos animais, a cada semana.

\section{Indução das lesões periapicais}

Um modelo clássico para indução de lesão periapical em roedores foi empregado (Kawashima e Stashenko, 1999; Bezerra da Silva et al., 2014), 21 dias antes da realização da eutanásia. Inicialmente, as ratas foram anestesiadas por meio de injeção intramuscular com Ketamina (Ketamina 10\% - Agener União Química Farmacêutica Nacional S/A, Embu-Guaçu, SP, Brasil), na dosagem de $55 \mathrm{mg} / \mathrm{Kg}$ de peso corporal e Xilazina (Xilazina 2\% - Dopaser, Laboratórios Calier, AS, Barcelona, Espanha), na dosagem de $10 \mathrm{mg} / \mathrm{Kg}$.

Os animais dos grupos II, IV, V e VI foram imobilizados e montados em uma mesa de retração da mandíbula, mantidos com a cavidade bucal aberta para permitir a adequada visualização e acesso. A abertura coronária dos primeiros molares superiores do lado esquerdo e dos inferiores de ambos os lados foi realizada com broca esférica em baixa rotação (nº 1/2 - KG Sorensen, Cotia, SP, Brasil) acoplada à peça de mão elétrica montada em motor de baixa rotação e contra-ângulo (Dabi Atlante Equipamentos Odontológicos, Ribeirão Preto, SP, Brasil), sendo o tecido pulpar do canal radicular distal removido com lima endodôntica tipo K número 10 (Dentsply Maillefer, Ballaigues, Suíça). Em seguida, os dentes foram mantidos expostos à microbiota bucal.

Após o período experimental de 21 dias, foi realizada a colheita microbiológica do conteúdo dos canais radiculares, introduzindo-se uma lima endodôntica tipo K número 8 no comprimento total do canal. As limas foram, então, armazenadas individualmente em tubos plásticos (Eppendorf AG, Barkhausenweg,

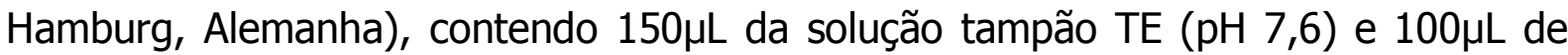
hidróxido de sódio 0,5M. Em seguida, os tubos foram agitados para dessorção microbiana na solução e armazenados em freezer à temperatura de $-20^{\circ} \mathrm{C}$ até o momento da análise por Checkerboard DNA-DNA Hybridization. Posteriormente, os animais foram submetidos à eutanásia por sobredose anestésica, por meio da associação de Ketamina $300 \mathrm{mg} / \mathrm{kg}$ e Xilazina $30 \mathrm{mg} / \mathrm{kg}$, como preconizado pelas 
Diretrizes da prática de eutanásia do CONCEA (Conselho Nacional de Controle de Experimentação Animal).

Os maxilares de cada animal foram divididos em quadrantes (hemimaxilas e hemimandíbulas) de acordo com a análise a ser empregada, conforme ilustrado na Figura 1.

Figura 1. Distribuição dos quadrantes de acordo com a análise a ser empregada. Micro-CT=microtomografia computadorizada, $\mathrm{BMD}=$ densidade mineral óssea, RT$\mathrm{PCR}=$ reação em cadeia da polimerase em tempo real, $\mathrm{LP}=$ lesão periapical, $\mathrm{HE}=$ hematoxilina e eosina e TRAP=fosfatase ácida resistente ao tartarato.

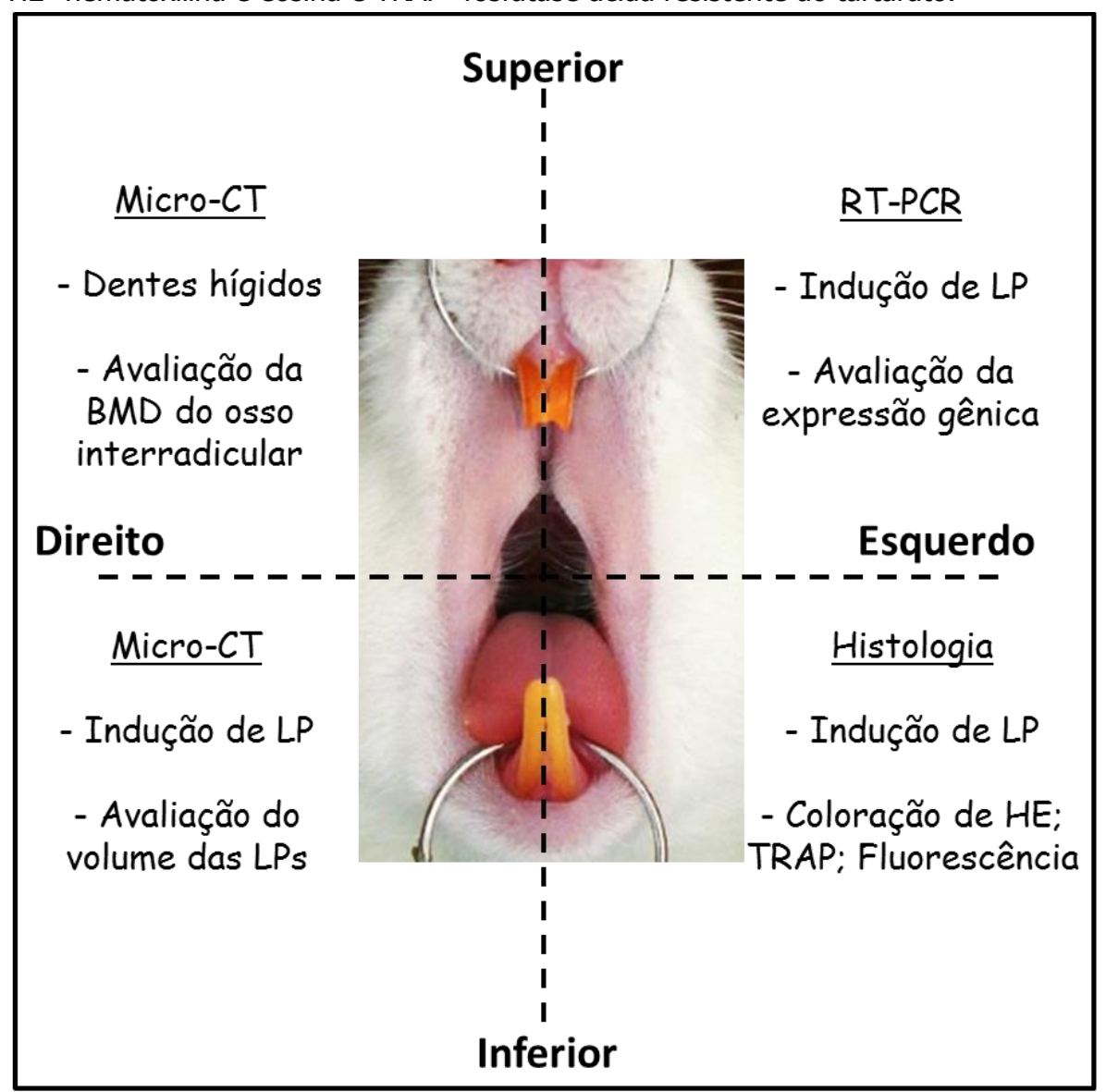

\section{1) Confirmação da eficácia da ovariectomia}

A eficácia da ovariectomia foi confirmada por meio do monitoramento do peso corporal dos animais e pelo peso do útero no dia da eutanásia, tendo em vista que este procedimento promove aumento no peso corporal e atrofia uterina (Chen, G. X. et al., 2014), em comparação ao grupo sham. 


\section{2) Avaliação microbiológica - Detecção molecular de micro-organismos por meio da técnica Checkerboard DNA-DNA Hybridization nos animais dos grupos II e IV}

Foi realizada a colheita microbiológica do conteúdo dos canais radiculares dos animais dos grupos II e IV, 21 dias após a indução das lesões periapicais, ou seja, no dia da realização da eutanásia. Não foi realizada a análise do material colhido dos canais radiculares dos grupos tratados com os medicamentos antirreabsortivos, uma vez que os medicamentos não têm como característica dos seus mecanismos de ação a atividade antimicrobiana. Portanto, essa análise foi realizada apenas nos grupos sham+LP (II) e OVX+LP (IV).

O conteúdo de cada amostra dos canais radiculares foi avaliado utilizando-se a técnica Checkerboard DNA-DNA Hybridization (Socransky et al., 1994) para verificar a presença de 40 espécies bacterianas (Tabela 2).

As amostras foram aquecidas para lisar as células bacterianas e o DNA contido nas mesmas foi depositado sobre uma membrana de nylon com carga positiva (Boehringer Mannheim, Indianápolis, IN, USA), com o auxílio de um dispositivo específico (Minislot-30 - Immunetics INC, Boston, MA, USA).

Após a fixação do DNA sobre a membrana, esta foi colocada em outro dispositivo (Miniblotter-45 - Immunetics Inc, Boston, MA, USA), com as linhas contendo o DNA das amostras posicionadas perpendicularmente às canaletas do Miniblotter-45. As sondas de DNA para as 40 espécies bacterianas marcadas com digoxigenina foram depositadas nas canaletas do Miniblotter-45 para a hibridização das sondas com o DNA das amostras. As membranas foram então lavadas em alta adstringência e as sondas de DNA foram detectadas utilizando-se o anticorpo antidigoxigenina, conjugado à fosfatase alcalina, por meio da observação dos sinais de quimioluminescência. As duas últimas linhas horizontais da membrana apresentaram controles nas concentrações de $10^{5}$ e $10^{6}$ células bacterianas de cada espécie que estará sendo investigada. Os sinais produzidos foram comparados aos controles e convertidos em contagem absoluta. 
Tabela 2. Relação de micro-organismos avaliados (Checkerboard DNA-DNA Hybridization)

\begin{tabular}{|c|c|c|c|}
\hline Espécie bacteriana & Procedência da cepa & Morfotipo & Fisiologia \\
\hline Actinomyces gerencseriae & $23860^{a}$ & Bastonete Gram-positivo & Facultativo \\
\hline Actinomyces naes/undii & $12104^{\mathrm{a}}$ & Bastonete Gram-positivo & Facultativo \\
\hline Actinomyces odontolyticus I & $17929^{a}$ & Bastonete Gram-positivo & Facultativo \\
\hline Actinomyces oris & $43146^{a}$ & Bastonete Gram-positivo & Facultativo \\
\hline Aggregatibacter actinomycetencomytans & $43718+29523^{a}$ & Bastonete Gram-negativo & Facultativo \\
\hline Campylobater rectus & $33238^{a}$ & Bastonete Gram-negativo & Facultativo \\
\hline Capnocytophaga gingivalis & $33624^{a}$ & Bastonete Gram-negativo & Facultativo \\
\hline Campylobacter gracilis & $33236^{a}$ & Bacilo Gram-negativo & Facultativo \\
\hline Capnocytophaga ochracea & $33596^{a}$ & Bastonete Gram-negativo & Facultativo \\
\hline Capnocytophaga sputigena & $33612^{a}$ & Bastonete Gram-negativo & Facultativo \\
\hline Corynebacterium matruchotti & $14266^{\mathrm{a}}$ & Bacilo Gram-positivo & Facultativo \\
\hline Eubacterium nodatum & $33099^{a}$ & Bastonete Gram-positivo & Anaeróbio \\
\hline Escherichia coli & $10799^{a}$ & Bacilo Gram-negativo & Facultativo \\
\hline Enterococcus faecallis & $29212^{a}$ & Coco Gram-positivo & Facultativo \\
\hline Enterococcus faecium & $6569^{a}$ & Coco Gram-positivo & Facultativo \\
\hline Enterococcus hirae & $10541^{a}$ & Coco Gram-positivo & Anaeróbio \\
\hline Fusobacterium nucleatum (sp. nucleatum) & $25586^{a}$ & Bastonete Gram-negativo & Anaeróbio \\
\hline $\begin{array}{l}\text { Fusobacterium nucleatum (sp. } \\
\text { polymorphum) }\end{array}$ & $10953^{a}$ & Bastonete Gram-negativo & Anaeróbio \\
\hline Fusobacterium nucleatum (sp. vincentii) & $49256^{a}$ & Bastonete Gram-negativo & Anaeróbio \\
\hline Fusobacterium periodonticum & $33693^{a}$ & Bastonete Gram-negativo & Anaeróbio \\
\hline Haemophilus influenzae & $33533^{a}$ & Cocobacilo Gram-negativo & Facultativo \\
\hline Helicobacter pylori & $43504^{a}$ & Bastonete Gram-negativo & Facultativo \\
\hline Leptotrichia buccalis & $14201^{a}$ & Bacilo Gram-negativo & Anaeróbio \\
\hline Porphyromonas endodontalis & $35406^{a}$ & Bastonete Gram-negativo & Anaeróbio \\
\hline Porphyromonas gingivalis & $33277^{a}$ & Bastonete Gram-negativo & Anaeróbio \\
\hline Prevotella intermedia & $25611^{a}$ & Bacilo Gram-negativo & Anaeróbio \\
\hline Prevotella melaninogenica & $25845^{a}$ & Bastonete Gram-negativo & Anaeróbio \\
\hline Streptococcus anginosus & $33397^{a}$ & Coco Gram-positivo & Facultativo \\
\hline Streptococcus constellatus & $27823^{a}$ & Coco Gram-positivo & Anaeróbio \\
\hline Streptococcus gordonii & $10558^{a}$ & Coco Gram-positivo & Facultativo \\
\hline Streptococcus intermedius & $27335^{a}$ & Coco Gram-positivo & Facultativo \\
\hline Streptococcus mitis & $49456^{a}$ & Coco Gram-positivo & Facultativo \\
\hline Streptococcus mutans & $25175^{a}$ & Coco Gram-positivo & Facultativo \\
\hline Streptococcus oralis & $35037^{a}$ & Coco Gram-positivo & Facultativo \\
\hline Streptococcus sanguinis & $10556^{a}$ & Coco Gram-positivo & Facultativo \\
\hline Streptococcus sobrinus & $33748^{a}$ & Coco Gram-positivo & Facultativo \\
\hline Tannerella forsythia & $43037^{a}$ & Bastonete Gram-negativo & Anaeróbio \\
\hline Treponema denticola & $B 1^{b}$ & Espiroqueta Gram-negativo & Anaeróbio \\
\hline Treponema Socranskii & $\mathrm{S} 1^{\mathrm{b}}$ & Espiroqueta Gram-negativo & Anaeróbio \\
\hline Veillonella parvula & $10790^{a}$ & Coco Gram-negativo & Anaeróbio \\
\hline
\end{tabular}

$\mathrm{a}=$ ATCC (American Type Culture Collection);

$\mathrm{b}=$ The Forsyth Institute, Boston, MA. 
Para permitir uma análise semiquantitativa dos sinais de quimioluminescência das espécies bacterianas em cada amostra, a intensidade dos sinais foi registrada em forma e escores: escore $0=$ bactérias não detectadas; escore $1=1 \times 10^{4}$ células bacterianas; escore $2=1 \times 10^{5}$ células bacterianas; escore $3=5 \times 10^{5}$ células bacterianas e escore $4=1 \times 10^{6}$.

Primeiramente, foi realizado um teste de associação para investigar se a realização da ovariectomia afeta ou não a presença/ausência de bactérias no sistema de canais radiculares. A segunda etapa da análise comparou a porcentagem de ocorrência dos diferentes escores obtidos entre os grupos.

A leitura dos resultados foi realizada duas vezes para a conferência dos resultados, por um único examinador calibrado (Kappa>0,8) e cego com relação aos grupos avaliados.

\section{3) Avaliação da densidade mineral óssea (BMD) dos fêmures, por meio} da técnica de absortometria radiológica de dupla energia (DXA)

Um fêmur de cada animal de todos os grupos (I a VI) foi removido cirurgicamente e analisado por meio do densitômetro de absorbância de raios-X de energia dual Lunar PIXImus (Lunar PIXImus Corp. Headquarters, Madison, WI, USA), para registro da BMD da metáfise distal, em $\mathrm{g} / \mathrm{cm}^{2}$. Os dados obtidos foram registrados e analisados pelo software Lunar PIXImus, versão 2.2 (Lunar PIXImus Corp. Headquarters), conforme descrito previamente (Lucisano et al., 2013).

\section{4) Avaliação da microarquitetura e da BMD dos fêmures e maxilas, por meio de microtomografia computadorizada (micro-CT)}

Fêmures e hemimaxilas do lado direito dos animais representando todos os grupos foram analisados por meio de microtomografia computadorizada (micro-CT), empregando o microtomógrafo SkyScan modelo 1174 v.2 (Bruker microCT, Kontich, Bélgica).

Cada espécime foi individualmente inserido de forma perpendicular em relação à fonte de radiação durante o escaneamento reduzindo-se, assim, a 
possibilidade de distorção da imagem. Uma vez confirmado o correto posicionamento do osso, as amostras foram escaneadas utilizando $50 \mathrm{kV}$ e $800 \mathrm{~mA}$ com o auxílio de um filtro de $0,5 \mathrm{~mm}$ de espessura de alumínio, para otimizar o contraste, em passos de rotação de $1^{0}$ e tamanho de resolução isotrópica de $19,7 \mu \mathrm{m}$, conforme preconizado por Falcai et al. (2015).

A reconstrução das secções transversais foi realizada por meio do programa NRecon v.1.6.3 (Bruker microCT, Kontich, Bélgica), sendo aplicada uma redução de artefatos em forma de anel (Ring Artifact) no valor de 10. Para as análises, foi utilizado o software CTAn v.1.12 (Bruker microCT, Kontich, Bélgica).

As regiões de interesse (ROI) nos fêmures e nas hemimaxilas foram limitadas a regiões de osso trabecular, sem o osso cortical, por serem mais sensíveis e comparáveis ao osso osteoporótico humano (Turner, 2001). A ROI selecionada para análise em cada osso foi baseada no estudo de Liu et al. (2015). Na maxila foi avaliada a área trabeculada do septo interradicular do primeiro molar e no fêmur foram avaliados $3 \mathrm{~mm}$ da área trabecular axial (abaixo da cartilagem de crescimento). Os seguintes parâmetros estruturais foram avaliados nas regiões de interesse: densidade mineral óssea (BMD); porcentagem de volume ósseo (BV/TV); espessura trabecular (Tb.Th.); número de trabéculas (Tb.N) e separação trabecular (Tb.Sp.) (Dai et al., 2014; Liu et al., 2015).

5) Detecção da expressão gênica de citocinas pró-inflamatórias, de marcadores da osteoclastogênese e de metaloproteinases da matriz, nos dentes com ou sem lesão periapical, por meio da reação em cadeia da polimerase em tempo real (RT-PCR)

As hemimaxilas do lado esquerdo foram seccionadas e os blocos contendo o primeiro molar superior e o osso ao seu redor foram removidos e submetidos ao isolamento do RNA. As amostras foram mantidas em RNAlater (Life Technologies Corporation - Carlsbad, CA, EUA) e congeladas a $-80^{\circ} \mathrm{C}$ até o dia do processamento, quando foram descongeladas, trituradas em gral e pistilo, homogeneizadas em homogeneizador de tecidos (BioSpec Products, Inc., Bartlesville, OK, EUA) e mantidas por 1 minuto à temperatura ambiente. A extração de RNA total foi 
realizada utilizando o kit de extração Pure link mini kit (Applied Biosystems, Foster City, California, EUA), seguindo as instruções do fabricante. Alíquotas de $2 \mu \mathrm{L}$ foram utilizadas para avaliar a pureza e estimar a concentração de RNA em $\mathrm{mg} / \mathrm{mL}$ de cada amostra, utilizando o Nanodrop 2000 (Thermo Fisher Scientific Inc., Waltham, MA, EUA).

Após a extração do RNA, o DNA complementar (cDNA) foi sintetizado utilizando $1 \mu \mathrm{g}$ de RNA total e o kit High Capacity (Applied Biosystems, Foster City, California, EUA).

A quantificação de citocinas (IL-1B, IL-6, IL-10 E TNF-a), de marcadores da osteoclastogênese (RANK, RANKL E OPG) e de MMPs (MMP-1, MMP-8 e MMP-13) foi avaliada por meio de expressão gênica (Il-1ß, Il-6, Il-10, Tnf-a, Rank, Rankl, Opg, Mmp-1, Mmp-8 e Mmp-13). A análise quantitativa da expressão de RNAm foi realizada por meio do StepOnePlus ${ }^{\mathrm{TM}}$ Real-Time PCR System (Applied Biosystems, Foster City, CA, EUA), utilizando o sistema de fluorescência TaqMan (Applied Biosystems ${ }^{\circledR}$, Foster City, CA, EUA) para a quantificação dos produtos de amplificação. As condições padrão de PCR consistiram de: $95^{\circ} \mathrm{C}$ (2 minutos), seguidas por 40 ciclos de $95^{\circ} \mathrm{C}$ ( 1 segundo) e $60^{\circ} \mathrm{C}$ (20 segundos).

Para a análise do RNAm, o cálculo para determinação da expressão relativa do gene de interesse foi realizado de acordo com as instruções do fabricante (Applied Byosystems User's Bulletin - P/N 4303859), utilizando como referência a expressão de beta-actina ( $A c t b$ ) e de gliceraldeído-3-fosfato desidrogenase (Gapdh) na mesma amostra, utilizando-se do método do $\Delta \Delta \mathrm{Ct}$. A média dos valores de $\mathrm{Ct}$ obtidas de duplicatas foi utilizada para o cálculo da expressão gênica, a qual foi comparada aos valores do gene alvo e gene de referência de uma amostra controle para o cálculo da expressão relativa, por meio da fórmula $2^{-\Delta \Delta \mathrm{Ct}}$.

\section{6) Estudo Histopatológico}

\section{Processamento histotécnico e avaliação microscópica}

Após a eutanásia dos animais, as hemimandíbulas inferiores foram removidas com tesoura cirúrgica esterilizada, fixadas por imersão em formol tamponado a $10 \%$ 
por 24 horas à temperatura ambiente e, em seguida, lavadas por, aproximadamente, 4 horas em água corrente. Em seguida, para a desmineralização das peças, foi utilizada solução à base de EDTA a 4,13\% (pH 7-7,4). As peças foram mantidas nesta solução, à temperatura ambiente, trocada semanalmente, até sua completa desmineralização. O grau de desmineralização das estruturas mineralizadas foi testado por meio da penetração de uma agulha nos tecidos, para verificação da sua consistência. Após esse procedimento, as peças foram submetidas ao processamento histotécnico de rotina, sendo lavadas em água corrente por 2 horas, desidratadas em álcool de concentrações crescentes (70\% e 95\% por 30 minutos cada; 2 trocas de $100 \%$ por 20 minutos cada e 2 trocas de álcool $100 \%$ por 40 minutos cada), diafanizadas em xilol ( 2 banhos de 20 minutos e 1 de 40 minutos) e incluídas em parafina.

Os blocos contendo os dentes foram cortados longitudinalmente em micrótomo (Leica RM2145; Leica Microsystems GmbH, Wetzlar, Alemanha) no sentido mésio-distal. Cortes semi-seriados de $5 \mu \mathrm{m}$, com intervalos de $15 \mu \mathrm{m}$, foram obtidos em toda a extensão da lesão periapical, exceto na região do forame apical, onde todos os cortes foram coletados sem intervalos.

Os cortes representativos de cada grupo (experimentais e controle) foram corados com hematoxilina e eosina (HE) e submetidos à análise em microscopia óptica convencional, para descrição das regiões apical e periapical.

Todas as análises foram realizadas no microscópio Axio Imager.M1 (Carl Zeiss MicroImaging $\mathrm{GmbH}$, Göttingen, Alemanha), com câmera AxioCam MRc5 acoplada (Carl Zeiss MicroImaging $\mathrm{GmbH}$, Göttingen, Alemanha). As análises foram realizadas apenas nas raízes distais dos primeiros molares inferiores por apresentarem canal radicular amplo, reto e com paredes de espessura uniforme até a região periapical. Os cortes mostraram simultaneamente os terços coronário, médio e apical do canal radicular, o forame apical e o osso alveolar. Todas as análises foram realizadas por um único avaliador experiente, sem conhecimento prévio do grupo analisado. 


\section{Análise microscópica descritiva das regiões apical e periapical}

A análise qualitativa descritiva das regiões apical e periapical foi realizada nos cortes representativos de cada grupo considerando:

- Ligamento periodontal/Lesão periapical: extensão do ligamento periodontal ou da lesão periapical, quando presente.

- Infiltrado celular inflamatório: Característica e intensidade.

- Cemento apical/Osso alveolar: Ausência/presença de reabsorção dos tecidos mineralizados.

\section{7) Mensuração da área das lesões periapicais ou da área do espaço do ligamento periodontal na região periapical, por meio da técnica de fluorescência}

A avaliação morfométrica das lesões periapicais (grupos II, IV, V e VI) ou do espaço do ligamento periodontal (grupos I e III) foi realizada nos espécimes corados com HE utilizando o microscópio Axio Imager.M1, em aumento de 5x, operando no modo fluorescente, filtro Alexa Fluor 488 (AF488) com as seguintes características: excitação de G365, refletores FT395 e emissão LP420, como previamente descrito (De Rossi et al., 2007; Cohenca et al., 2015). Para cada espécime, a área da lesão periapical ou do espaço do ligamento periodontal na região foi delineada e medida em $\mathrm{mm}^{2}$. A delimitação da lesão excluiu as estruturas intactas (ligamento periodontal, cemento e osso alveolar), facilmente identificadas pela fluorescência verde intensa, assim como incluiu áreas de reabsorção e infiltrado inflamatório, identificadas pela ausência de fluorescência e aparência escurecida. A delimitação da área do ligamento periodontal normal incluiu todo o ligamento da região periapical (1 $\mathrm{mm}$ acima do ápice radicular). 


\section{8) Histoenzimologia para a atividade da fosfatase ácida resistente ao tartarato (TRAP), para contagem de osteoclastos}

A atividade da TRAP foi utilizada para a marcação de células gigantes multinucleadas (osteoclastos). Os cortes foram desparafinizados (2 banhos de xilol de 5 minutos cada) e hidratados (álcool $100 \%$ por duas vezes de cinco minutos cada; álcoois 95\%, 70\% e 50\% por dois minutos cada e água destilada pelo mesmo período). A seguir, as lâminas foram colocadas em solução de álcool/acetona a 50\% durante um minuto e os cortes secos à temperatura ambiente. Em seguida, uma solução contendo $10 \mathrm{~mL}$ de tampão de ácido acético, $0,1 \mathrm{~mL}$ de dimetilformamida, $5 \mathrm{mg}$ de Fast-red e $1 \mathrm{mg}$ de ácido fosfórico naftol AS-BI (Sigma-Aldrich Corporation, Saint Louis, EUA) foi pipetada sobre os cortes, que foram mantidos protegidos da luz, em estufa a $37^{\circ} \mathrm{C}$, pelo tempo suficiente para se observar a marcação (Cohenca et al., 2015). Após a incubação, foi realizada a contra-coloração com hematoxilina por um minuto. A seguir, as lâminas foram montadas e avaliadas no microscópio Axio Imager.M1 sob luz convencional, para contagem do número de células TRAPpositivas, com três ou mais núcleos, presentes em lacunas de reabsorção, em contato direto com o osso alveolar ao redor da lesão periapical. Os resultados foram expressos em número de células por $\mathrm{mm}$.

\section{9) Mensuração do volume das lesões periapicais ou do volume do espaço do ligamento periodontal na região periapical, por meio de microtomografia computadorizada (micro-CT)}

As hemimandíbulas do lado direito foram escaneadas e reconstruídas, conforme descrito anteriormente para os fêmures e as hemimaxilas. A delimitação do espaço do ligamento periodontal (1 $1 \mathrm{~mm}$ acima do ápice radicular) ou das lesões periapicais foi realizada no plano sagital, por meio da delimitação personalizada da ROI de forma manual, ajustada a cada 10 cortes, para garantir a inclusão do volume total de perda óssea na região apical da raiz distal do primeiro molar inferior. 0 parâmetro avaliado foi o volume ósseo $\left(\mathrm{mm}^{3}\right)$ que representa a versão tridimensional da lesão periapical. 


\section{0) Correlação entre a mensuração da área e do volume das lesões periapicais ou do espaço do ligamento periodontal na região periapical, em microscopia de fluorescência e em micro-CT}

Os valores obtidos a partir da análise histomorfométrica (área em $\mathrm{mm}^{2}$, obtida nas imagens no modo fluorescente) e da análise tridimensional das lesões periapicais ou do espaço do ligamento periodontal (volume em $\mathrm{mm}^{3}$, obtido em micro-CT) foram submetidos ao teste de correlação de Pearson para avaliar o grau de correlação entre esses parâmetros.

\section{Análise Estatística}

Os dados obtidos foram submetidos a testes estatísticos específicos, para verificação da distribuição dos dados. Em seguida, foram submetidos à análise estatística apropriada, por meio do programa Graph Pad Prism 4.0 (Graph Pad Software Inc, San Diego, CA, EUA). Para a comparação dos resultados obtidos, nos diferentes grupos, com relação à análise do peso corporal e do útero foi utilizado o teste T. Com relação à avaliação microbiológica, foi aplicado o teste qui-quadrado para verificar a associação e o teste de Mann-Whitney para a comparação dos diferentes escores. Com relação à avaliação da microarquitetura óssea e da área das lesões periapicais, foi utilizado o teste one-way ANOVA e, quando necessário, o pósteste de Tukey. Com relação à avaliação dos osteoclastos, foi utilizada a análise de variância 2 fatores (two-way ANOVA), considerando como variáveis independentes ovariectomia e lesão periapical e o teste one-way ANOVA na comparação entre os grupos onde a lesão periapical foi induzida. Nas demais análises foi aplicado o teste não-paramétrico de Kruskal-Wallis e, quando necessário, o pós-teste de Dunn. O teste de correlação de Pearson foi utilizado para correlacionar os dados obtidos a partir da mensuração da área e do volume das lesões periapicais ou do espaço do ligamento periodontal. Todas as análises foram realizadas com nível de significância de $5 \%$. 

Resultados 



\section{RESULTADOS}

\section{1) Confirmação da eficácia da ovariectomia}

A eficácia da ovariectomia foi confirmada pelo aumento do peso corporal dos animais (Figura 2) e pela diminuição do peso do útero (Figura 3), no dia da eutanásia.

A média do peso corporal dos animais do grupo sham foi de $465,1( \pm 15,72)$ gramas, enquanto que para o grupo ovariectomizado foi de $522,5( \pm 7,24)$ gramas. Houve diferença estatisticamente significante entre os grupos $(p<0,001)$.

A média do peso do útero dos animais do grupo sham foi de $558,2( \pm 42,18)$ miligramas, enquanto que para o grupo ovariectomizado foi de $149,1( \pm 6,65)$ miligramas. Também houve diferença estatisticamente significante entre os grupos $(p<0,001)$.

Figura 2. Peso final dos animais no dia da eutanásia, 12 semanas após a realização da ovariectomia (OVX) ou da cirurgia fictícia (sham). Letras diferentes significam que foi possível encontrar diferença estatisticamente significante entre os grupos $(p<0,001)$.

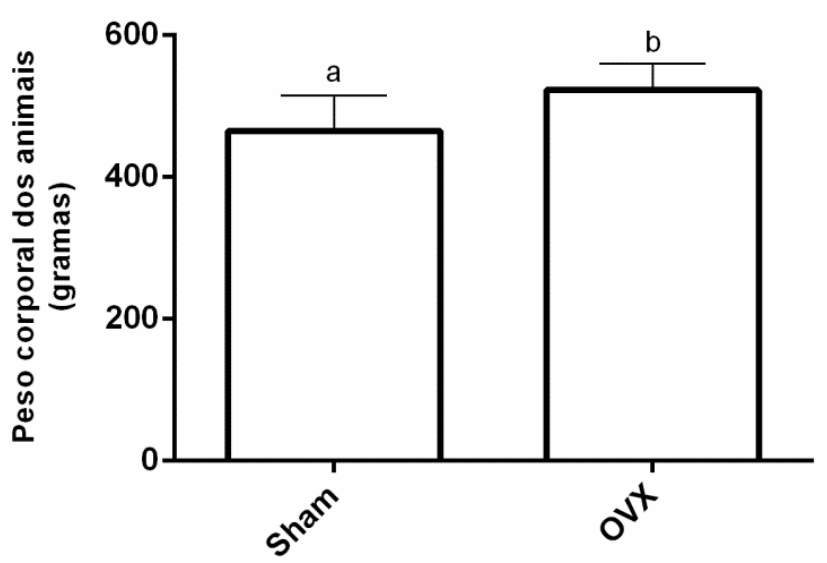


Figura 3. Peso do útero dos animais no dia da eutanásia, 12 semanas após a realização da ovariectomia (OVX) ou da cirurgia fictícia (sham). Letras diferentes significam que foi possível encontrar diferença estatisticamente significante entre os grupos $(p<0,001)$.

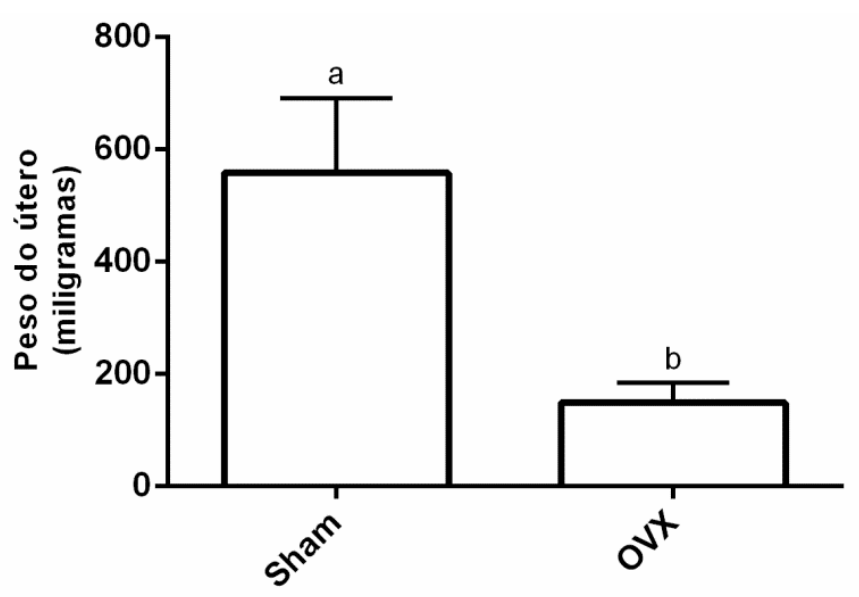

\section{2) Avaliação microbiológica - Detecção molecular de micro-organismos por meio da técnica Checkerboard DNA-DNA Hybridization nos animais dos grupos II e IV}

A análise microbiológica foi realizada considerando a presença ou ausência de micro-organismos nos canais radiculares de maneira geral. Dos 40 microorganismos avaliados, apenas 4 ( C. matruchotti, H. influenzae, $P$. endodontalis e $P$. intermedia) não foram detectados em nenhum dos canais radiculares avaliados dos grupos II e IV.

Com relação à análise de associação entre a realização da ovariectomia e a presença ou não de bactérias no sistema de canais radiculares, não foi possível encontrar diferença estatisticamente significante entre os grupos sham+LP e $O V X+L P(p=0,78)$.

Ao se avaliar a quantidade de bactérias, por meio de escores, também não foi possível encontrar diferença estatisticamente entre os grupos $(p>0,05)$. A porcentagem de ocorrência dos escores avaliados encontra-se na Figura 4. 
Figura 4. Avaliação da quantidade de bactérias presentes nos canais radiculares, por meio de escores, nos grupos sham ou ovariectomizado (OVX). Escore $0=$ bactérias não detectadas; escore $1=1 \times 10^{4}$ células bacterianas; escore $2=1 \times 10^{5}$; escore $3=5 \times 10^{5}$ e escore $4=1 \times 10^{6}$ células bacterianas. Não foi possível encontrar diferença estatisticamente significante entre os grupos $(p>0,05)$.

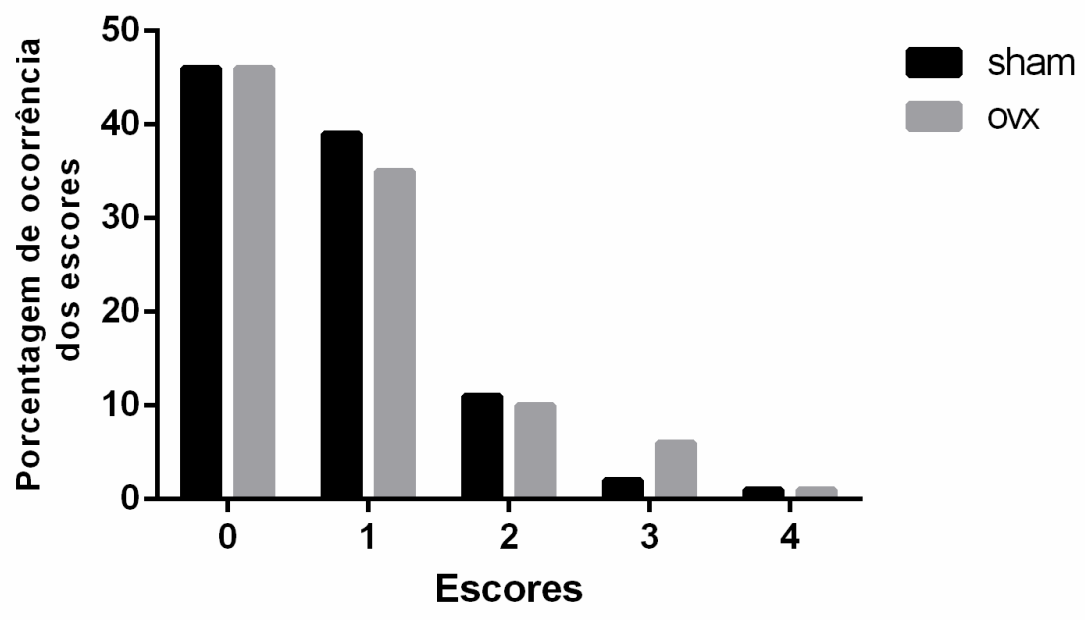

3) Avaliação da densidade mineral óssea (BMD) dos fêmures, por meio da técnica de absortometria radiológica de dupla energia (DXA)

Os resultados obtidos após a avaliação da densidade mineral óssea (BMD) da metáfise distal dos fêmures encontram-se na Figura 5. As medianas dos grupos sham, OVX, OVX+ALD e OVX+ODN foram, respectivamente, 0,257, 0,167, 0,248 e $0,172 \mathrm{~g} / \mathrm{cm}^{2}$. Houve diferença estatisticamente significante $(p=0,0006)$ entre os grupos sham e OVX, demonstrando que a ovariectomia reduziu a BMD do osso longo, e também entre os grupos OVX e OVX+ALD, demonstrando que este medicamento foi capaz de restabelecer a BMD aos níveis de normalidade. O medicamento Odanacatib (ODN) foi estatisticamente semelhante aos demais grupos. 
Figura 5. Densidade mineral óssea (BMD), 12 semanas após a realização da ovariectomia (OVX) ou da cirurgia fictícia (sham) e da administração dos medicamentos Alendronato (ALD) ou Odanacatib (ODN). Letras diferentes indicam diferença estatisticamente significante entre os grupos $(p=0,0006)$.

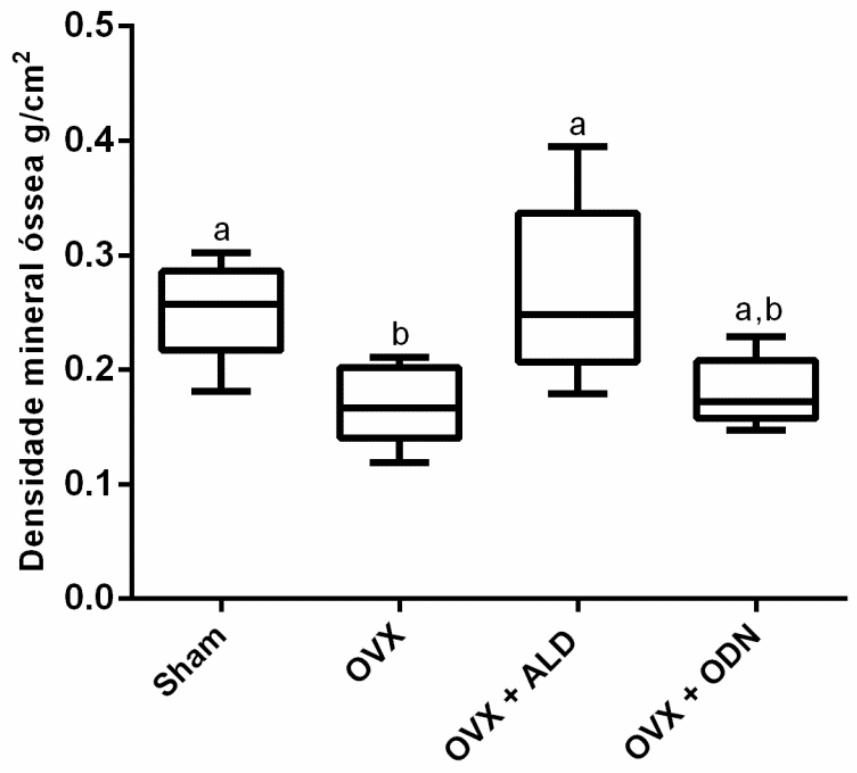

\section{4) Avaliação da microarquitetura e da BMD dos fêmures e maxilas, por meio de microtomografia computadorizada (micro-CT)}

Os resultados obtidos após a avaliação da BMD dos fêmures encontram-se na Figura 6. As médias de BMD dos grupos sham, OVX, OVX+ALD e OVX+ODN foram, respectivamente, $0,35( \pm 0,03), 0,21( \pm 0,01), 0,30( \pm 0,04)$ e $0,26( \pm 0,03)$ $\mathrm{g} / \mathrm{cm}^{3}$. Houve diferença estatisticamente significante $(p<0,001)$ entre os grupos sham e OVX, ou seja, os animais ovariectomizados apresentaram menor BMD que os animais sham. A administração dos medicamentos aumentou a BMD do fêmur; entretanto, apenas o medicamento ALD foi capaz de recuperar o fenótipo semelhante aos animais sham.

Após a avaliação da microarquitetura óssea do fêmur (Figura 7), com relação à porcentagem de volume ósseo (BV/TV), ao número de trabéculas (Tb.N.) e à separação trabecular (Tb.Sp.) foi possível encontrar diferença estatisticamente significante $(p<0.05)$ entre os grupos sham e OVX, ou seja, a ovariectomia provocou alterações nestes parâmetros. Ambos os medicamentos avaliados atuaram nos 
parâmetros BV/TV e Tb.N., porém, não foram capazes de restabelecer o fenótipo semelhante aos animais sham. O ALD foi capaz de recuperar o fenótipo apenas no parâmetro Tb.Sp. do fêmur. Com relação à espessura trabecular (Tb.Th.), não foi possível encontrar diferenças entre os grupos $(p=0,10)$.

Os resultados obtidos após a avaliação da BMD das maxilas encontram-se na Figura 8. As médias de BMD dos grupos sham, OVX, OVX+ALD e OVX+ODN foram, respectivamente, $1,11( \pm 0,02), 0,97( \pm 0,08), 1,09( \pm 0,03)$ e $1,02( \pm 0,04) \mathrm{g} / \mathrm{cm}^{3}$. Houve diferença estatisticamente significante $(p=0,004)$ entre os grupos sham e OVX, ou seja, os animais ovariectomizados apresentaram menor BMD maxilar que os animais sham. A administração dos medicamentos aumentou a BMD da maxila; entretanto, apenas o medicamento ALD foi capaz de recuperar o fenótipo semelhante aos animais sham.

Após a avaliação da microarquitetura óssea das maxilas (Figura 9), não foi possível encontrar diferença estatisticamente significante $(p>0,05)$ entre os grupos com relação à porcentagem de volume ósseo (BV/TV), à espessura trabecular (Tb.Th.), ao número de trabéculas (Tb.N.) e à separação trabecular (Tb.Sp.).

As figuras 10 e 11 ilustram espécimes representativos dos diferentes grupos avaliados.

Figura 6. Densidade mineral óssea dos fêmures, em $\mathrm{g} / \mathrm{cm}^{3}$, após 12 semanas da realização da ovariectomia (OVX) ou da cirurgia fictícia (sham) e da administração do Alendronato (ALD) ou do Odanacatib (ODN). Letras diferentes indicam diferença significante entre os grupos $(p<0,001)$.

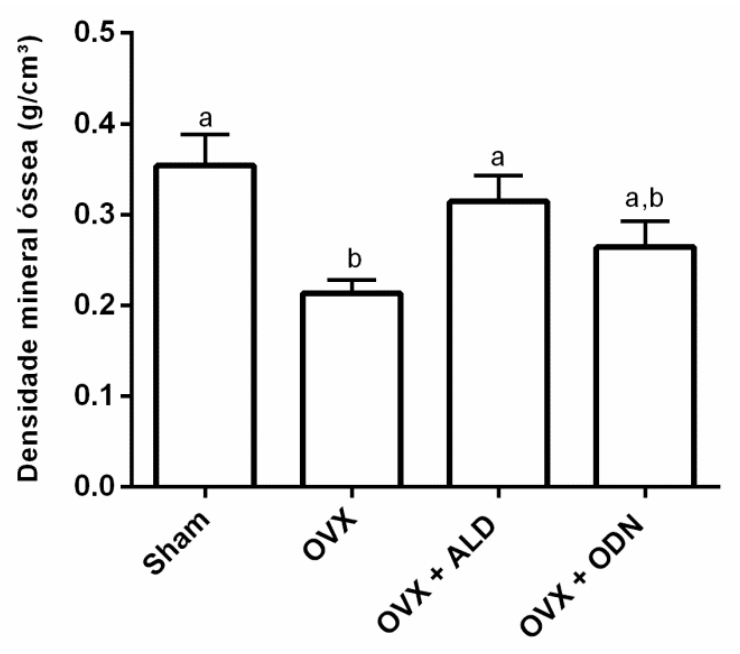


Figura 7. Microarquitetura óssea dos fêmures, após 12 semanas da realização da ovariectomia (OVX) ou da cirurgia fictícia (sham) e da administração do Alendronato (ALD) ou do Odanacatib (ODN). Letras diferentes indicam diferença significante entre os grupos $(p<0,05)$.
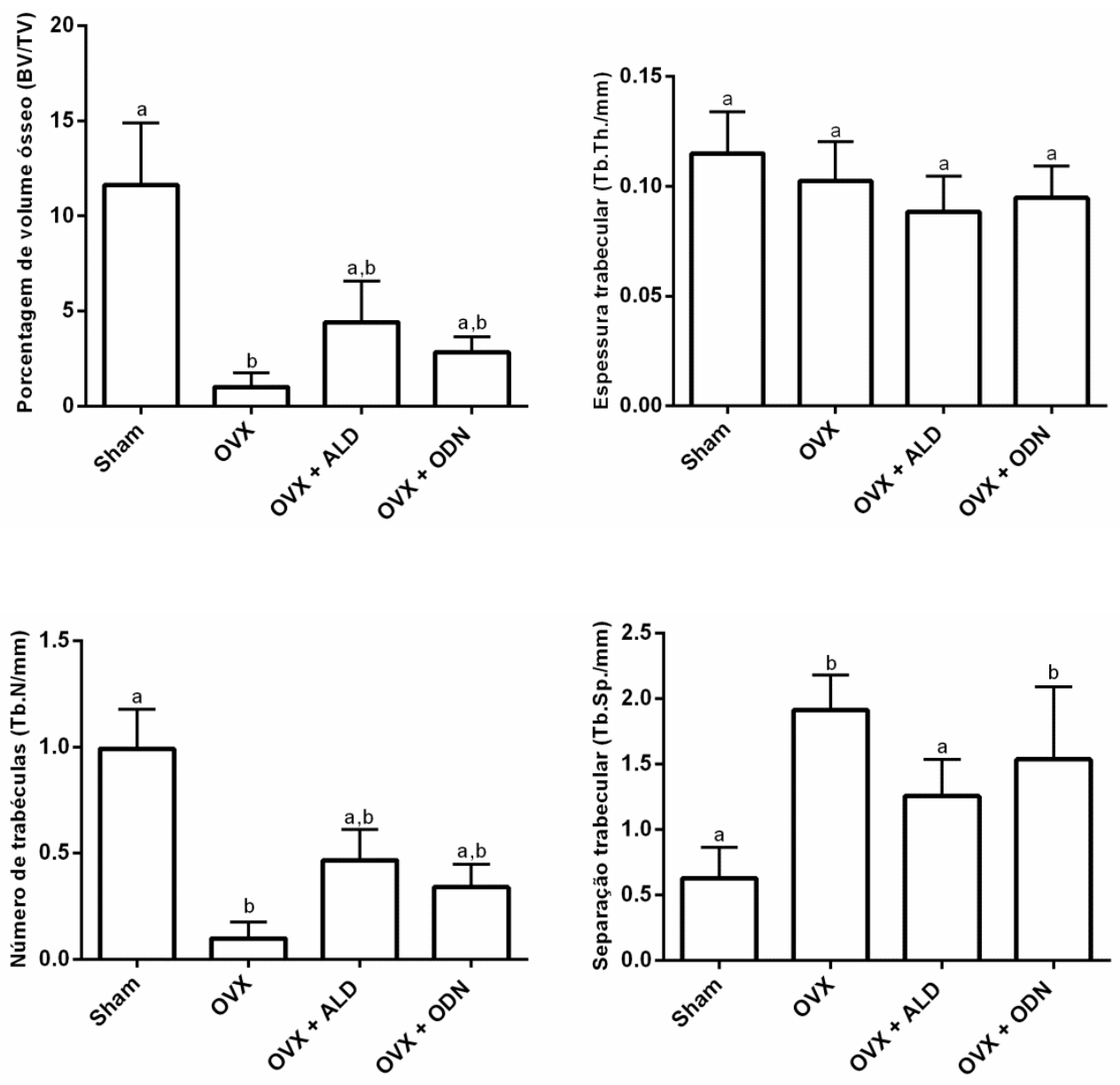

Figura 8. Densidade mineral óssea das maxilas, em $\mathrm{g} / \mathrm{cm}^{3}$, após 12 semanas da realização da ovariectomia (OVX) ou da cirurgia fictícia (sham) e da administração do Alendronato (ALD) ou do Odanacatib (ODN). Letras diferentes indicam diferença significante entre os grupos $(p=0,004)$.

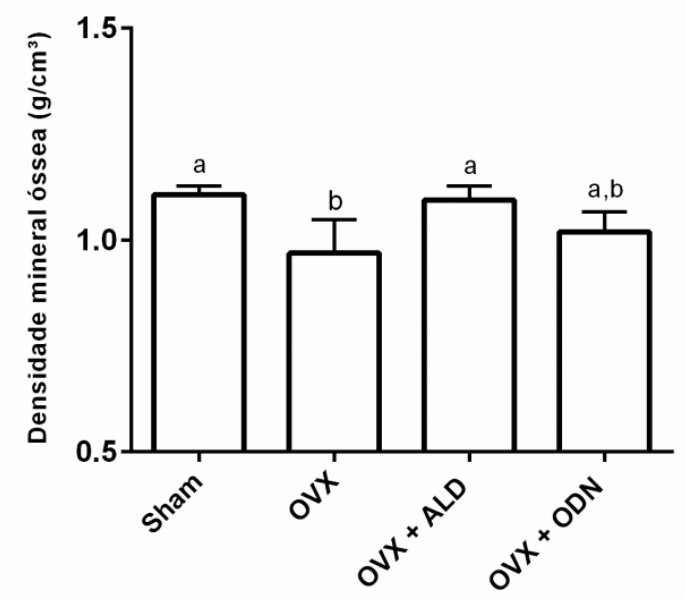


Figura 9. Microarquitetura óssea das maxilas, após 12 semanas da realização da ovariectomia (OVX) ou da cirurgia fictícia (sham) e da administração do Alendronato (ALD) ou do Odanacatib (ODN). Letras iguais indicam que não foi possível encontrar diferença significante entre os grupos $(p>0,05)$.
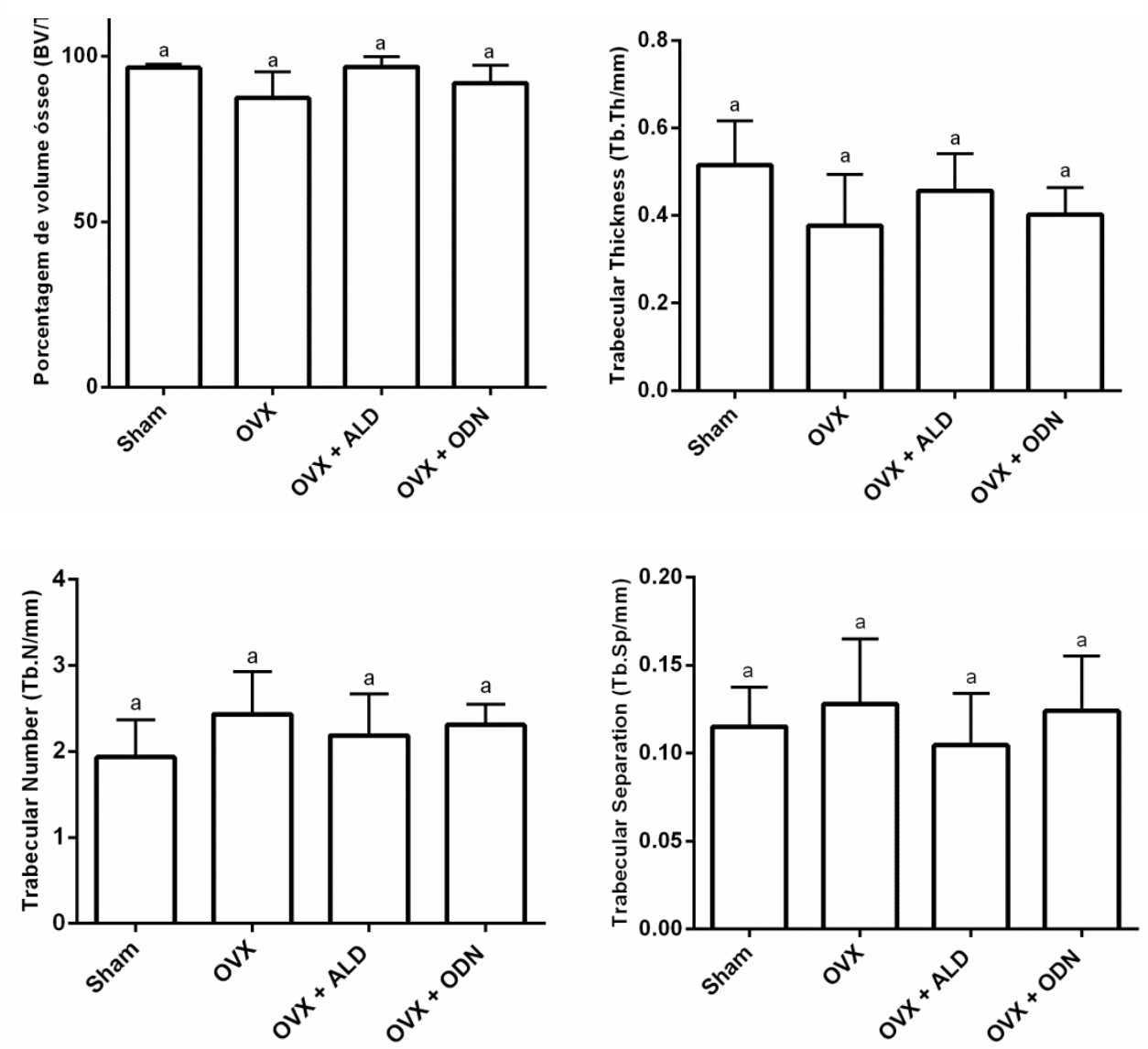

Figura 10. Imagens representativas da região de interesse (ROI) de fêmures dos diferentes grupos avaliados, 12 semanas após a realização da ovariectomia (OVX) ou da cirurgia fictícia (sham) e da administração do Alendronato (ALD) ou do Odanacatib (ODN).

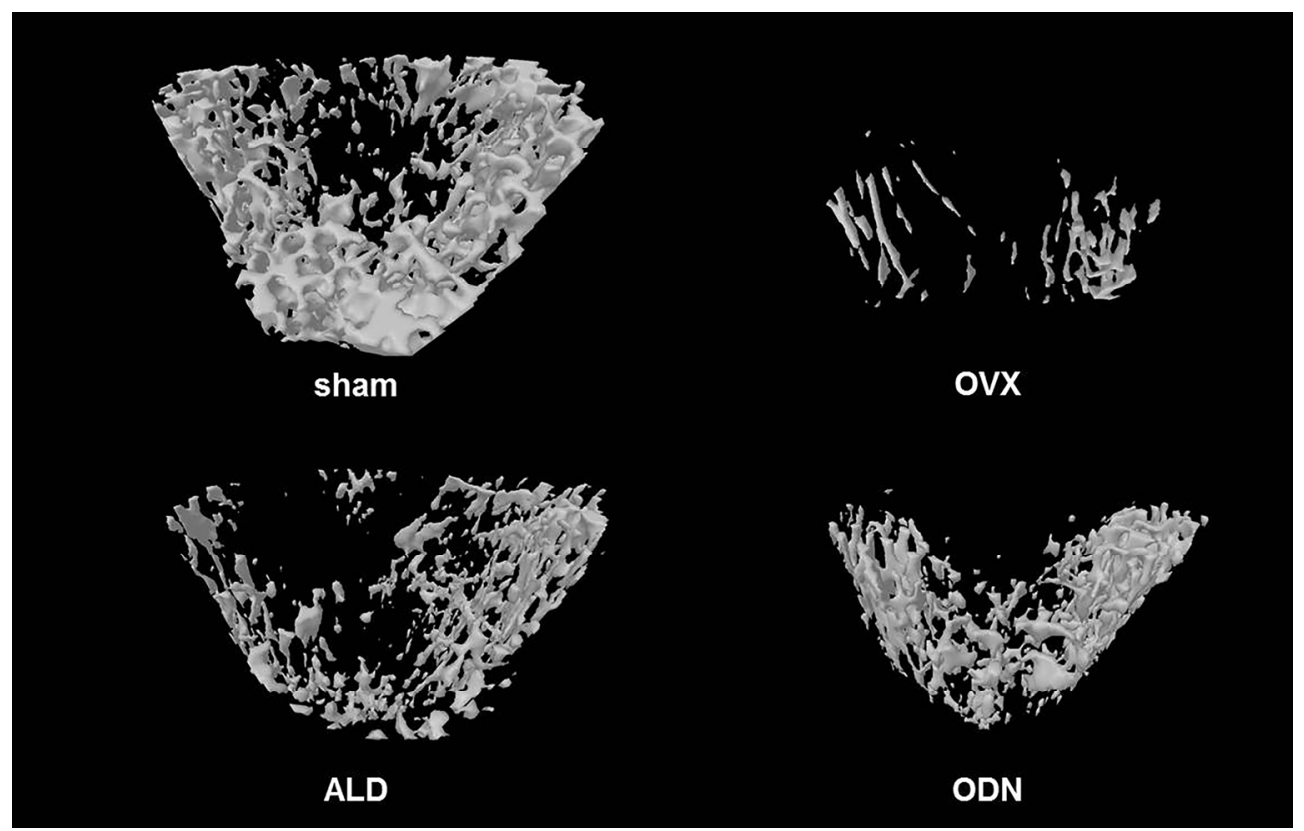

Figura 11. Imagens representativas da região de interesse (ROI) de maxilas dos diferentes grupos avaliados, 12 semanas após a realização da ovariectomia (OVX) ou da cirurgia fictícia (sham) e da administração do Alendronato (ALD) ou do Odanacatib (ODN).

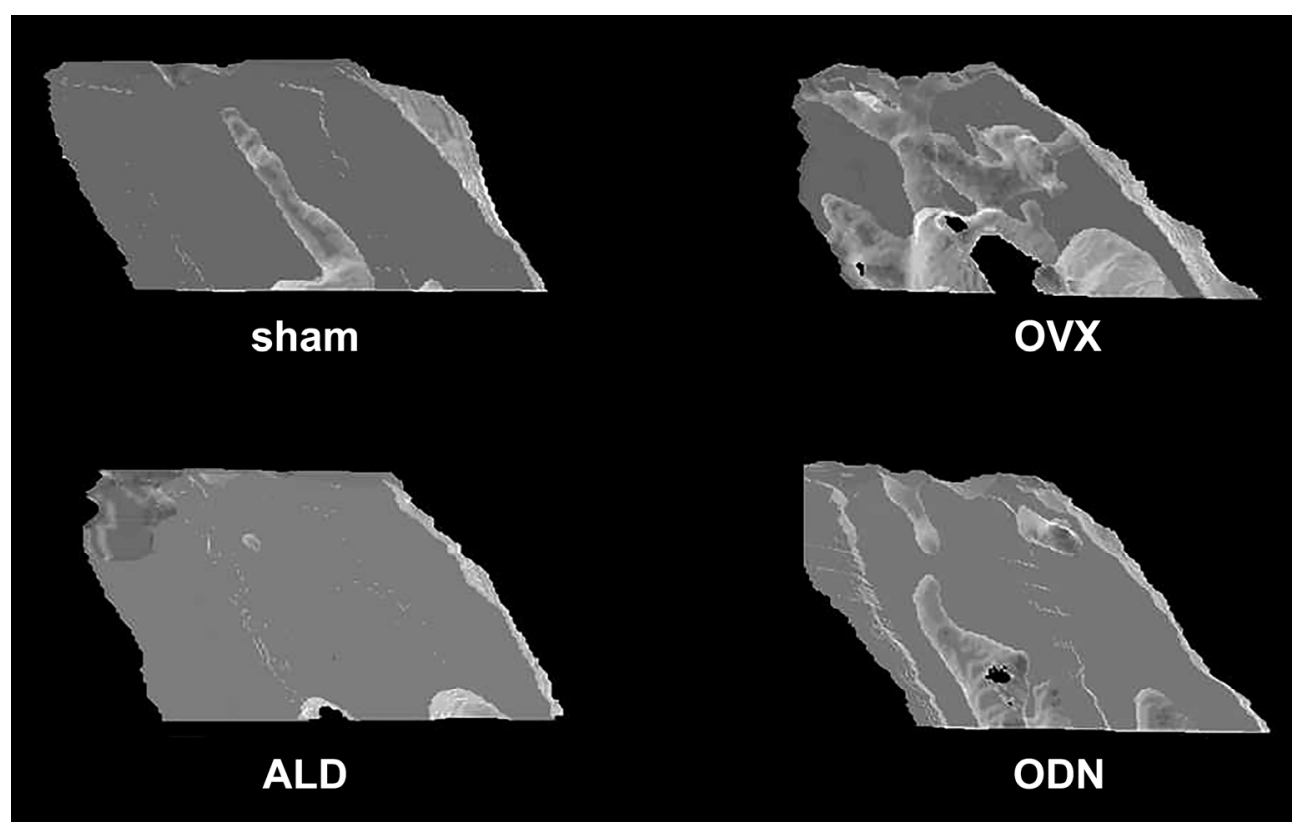



5) Detecção da expressão gênica de citocinas pró-inflamatórias, de marcadores da osteoclastogênese e de metaloproteinases da matriz, nos dentes com ou sem lesão periapical por meio da reação em cadeia da polimerase em tempo real (RT-PCR)

Com relação à expressão dos marcadores da osteoclastogênese (RANK, RANKL e OPG), a indução da lesão periapical promoveu um aumento significante $(p<0,05)$ de RANK, RANKL e da razão RANKL/OPG nos animais ovariectomizados (Figura 12). Os tratamentos não tiveram efeito na expressão de RANK, RANKL e OPG (Figura 13).

Com relação às citocinas pró-inflamatórias (IL-1 $\beta$, IL-6 e TNF-a), observouse que a indução da lesão periapical promoveu uma tendência de aumento na expressão destas citocinas nos animais sham+LP. Entretanto, esse aumento foi estatisticamente significante apenas para IL-6. Já nos animais ovariectomizados, a indução da lesão periapical promoveu um aumento significante $(p<0,05)$ na expressão das citocinas IL-1 $\beta$, IL-6 e TNF-a (Figura 14). Os tratamentos não alteraram a expressão de IL-1 $\beta$ e TNF-a nas lesões periapicais e, embora ambos os tratamentos tenham diminuído a expressão de IL-6, apenas o tratamento com ALD promoveu uma redução estatisticamente significante $(p<0,05)$ (Figura 15).

Com relação à expressão de metaloproteinases da matriz (MMP-1, 8 e 13), houve uma tendência à redução na expressão de MMP-1 após a indução da lesão periapical nos animais ovariectomizados ou sham. Entretanto, esta redução não foi estatisticamente significante $(p>0,05)$. As lesões periapicais nos animais ovariectomizados apresentaram maior expressão de MMP-8 em comparação às lesões induzidas nos animais sham $(p<0,05)$. Ainda, a indução da lesão periapical, em animais ovariectomizados ou sham, modulou o aumento significante de MMP-13 $(p<0,05)$ (Figura 16). O tratamento com ALD inibiu a MMP-8 de forma significativa $(p<0,05)$. Os tratamentos não modularam a expressão de MMP-1 e MMP-13 (Figura 17). 
Figura 12. Expressão dos marcadores da osteoclastogênese (RANK, RANKL e OPG), evidenciando a comparação realizada entre os grupos controles, ou seja, que não receberam tratamento com antirreabsortivos. Sham = cirurgia de ovariectomia fictícia; OVX = ovariectomia; LP = lesão periapical; \# = diferença estatisticamente significante entre os grupos OVX e OVX+LP.

\section{Tnfrs11a (RANK)}

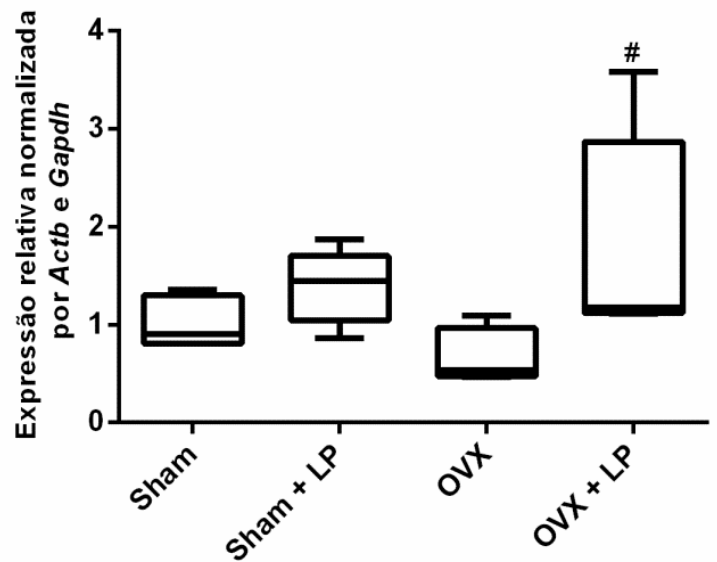

Tnfrsf11b (OPG)

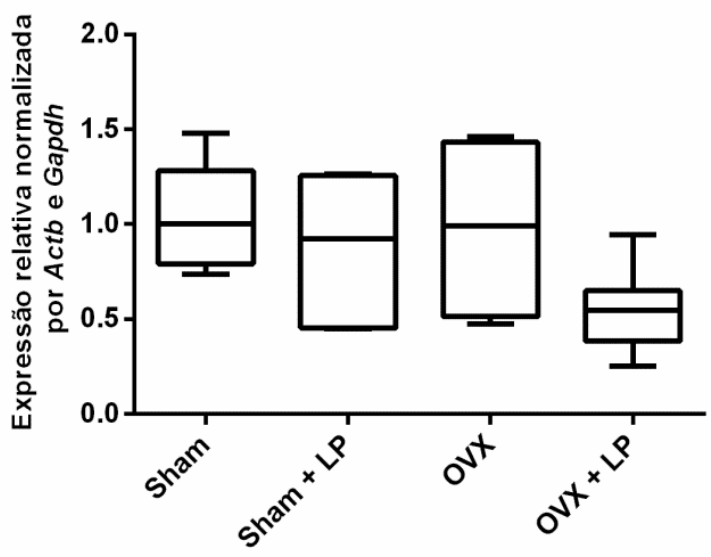

Tnfsf11 (RANKL)

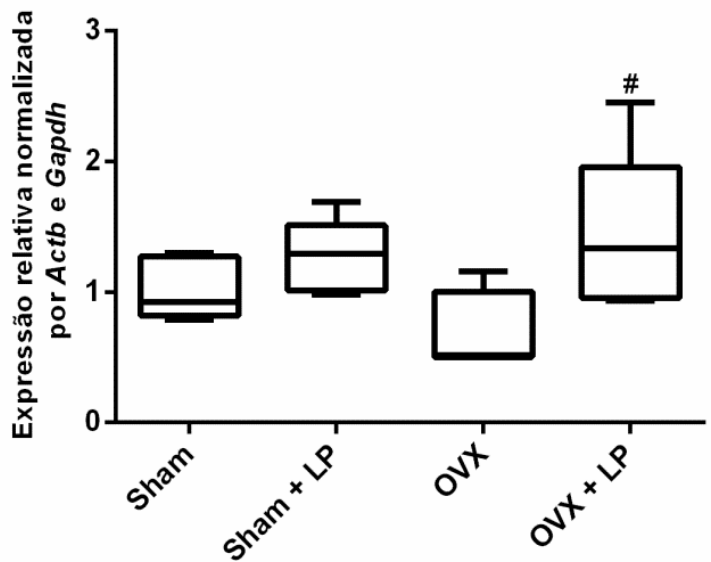

Tnfsf11/Tnfrsf11b (RANKL/OPG)

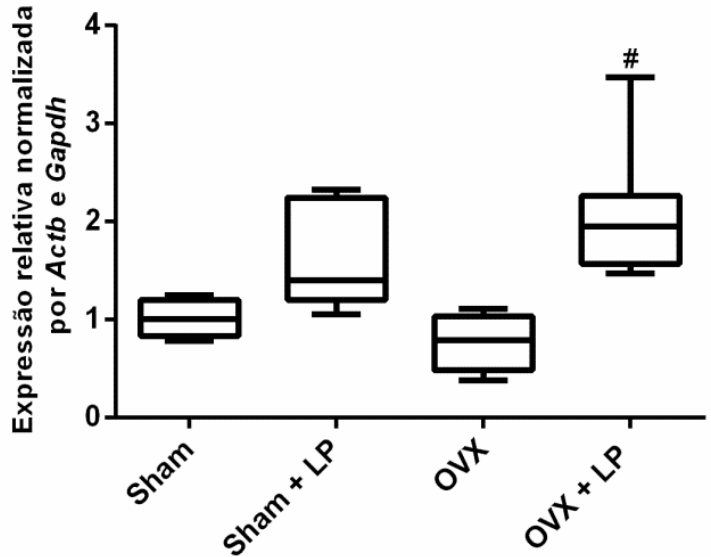


Figura 13. Expressão dos marcadores da osteoclastogênese (RANK, RANKL e OPG), evidenciando a comparação realizada entre os grupos experimentais. Sham = cirurgia de ovariectomia fictícia; OVX = ovariectomia; LP = lesão periapical; ALD = Alendronato; ODN = Odanacatib. Não foi possível encontrar diferença estatisticamente significante entre os grupos $(p>0,05)$.
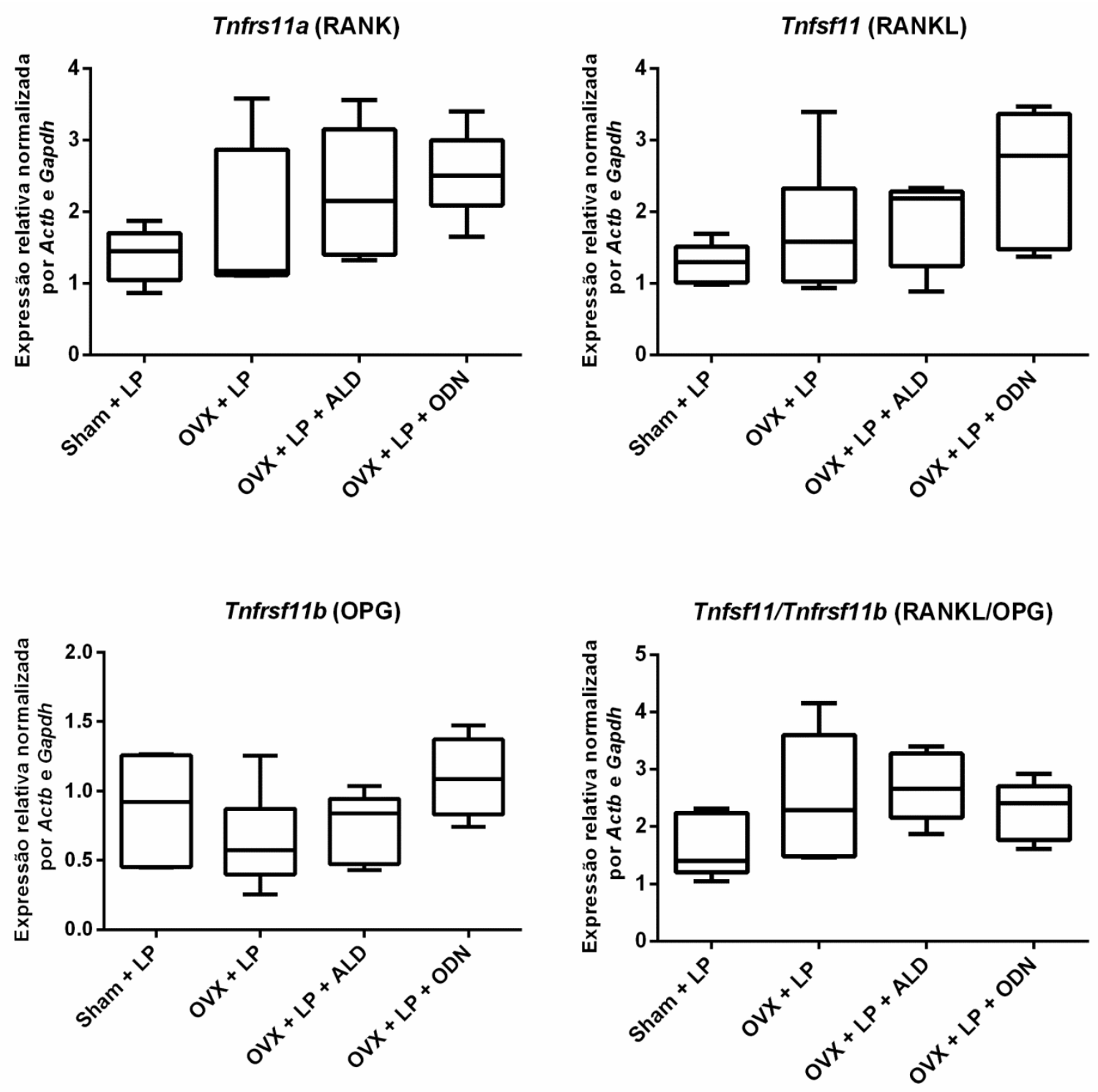
Figura 14. Expressão de citocinas pró-inflamatórias (IL-1ß, IL-6 e TNF-a), evidenciando a comparação realizada entre os grupos controles, ou seja, que não receberam tratamento com antirreabsortivos. Sham = cirurgia de ovariectomia fictícia; OVX = ovariectomia; LP = lesão periapical.

* = diferença estatisticamente significante entre os grupos sham e sham+LP.

\# = diferença estatisticamente significante entre os grupos OVX e OVX+LP.

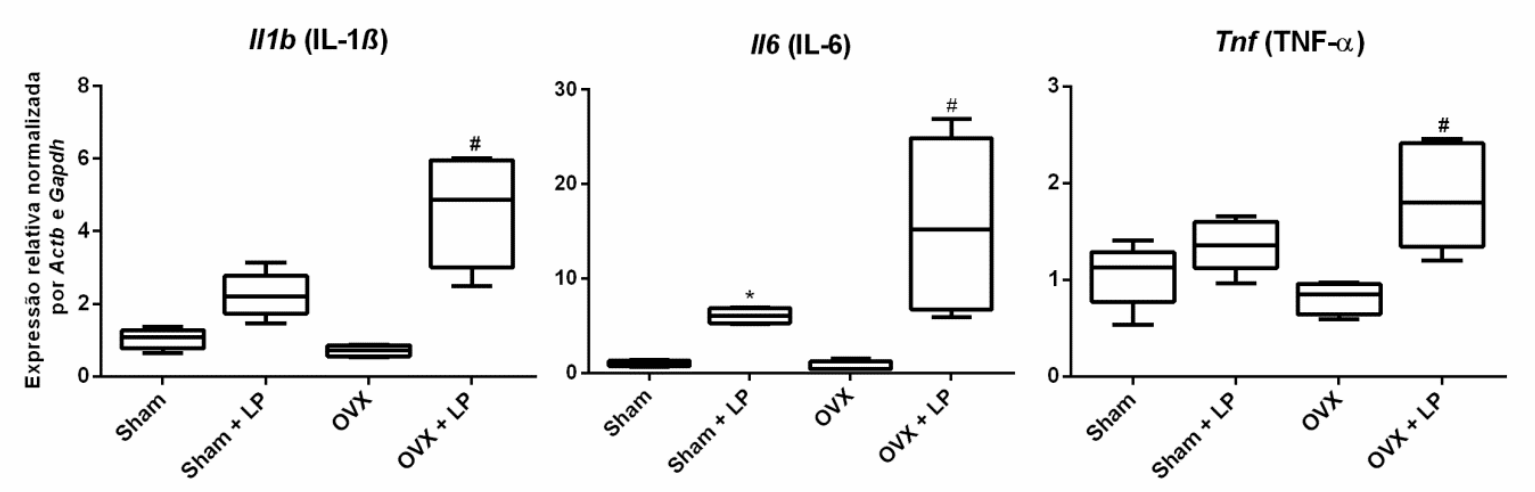

Figura 15. Expressão de citocinas pró-inflamatórias (IL-1ß, IL-6 e TNF-a), evidenciando a comparação realizada entre os grupos experimentais. Sham = cirurgia de ovariectomia fictícia; OVX = ovariectomia; $L P=$ lesão periapical; ALD = Alendronato; ODN = Odanacatib.

$\$=$ diferença estatisticamente significante entre os grupos OVX+LP e OVX+LP+ALD.
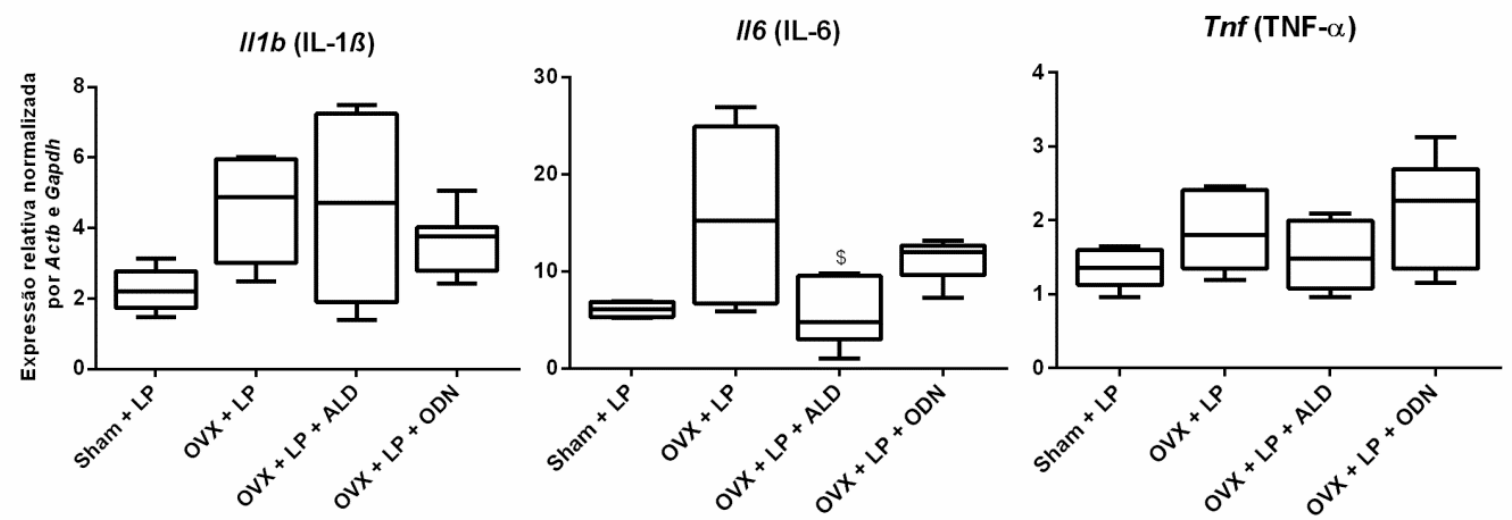
Figura 16. Expressão de metaloproteinases da matriz (MMP-1, 8 e 13), evidenciando a comparação realizada entre os grupos controles, ou seja, que não receberam tratamento com antirreabsortivos. Sham = cirurgia de ovariectomia fictícia; OVX = ovariectomia; LP = lesão periapical.

* = diferença estatisticamente significante entre os grupos sham e sham+LP.

\# = diferença estatisticamente significante entre os grupos OVX e OVX+LP.
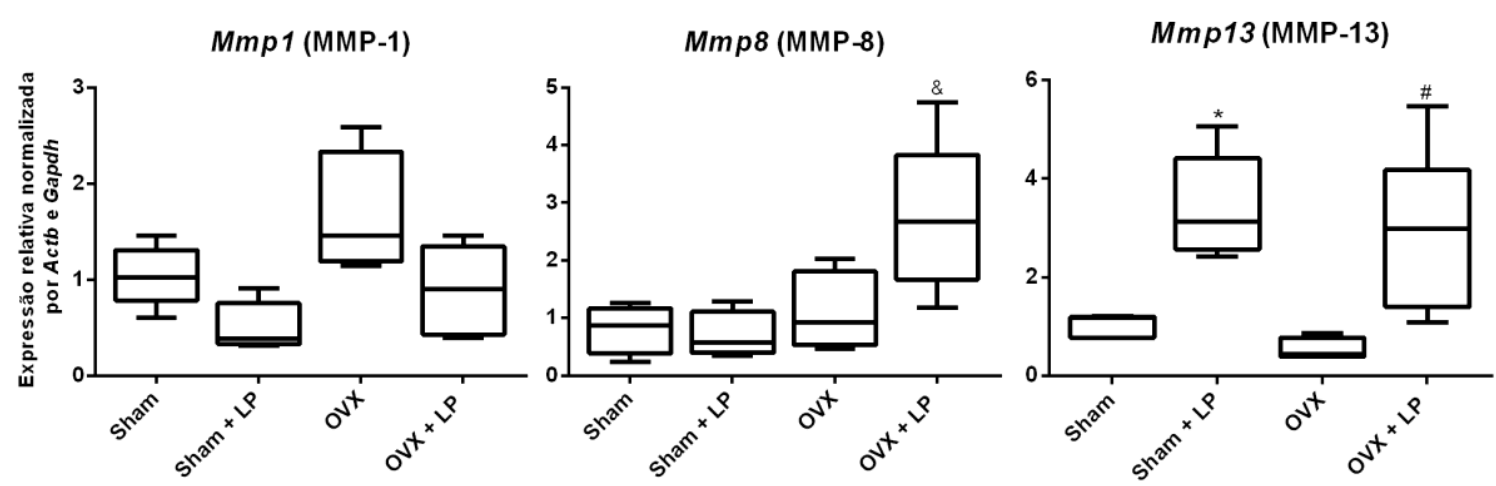

Figura 17. Expressão de metaloproteinases da matriz (MMP-1, 8 e 13), evidenciando a comparação realizada entre os grupos experimentais. Sham = cirurgia de ovariectomia fictícia; OVX = ovariectomia; $\mathrm{LP}=$ lesão periapical; ALD = Alendronato; ODN = Odanacatib.

$\$=$ diferença estatisticamente significante entre os grupos OVX+LP e OVX+LP+ALD.
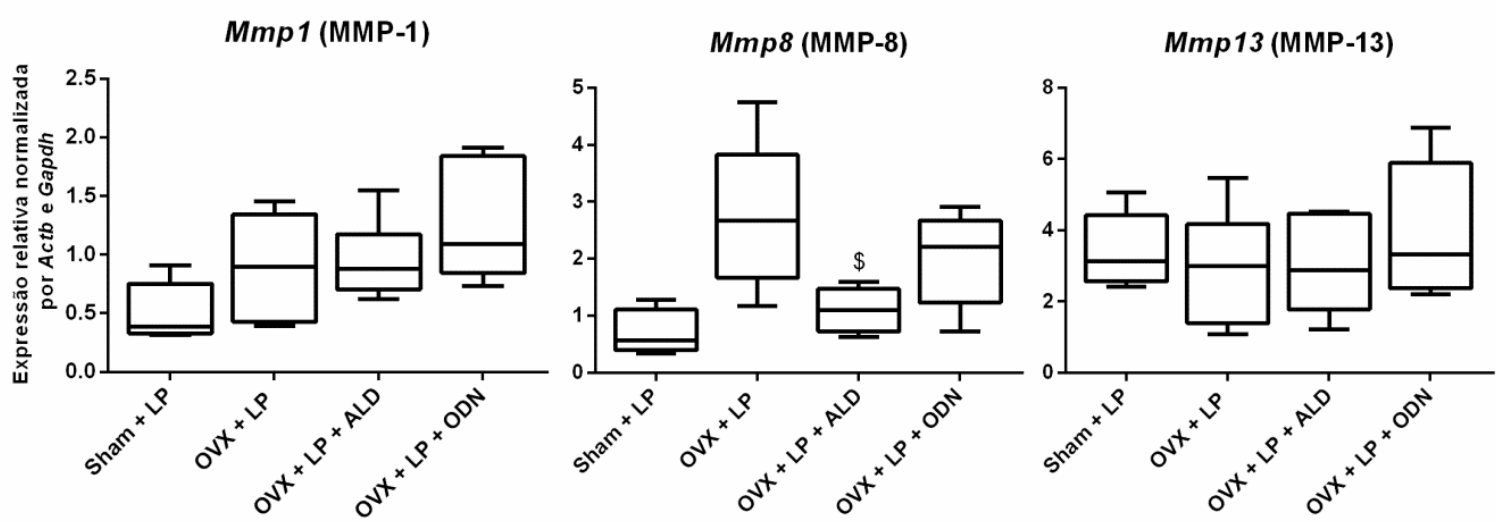


\section{6) Estudo Histopatológico}

\section{Análise microscópica descritiva das regiões apical e periapical}

De acordo com a análise microscópica descritiva da região apical e periapical, verificou-se que os grupos sem a indução de lesão periapical (sham e OVX) apresentaram resultados muito homogêneos. Em ambos os grupos, todos os espécimes avaliados evidenciaram espessura do ligamento periodontal normal, ausência de infiltrado inflamatório, presença abundante de fibras e ausência de processos reabsortivos dos tecidos mineralizados (osso e cemento). Assim, observouse que a ovariectomia não influenciou no aspecto microscópico das estruturas da região apical e periapical.

Com relação à espessura do ligamento periodontal, o grupo sham+LP apresentou um moderado aumento na espessura do ligamento periodontal na maioria dos espécimes avaliados. Por outro lado, o grupo OVX+LP não apresentou uniformidade na resposta tecidual, sendo que metade dos espécimes apresentou espessura moderadamente aumentada e a outra metade apresentou um severo aumento da espessura do ligamento periodontal. O grupo OVX+LP+ALD apresentou um padrão similar ao grupo sham+LP. Por outro lado, o grupo OVX+LP+ODN apresentou resposta tecidual semelhante ao grupo $\mathrm{OVX}+\mathrm{LP}$, não apresentando uniformidade.

O mesmo padrão foi observado com relação ao infiltrado inflamatório. Nos grupos sham+LP e OVX+LP+ALD também houve maior uniformidade na resposta tecidual. A maioria dos espécimes destes dois grupos apresentou apenas um moderado aumento na intensidade de células inflamatórias. Por outro lado, os grupos $O V X+L P$ e $O V X+L P+O D N$ não apresentaram uniformidade, sendo que nestes grupos a metade dos espécimes apresentou moderado aumento na intensidade de células inflamatórias e a outra metade apresentou um severo aumento na quantidade destas células.

Em todos os grupos com lesão periapical o infiltrado inflamatório, independentemente da intensidade, apresentou sempre o mesmo padrão, sendo 
predominantemente macrofágico com presença de células espumosas ou pseudoxantomatosas, representadas por macrófagos carregados de lipídeos.

Com relação à reabsorção dos tecidos mineralizados (osso e cemento), todos os grupos onde foi induzida a lesão periapical, com ou sem tratamento, apresentaram processos de reabsorção na maioria dos espécimes avaliados.

A Figura 18 apresenta imagens representativas dos parâmetros avaliados. 
Figura 18. Fotomicrografias representativas dos grupos avaliados, evidenciando os eventos microscópicos observados na análise descritiva das regiões apical e periapical, em microscopia de luz convencional (coloração de $\mathrm{HE})$.

(A) Fotomicrografia de um dente hígido, sem lesão periapical. As regiões apical e periapical encontram-se normais, com espessura do ligamento periodontal normal, ausência de infiltrado inflamatório e ausência de reabsorção dos tecidos mineralizados. (Zeiss, 5X).

(B) Fotomicrografia da região apical e periapical de um dente com lesão periapical. A espessura do ligamento periodontal e a intensidade do infiltrado inflamatório encontram-se moderadamente aumentadas. (Zeiss, 5X).

(C) Fotomicrografia da região apical e periapical de um dente com lesão periapical. A espessura do ligamento periodontal e a intensidade do infiltrado inflamatório encontram-se severamente aumentadas. (Zeiss, 5X).

(D) Maior aumento da imagem C, evidenciando o infiltrado inflamatório predominantemente macrofágico. (Zeiss, 40X). 

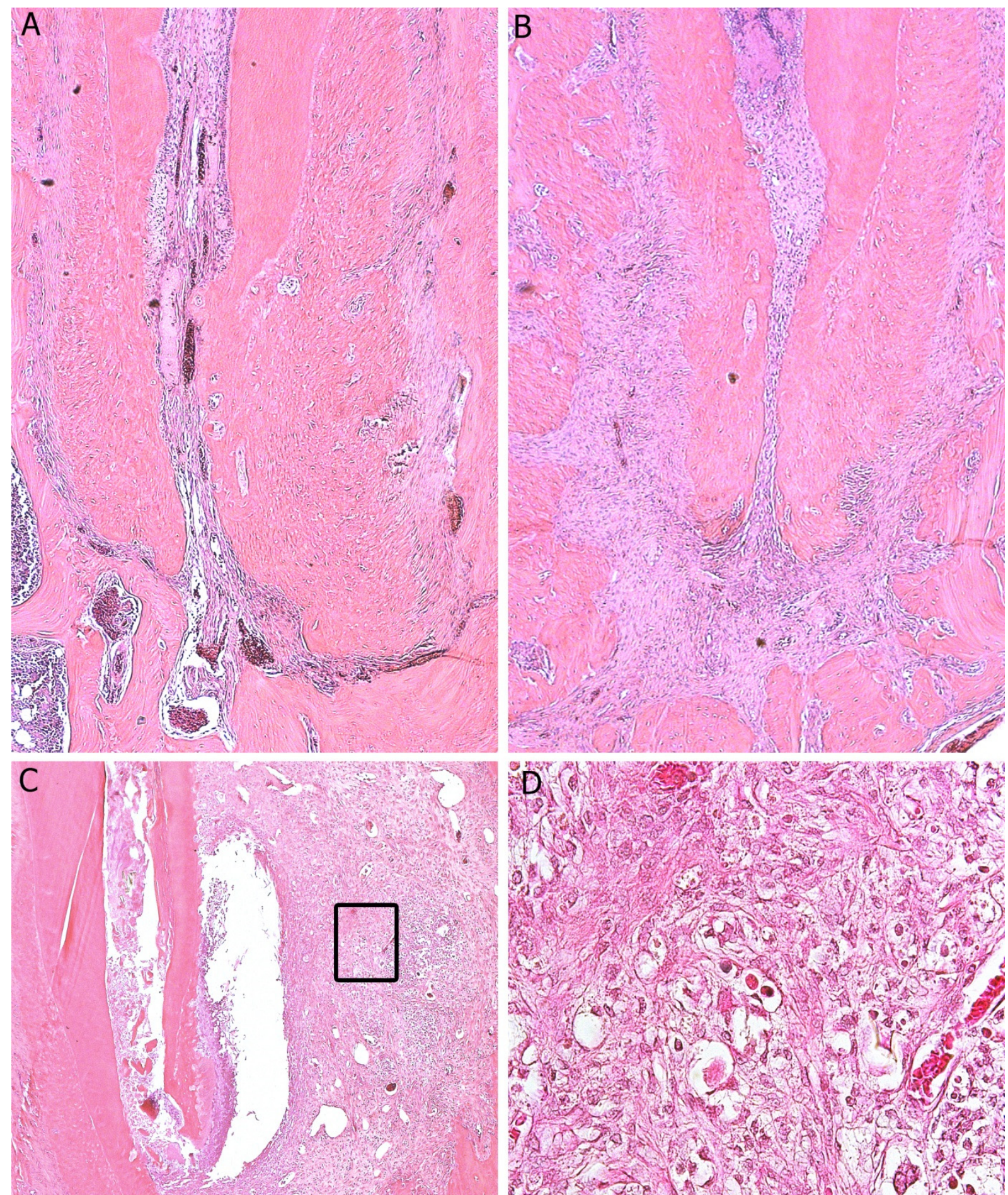

D. 1 -

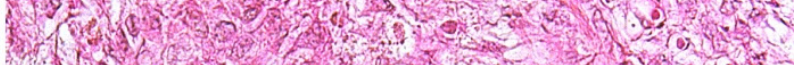

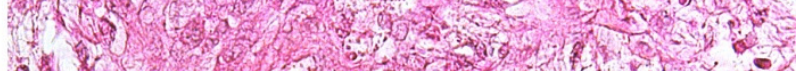
1.1.

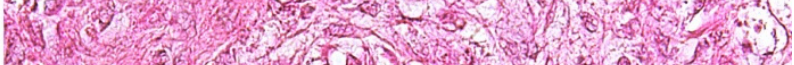

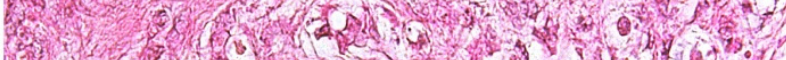

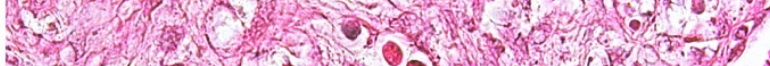

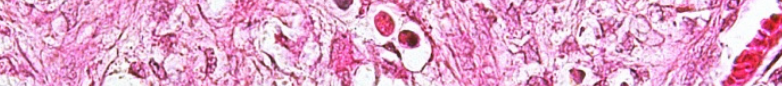

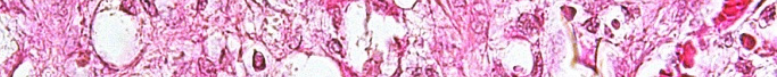

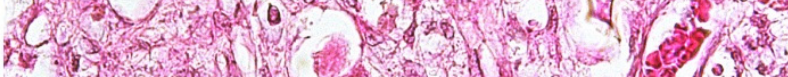

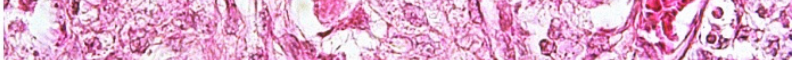

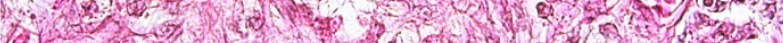

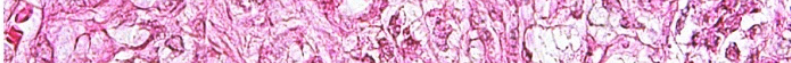

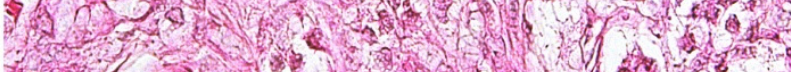

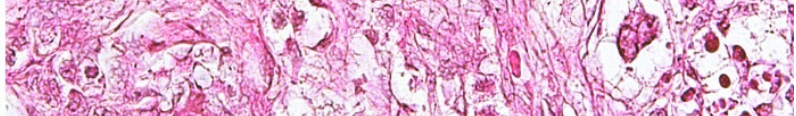

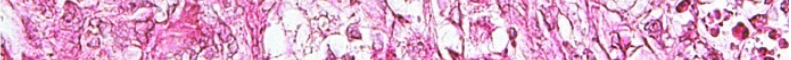

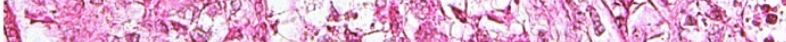

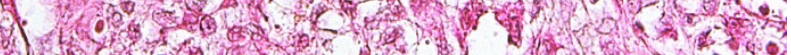

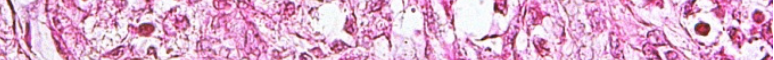

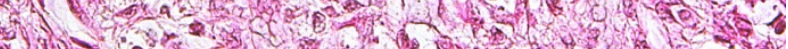

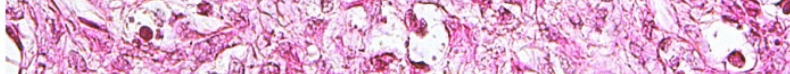

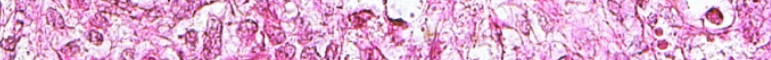
Q1

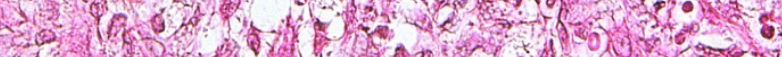

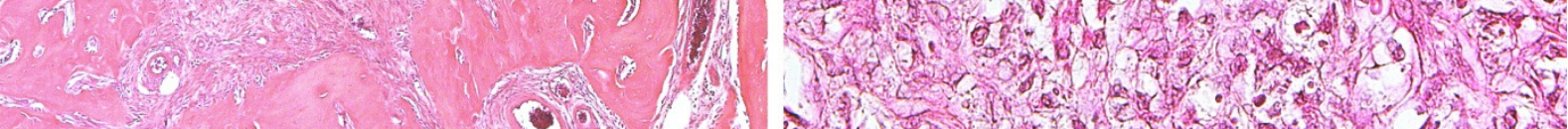

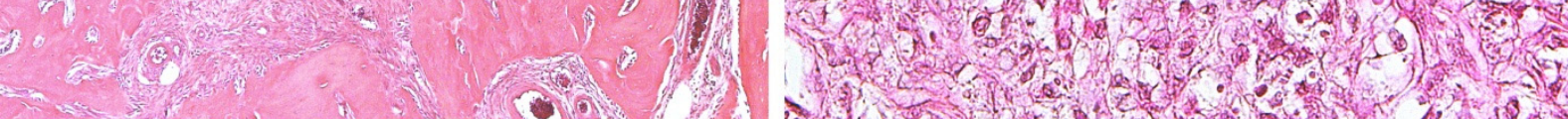





\section{7) Mensuração da área das lesões periapicais ou da área do espaço do ligamento periodontal na região periapical, por meio da técnica de fluorescência}

No grupo sham sem indução de lesão periapical a média da área do espaço do ligamento periodontal foi de $0,27 \mathrm{~mm}^{2}$ e, no grupo ovariectomizado, foi de $0,30 \mathrm{~mm}^{2}$. Não foi possível encontrar diferença estatisticamente significante entre esses grupos $(p=0,66)$.

No grupo sham com indução de lesão periapical a média da área das lesões foi de $1,00( \pm 0,82) \mathrm{mm}^{2}$ e, no grupo ovariectomizado com lesão, foi de 2,07 $( \pm 0,91)$ $\mathrm{mm}^{2}$, demonstrando que as lesões no grupo ovariectomizado sem tratamento foram maiores que no grupo sham. No grupo ovariectomizado tratado com ALD, a média da área das lesões foi de $0,83( \pm 0,24) \mathrm{mm}^{2}$, enquanto no grupo ovariectomizado tratado com ODN foi de $1,21( \pm 0,85) \mathrm{mm}^{2}$. Em geral, nos grupos com lesão periapical houve redução da área das lesões periapicais após a administração dos medicamentos antirreabsortivos. Entretanto, foi possível encontrar diferença estatisticamente significante apenas entre o grupo ovariectomizado sem tratamento e o grupo ovariectomizado tratado com $\operatorname{ALD}(p=0,009)$. As Figuras 19 e 20 ilustram os resultados obtidos nos grupos onde a lesão periapical foi induzida.

Figura 19. Área das lesões periapicais em $\mathrm{mm}^{2}$ nos grupos com lesão periapical. Sham=cirurgia de ovariectomia fictícia; OVX=ovariectomia; LP=lesão

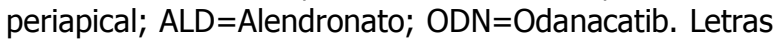
diferentes indicam diferença significante entre os grupos $(p=0,009)$.

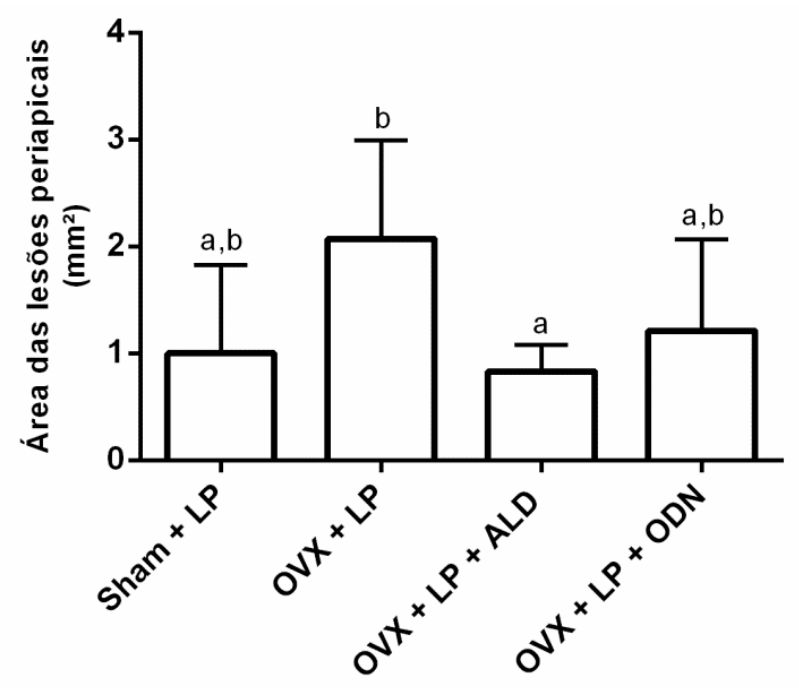



Figura 20. Fotomicrografias de cortes microscópicos representativos dos grupos onde a lesão periapical foi induzida. (A) Sham+LP; (B) OVX+LP; (C) OVX+LP+ALD; (D) OVX+LP+ODN. As imagens foram analisadas no modo fluorescente, para mensuração da área das lesões periapicais, como delimitado nas figuras. OVX = ovariectomia; LP = lesão periapical; $A L D=$ Alendronato; ODN = Odanacatib. (HE, Zeiss, 5X).
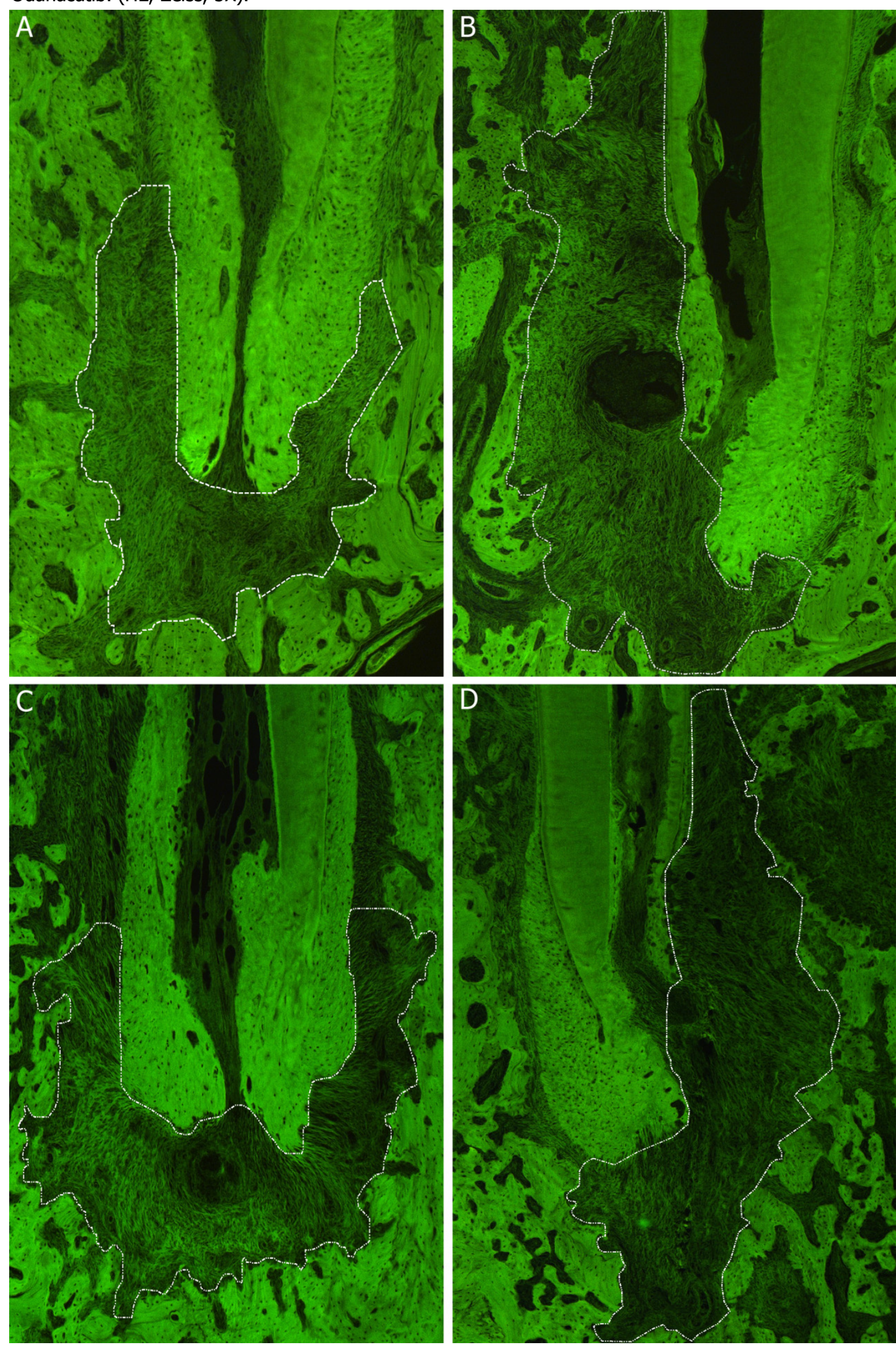



\section{8) Histoenzimologia para a atividade da fosfatase ácida resistente ao tartarato (TRAP), para contagem de osteoclastos}

Foi possível encontrar diferença estatisticamente significante apenas para a variável lesão periapical $(p<0,0001)$, ou seja, apenas a indução da lesão interferiu aumentando o número dos osteoclastos, enquanto a OVX não interferiu nesse aspecto (Figura 21). Na comparação entre os grupos onde a lesão periapical foi induzida (Figura 22), com ou sem tratamento, não foi possível encontrar diferença estatística significante $(p=0,38)$. A Figura 23 ilustra os dados obtidos após a realização da histoenzimologia.

Figura 21. Distribuição do número de osteoclastos (células TRAP-positivas $/ \mathrm{mm}$ ). Sham=cirurgia de ovariectomia fictícia; $\mathrm{OVX}=$ ovariectomia; $\mathrm{LP}=$ lesão periapical; $*=$ diferença estatisticamente significante $(p<0,0001)$.

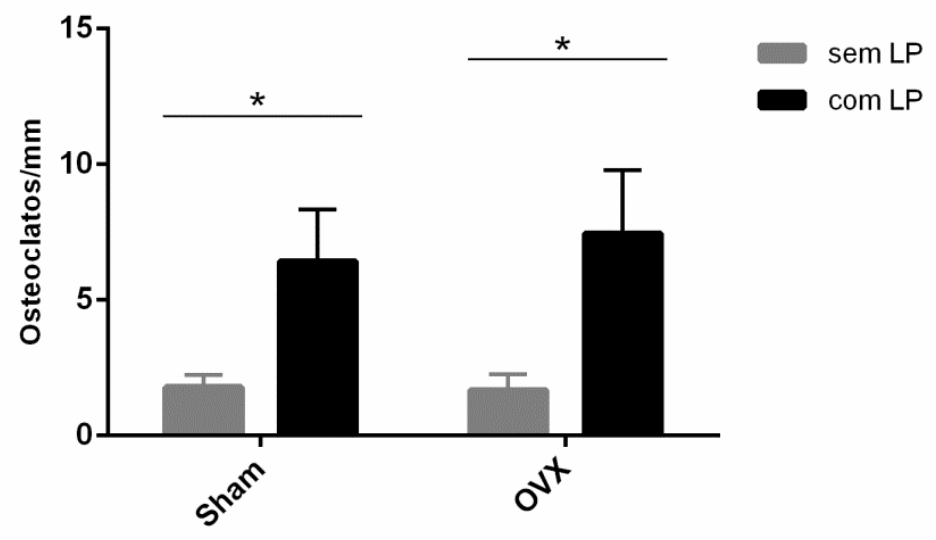

Figura 22. Distribuição do número de osteoclastos. Sham=cirurgia de ovariectomia fictícia; OVX=ovariectomia; $\mathrm{LP}=$ lesão periapical; $\mathrm{ALD}=$ Alendronato; $\mathrm{ODN}=$ Odanacatib. Letras iguais indicam que não houve diferença significante $(p=0,38)$.

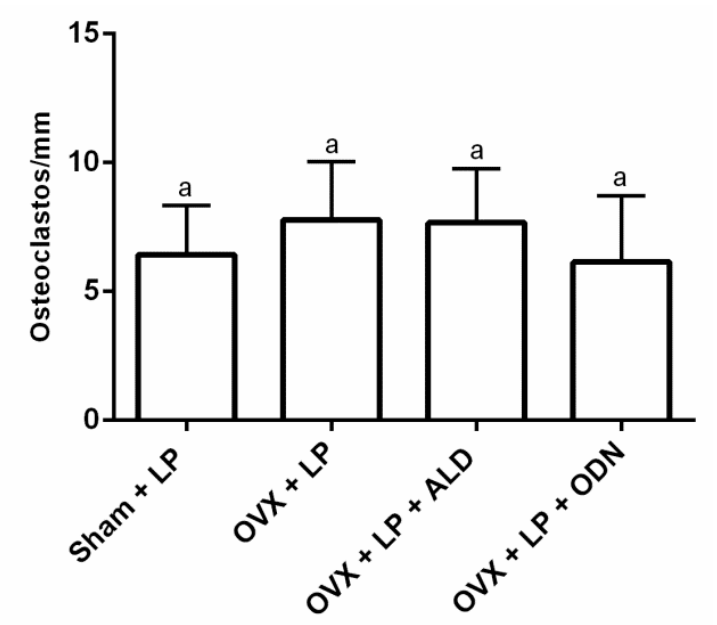


Figura 23. Fotomicrografias dos cortes microscópicos representativos dos resultados obtidos, corados por meio da técnica de histoenzimologia para a atividade da fosfatase ácida resistente ao tartarato (TRAP), para identificação e contagem de células osteoclásticas.

(A) Fotomicrografia da região apical e periapical de um dente hígido, sem lesão periapical, com número reduzido de osteoclastos (Zeiss, 10X).

(B) Fotomicrografia da região apical e periapical de um dente com lesão periapical, evidenciando a presença de osteoclastos (Zeiss, 10X).

(C) Maior aumento da imagem B, destacando osteoclastos (vermelho) presentes no osso alveolar, ao redor da lesão periapical (Zeiss, 40X). 

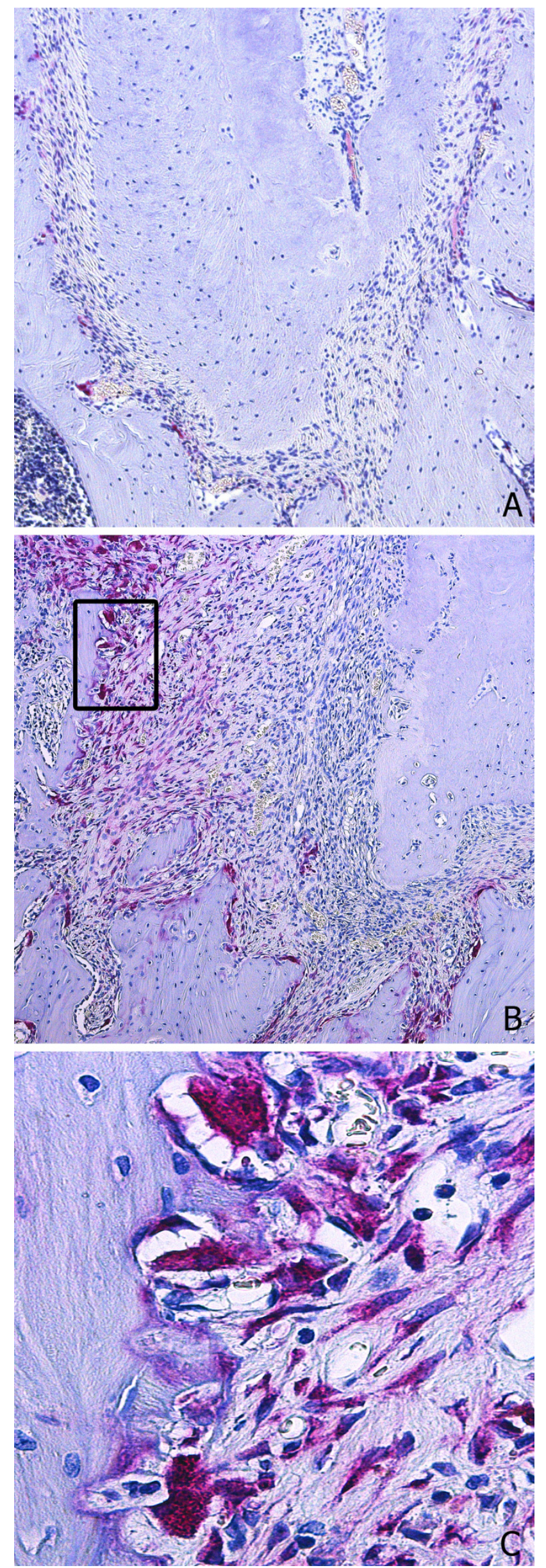



\section{9) Mensuração do volume das lesões periapicais ou do volume do espaço do ligamento periodontal na região periapical, por meio de microtomografia computadorizada (micro-CT)}

Nos grupos onde não foi induzida lesão periapical, a micro-CT evidenciou que a mediana do volume do ligamento periodontal nos animais do grupo sham foi de $0,41 \mathrm{~mm}^{3}(\mathrm{Q} 1=0,3460 ; \mathrm{Q} 3=0,4473)$, enquanto que no grupo ovariectomizado foi de $0,44 \mathrm{~mm}^{3}(\mathrm{Q} 1=0,38 ; \mathrm{Q} 3=0,53)$. Não foi possível detectar diferença estatisticamente significante $(p=0,48)$ entre os dois grupos, ou seja, apenas a ovariectomia não foi capaz de promover alterações no volume do ligamento periodontal.

No grupo sham com indução de lesão periapical a mediana da área das lesões foi de 1,70 mm $\mathrm{mm}^{3}(\mathrm{Q} 1=0,82 ; \mathrm{Q} 3=2,86)$ e, no grupo ovariectomizado com lesão, foi de $3,93 \mathrm{~mm}^{3} \quad(\mathrm{Q} 1=3,65 ; \quad Q 3=4,13)$. Foi possível encontrar diferença estatisticamente significante entre estes dois grupos $(p=0,002)$, demonstrando que as lesões no grupo ovariectomizado sem tratamento foram maiores do que no grupo sham.

No grupo ovariectomizado tratado com ALD a mediana da área das lesões foi de $1,07 \mathrm{~mm}^{3}$ ( $\left.\mathrm{Q} 1=0,838 ; \mathrm{Q} 3=1,19\right)$ e, no grupo ovariectomizado tratado com ODN, foi de 2,59mm $\mathrm{m}^{3}(\mathrm{Q} 1=2,18 ; \mathrm{Q} 3=3,84)$. Em geral, nos grupos com lesão periapical houve redução do volume das lesões periapicais após a administração dos medicamentos antirreabsortivos. Entretanto, foi possível encontrar diferença estatisticamente significante apenas entre o grupo ovariectomizado sem tratamento e o grupo ovariectomizado tratado com $\operatorname{ALD}(p=0,002)$. As Figuras 24 e 25 ilustram os resultados obtidos nos grupos onde a lesão periapical foi induzida. 
Figura 24. Volume das lesões periapicais em $\mathrm{mm}^{3}$ nos grupos com lesão periapical. Sham=cirurgia de ovariectomia fictícia; $\quad \mathrm{OVX}=$ ovariectomia; $\quad \mathrm{LP}=$ lesão periapical; $\mathrm{ALD}=$ =Alendronato; $\mathrm{ODN}=$ Odanacatib. Letras diferentes indicam diferença significante entre os grupos $(p=0,002)$.

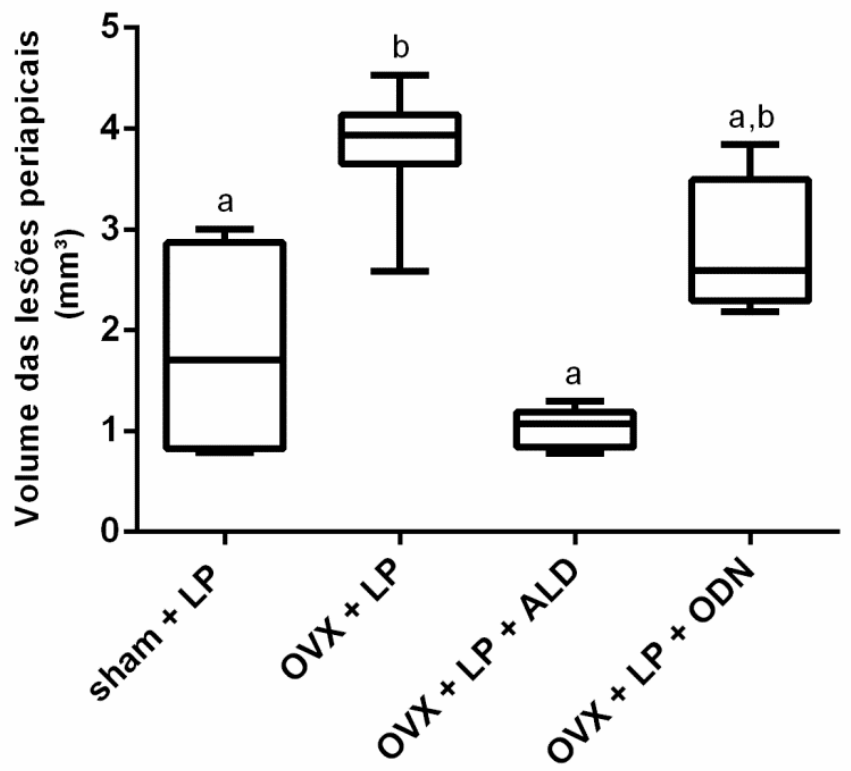


Figura 25. Imagens representativas da análise volumétrica das lesões periapicais, em $\mathrm{mm}^{3}$, nos grupos com lesão periapical. Sham=cirurgia de ovariectomia fictícia; $\mathrm{OVX}=$ ovariectomia; $\mathrm{LP}=$ lesão periapical; $\mathrm{ALD}=$ Alendronato; ODN=Odanacatib.
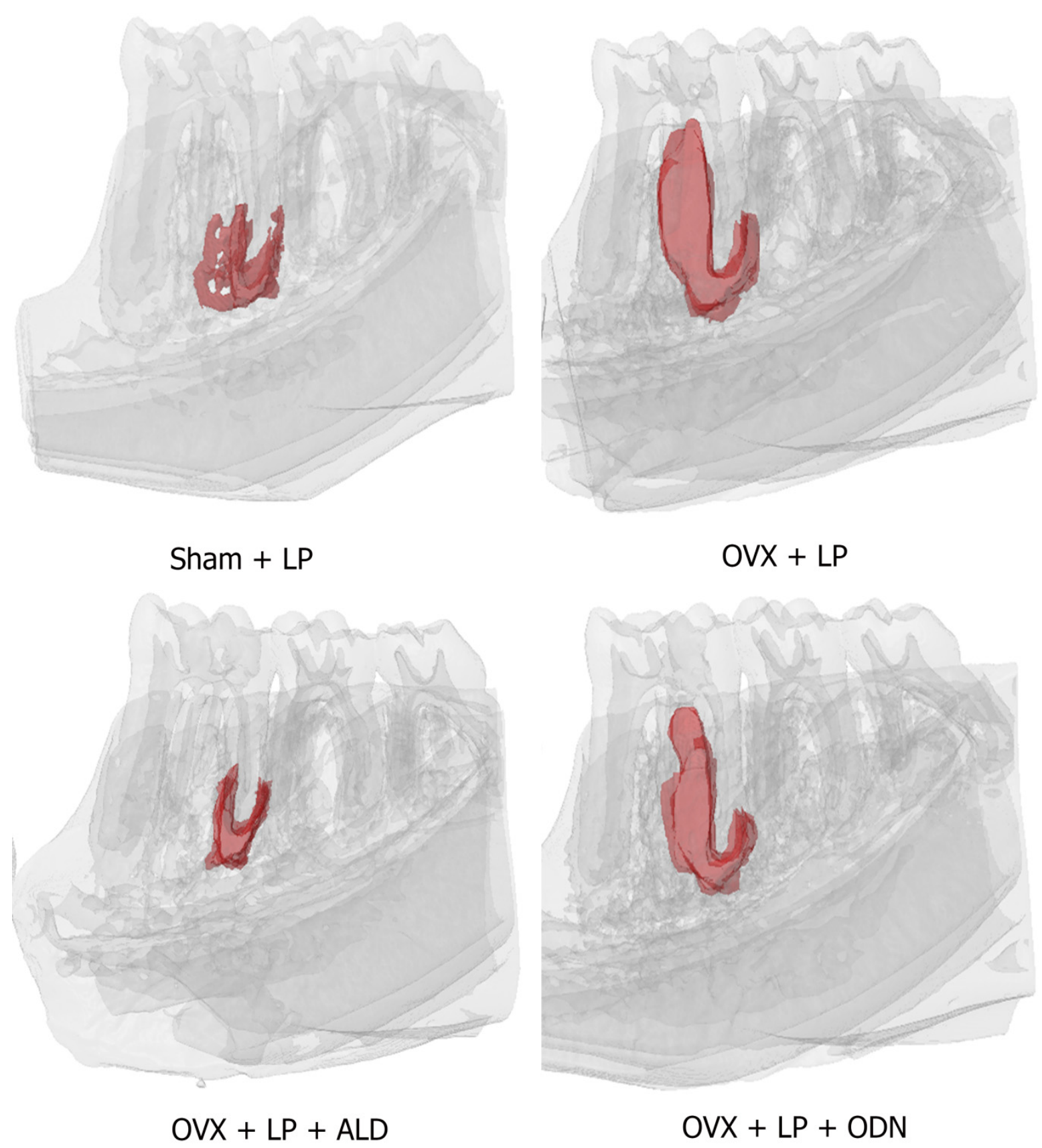

10) Correlação entre a mensuração da área e do volume das lesões periapicais ou do espaço do ligamento periodontal na região periapical, em microscopia de fluorescência e em micro-CT

Após a realização do teste de correlação de Pearson com os valores obtidos a partir da análise histomorfométrica (área em $\mathrm{mm}^{2}$, obtida nas imagens no modo fluorescente) e da análise tridimensional das lesões periapicais ou do espaço do ligamento periodontal (volume em $\mathrm{mm}^{3}$, obtido em micro-CT) foi possível observar uma forte correlação positiva $\left(p<0,0001 ; r^{2}=0,92\right)$ entre a área e o volume. A Figura 26 ilustra a correlação observada.

Figura 26. Representação gráfica da correlação entre área e volume das lesões periapicais ou do espaço do ligamento periodontal.

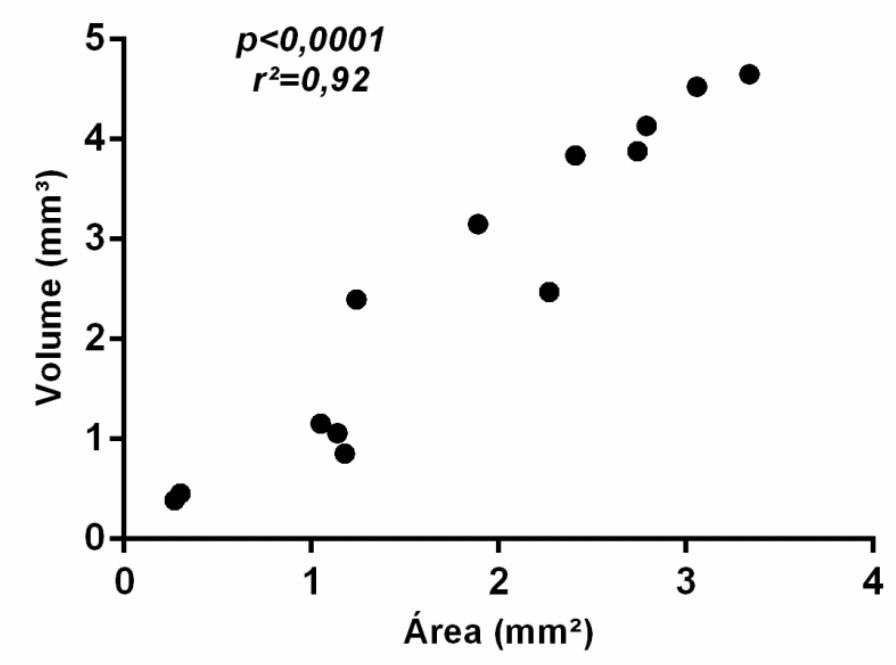



$D_{\text {iscussão }}$ 



\section{DisCUSSÃO}

A rata ovariectomizada é um modelo experimental pré-clínico aprovado pela Food and Drug Administration (FDA) para o estudo da osteoporose, como resultado do efeito da redução na produção de estrógeno pelos ovários pós-menopausa e para avaliar como potenciais intervenções podem preservar o metabolismo ósseo, nesta condição (Thompson et al., 1995). É um modelo animal bem estabelecido e comumente utilizado na área da saúde para investigar os efeitos da osteoporose, bem como das terapias antirreabsortivas (Kalu, 1991; Peng et al., 1997; Kim et al., 2015; Mathavan et al., 2015).

Roedores ovariectomizados desenvolvem hiperfagia e diminuição do gasto de energia, o que resulta em obesidade e resistência à insulina (Rogers et al., 2009; Zhu et al., 2013). Sabe-se que a ovariectomia promove aumento no peso corporal e atrofia uterina (Chen, G. X. et al., 2014) e, portanto, o monitoramento destes dois índices é de grande importância para confirmação do sucesso do procedimento cirúrgico. No presente estudo, o sucesso da ovariectomia foi confirmado por meio do monitoramento do peso corporal dos animais e pelo peso do útero no dia da eutanásia. Nossos resultados estão de acordo com trabalhos prévios (Ochi et al., 2014; Wayama et al., 2015; Cui et al., 2016) que também observaram que os animais ovariectomizados apresentam maior ganho de peso corporal e atrofia uterina, indicando que a técnica foi bem executada.

No presente estudo, o registro da densidade mineral óssea (BMD) da metáfise distal dos fêmures por meio da técnica de absortometria radiológica de dupla energia (DXA) indicou que a ovariectomia foi capaz de reduzir a BMD deste osso longo, 12 semanas após a realização do procedimento cirúrgico, indicando que foi obtido o efeito de redução dos níveis de estrógeno e consequente redução da BMD. Esses resultados estão de acordo com trabalhos prévios que também demonstraram que em 12 semanas é possível observar redução na BMD dos ossos longos de ratas ovariectomizadas (Chen et al., 2013; Liu et al., 2015).

A microtomografia computadorizada (micro-CT) foi também utilizada para avaliar a BMD e a microarquitetura óssea, no presente estudo. Para a avaliação da morfologia e da microarquitetura óssea em roedores e em outros modelos animais, a 
microtomografia computadorizada, introduzida por Feldkamp et al. (1989), é considerada como o padrão-ouro, apresentando excelente reprodutibilidade e precisão (Bouxsein et al., 2010; Gonzalez-Garcia e Monje, 2013). O efeito da deficiência de estrógeno, avaliada por meio da micro-CT, depende do osso avaliado, sendo os ossos longos (fêmur e tíbia) e ossos vertebrais os mais comumente estudados. O presente estudo demonstrou que a redução nos níveis de estrógeno, após 12 semanas da realização da OVX, afetou a BMD e a microarquitetura do osso longo (fêmur). Nossos achados estão de acordo com estudos prévios (Liu et al., 2015; Hao et al., 2016; Chun et al., 2017) que também observaram alterações semelhantes às encontradas no presente estudo, após a avaliação da densidade e da microarquitetura trabecular de fêmures em roedores ovariectomizados, 12 semanas após a realização da OVX. Adicionalmente, Cline-Smith et al., (2016) também observaram redução na BMD e no parâmetro BV/TV em tíbias de camundongos ovariectomizados, em comparação aos animais sham, por meio de micro-CT.

Além disso, os resultados do presente estudo demonstraram que 0 medicamento Alendronato (ALD) foi capaz de restabelecer a BMD dos fêmures aos níveis de normalidade, concordando com outras pesquisas que demonstraram a eficácia deste medicamento no aumento da BMD de ossos longos em ratas ovariectomizadas (Chen et al., 2013; Sugimoto et al., 2013; Chen, G. X. et al., 2014). Por outro lado, o Odanacatib (ODN), embora tenha aumentado numericamente a BMD dos fêmures dos animais ovariectomizados, não foi capaz de restabelecer o fenótipo, ou seja, retorno da BMD aos mesmos níveis dos animais sham. Um estudo recente (Chun et al., 2017) testou o efeito de diferentes doses de ODN em fêmures de ratas ovariectomizadas e observou que a BMD e o parâmetro BV/TV foram significativamente maiores após uso de altas doses $(30 \mathrm{mg} / \mathrm{kg})$ de ODN, em comparação ao grupo não tratado. Além disso, o tratamento com uma dose menor $(5 \mathrm{mg} / \mathrm{kg})$ do medicamento levou a um aumento numérico do BV/TV, mas não estatisticamente significativo, concordando com o presente estudo. No entanto, as doses e frequência de administração utilizadas no estudo de Chun et al. (2017) foram mais elevadas do que as aplicadas no presente estudo.

Na Odontologia, o efeito da redução dos níveis de estrógeno ainda é um assunto pouco explorado. Alterações no osso subcondral da articulação 
temporomandibular, incluindo redução dos parâmetros BV/TV, Tb.Th, e Tb.N e aumento do Tb.Sp, foram observadas em ratas ovariectomizadas, 10 semanas após a realização da OVX, em comparação aos animais sham (Chen, K. et al., 2014). Ainda, ratas ovariectomizadas apresentaram alterações na densidade e na microarquitetura óssea da região peri-implantar (Ying et al., 2016), o que permitiu sugerir que a cirurgia para colocação de implante dentário em mulheres osteoporóticas deve ser realizada com cautela (Hsu et al., 2013; Hsu et al., 2016). Além disso, foi demonstrado que a progressão da doença periodontal é maior em animais após OVX, com maior perda óssea vertical, em comparação aos animais sham (Dai et al., 2016).

Embora o efeito da osteoporose na microarquitetura e na densidade mineral dos ossos maxilares venha sendo estudado, os resultados ainda são inconsistentes (Du et al., 2015). De acordo com Ishihara et al., (1999), a OVX leva a uma redução significativa da densidade óssea do fêmur e da tíbia, que são formados por ossificação endocondral, mas o mesmo não ocorre nos ossos maxilares, que são formados por ossificação intramembranosa. No presente estudo, foi observada uma redução da BMD do osso maxilar nas ratas ovariectomizadas, discordando dos achados de Ishihara et al. (1999) e concordando com Dai et al. (2014) e Liu et al. (2015) que também observaram tal redução, após 12 e 24 semanas da realização da OVX em ratas, respectivamente.

Por outro lado, no presente estudo, a realização da OVX não provocou alterações na microarquitetura do osso maxilar, após 12 semanas da realização da cirurgia. Esse resultado discorda dos obtidos por Dai et al. (2014), que observaram alteração na microarquitetura da maxila, possivelmente em função de terem utilizado animais mais jovens ( 6 semanas de idade).

Assim, os resultados do presente estudo estão de acordo com trabalhos anteriores que observaram que os ossos longos respondem mais rapidamente à OVX do que os ossos maxilares (Du et al., 2015; Liu et al., 2015).

No geral, quanto maior o tempo decorrido desde a OVX, maior será a severidade das alterações observadas no osso alveolar. Tendo em vista que as maiores alterações no osso alveolar ocorrem durante ou 12 semanas após a OVX (Du et al., 2015; Johnston e Ward, 2015), no presente estudo foi utilizado este tempo 
pós-OVX para avaliação dos ossos selecionados. Da mesma forma, a idade do rato no momento da ovariectomia determina a maturidade do seu esqueleto e as alterações ósseas na estrutura de um rato adulto aproximam-se mais do esqueleto humano maduro. Assim, o rato deve ter pelo menos 3 meses de idade no momento da ovariectomia (Johnston e Ward, 2015), que foi a idade dos animais utilizados neste estudo.

Por outro lado, pouco se sabe sobre o efeito do uso de medicamentos antirreabsortivos nos ossos maxilares. Alguns estudos avaliaram o efeito dos bisfosfonatos na Odontologia. Jee et al. (2010) demonstraram que o ALD ajuda na cicatrização de alvéolos pós-extração dentária e na redução da perda óssea alveolar adjacente, em ratas com deficiência de estrógeno. Abtahi et al. (2013) demonstraram que o tratamento local com bisfosfonato melhora a fixação de implantes dentários. Além disso, Anbinder et al. (2007) demonstraram que a OVX reduz a densidade óssea alveolar e, concordando com os resultados do presente estudo, o tratamento com ALD foi eficiente no tratamento desta condição, restabelecendo a densidade aos mesmos níveis dos animais sham. Entretanto, estes autores avaliaram a densidade alveolar por meio de radiografias.

Ainda na Odontologia, sabe-se que o ODN pode inibir o desenvolvimento da lesão periapical, a reabsorção óssea e a resposta imune, em camundongos normais (não-ovariectomizados) (Hao et al., 2015). Além disso, este medicamento reduz a reabsorção radicular externa induzida pelo tratamento ortodôntico, aumentando o metabolismo ósseo alveolar (Wei et al., 2015). No presente estudo, o ODN aumentou a BMD da maxila dos animais ovariectomizados, porém não foi capaz de restabelecer o fenótipo, ou seja, a BMD não retornou aos níveis observados nos animais sham. Entretanto, até o presente momento, não existe na literatura específica estudos avaliando a BMD e a microarquitetura do osso maxilar interradicular em animais ovariectomizados, sob tratamento com ALD ou com ODN nos ossos maxilares, o que impossibilita a comparação dos nossos achados com a literatura.

Sabe-se que a deficiência estrogênica pode resultar em perda óssea afetando o sistema RANK/RANKL/OPG (Michael et al., 2005). Com relação aos altos níveis dos marcadores da osteoclastogênese (RANK e RANKL) encontrados na lesão periapical dos animais ovariectomizados do presente estudo, nossos resultados estão de acordo 
com Gomes-Filho et al. (2015). Estes autores encontraram maior expressão de RANKL nas lesões periapicais do grupo ovariectomizado, sugerindo que a redução nos níveis de estrógeno estimularia a osteoclastogênese durante a progressão da lesão periapical. Além disso, a razão RANKL/OPG também se encontrou aumentada nas lesões do grupo ovariectomizado, no presente estudo, e os tratamentos administrados não tiveram efeito na produção de RANK, RANKL e na razão RANKL/OPG. Não há estudos investigando o efeito do ALD e do ODN sobre esses marcadores no microambiente periapical, o que também impossibilita a comparação com os nossos resultados.

Estudos prévios demonstraram que o infiltrado de células inflamatórias na região periapical desempenha um importante papel no desenvolvimento da lesão por liberarem uma variedade de citocinas pró-inflamatórias, tais como IL-1, TNF-a e IL-6, participando da regulação do processo de reabsorção óssea (Schett, 2011; Hao et al., 2015). O presente estudo demonstrou que a indução da lesão periapical promoveu uma tendência numérica de aumento na expressão destas citocinas nos animais sham. Entretanto, esse aumento foi estatisticamente significante apenas para IL-6. Trabalhos prévios demonstraram aumento significante nos níveis de IL-1 $\beta$, IL-6 e TNF-a após indução de lesão periapical em ratas normais, em comparação aos tecidos periapicais saudáveis (Kawashima et al., 2007; Wei et al., 2013).

Adicionalmente, tem sido relatado que a realização da ovariectomia em roedores pode agravar a reabsorção nas lesões periapicais induzidas, devido a esse procedimento promover a deficiência de estrógeno (Xiong et al., 2007; Gomes-Filho et al., 2015). Neste modelo animal, a resposta sistêmica a lesões periapicais é exacerbada, com altos níveis séricos de citocinas pró-inflamatórias, sugerindo que o estrógeno é um protetor essencial contra os efeitos da inflamação (Zhang et al., 2011). Sabe-se que este hormônio participa do metabolismo ósseo atuando em mediadores da osteoclastogênese e em citocinas tais como IL-1, IL-6 e TNF, no fator estimulante de colônias de macrófagos e granulócitos e na prostaglandina E2. Estes fatores exacerbam a reabsorção óssea, principalmente atuando na osteoclastogênese (Pacifici, 1996). Entretanto, pouco se sabe sobre a expressão de citocinas próinflamatórias na lesão periapical de animais ovariectomizados, ou seja, em condições hipoestrogênicas. 
Nos animais ovariectomizados, o presente estudo demonstrou que a resposta frente à indução da lesão periapical foi mais intensa, promovendo um aumento significante na expressão de todas as citocinas pró-inflamatórias avaliadas. Nossos resultados estão de acordo com Hao et al. (2015) que demonstraram um aumento na expressão de TNF-a e IL-6 nas lesões periapicais de camundongos saudáveis, 7, 21 e 42 dias após a indução das lesões.

Segundo Yang et al. (2015), a adição de ALD e ODN em cultura de células osteoclásticas ocasiona efeitos anti-inflamatórios, inibindo IL-1 $\beta$, IL-6, PGE2 e TNF-a. No presente estudo, os tratamentos antirreabsortivos não alteraram a expressão de IL-1 $\beta$ e TNF-a nas lesões periapicais e, embora ambos os tratamentos tenham diminuído a expressão de IL-6, apenas o tratamento com ALD promoveu uma redução estatisticamente significante. Não há estudos investigando o efeito do ALD sobre essas citocinas no microambiente periapical, o que impossibilita a comparação dos nossos resultados com outros achados. Além disso, nossos resultados não estão de acordo com Hao et al. (2015) que demonstraram que o tratamento sistêmico com ODN reduziu a expressão destas citocinas pró-inflamatórias na lesão periapical. Entretanto, estes autores utilizaram camundongos saudáveis como modelo experimental, sem realização da ovariectomia e não simularam, portanto, o efeito do ODN frente à redução nos níveis de estrógeno. No presente estudo, tentamos reproduzir a dose e a frequência de administração utilizada por Hao et al. (2015), por meio de extrapolação alométrica das doses do medicamento de camundongos para ratos. Entretanto, não foi possível observarmos resultados significativos, provavelmente porque a lesão periapical no animal ovariectomizado apresentou reação inflamatória e reabsortiva exacerbada.

Com relação às metaloproteinases da matriz (MMPs), há evidências de que algumas MMPs desempenham um papel importante na perda óssea induzida pela deficiência de estrógeno (Li et al., 2004; Tian et al., 2015). Discos intervertebrais lombares de ratas ovariectomizadas apresentaram maior imunomarcação para MMP1, MMP-3 e MMP-13, em comparação ao grupo sham (Luo et al., 2013; Tian et al., 2015). Também, já foi demonstrado que a realização da ovariectomia causa um aumento na expressão de MMP-13 na interface entre a cartilagem e o osso subcondral, na articulação temporomandibular (Chen, K. et al., 2014) e que ratas 
ovariectomizadas apresentam maior número de células-positivas para MMP-8 na cartilagem condilar, em comparação a ratas saudáveis (Orajarvi et al., 2011).

Matsui et al. (2011) demonstraram que as MMPs-8 e -13 estão relacionadas ao desenvolvimento de lesões periapicais em ratos saudáveis, sugerindo ainda que os níveis de MMP-13 aumentam na fase inicial, durante o desenvolvimento da lesão, e que a MMP-8 está envolvida na progressão da reabsorção óssea. No presente estudo, a indução da lesão periapical em animais ovariectomizados ou sham também induziu o aumento significante de MMP-13. Além disso, as lesões periapicais nos animais ovariectomizados apresentaram maior expressão de MMP-8. Embora, nossos achados concordem com os achados de Matsui et al. (2011) em ratos saudáveis, sugerimos adicionalmente que essas MMPs também estão relacionadas ao agravamento de lesões periapicais em animais ovariectomizados.

No presente estudo ambos os tratamentos não foram capazes de modular a expressão de MMP-13, porém o ALD inibiu a expressão de MMP-8 de forma significativa. Há relatos de que os bisfosfonatos podem inibir ou controlar a expressão de MMPs (Llavaneras et al., 2001; Buduneli et al., 2007; FernandezGonzalez et al., 2016). Ainda, foi demonstrado que a administração de ALD inibe a expressão de MMP-1 e MMP-13 em discos intervertebrais com perda óssea induzida pela OVX, em ratas (Song et al., 2017). A ausência de trabalhos avaliando o efeito da deficiência estrogênica e dos medicamentos antirreabsortivos sobre as MMPs no microambiente periapical impossibilita a comparação dos nossos achados com a literatura específica.

Com relação à análise microscópica descritiva das regiões apical e periapical, o presente estudo demonstrou que os grupos sem a indução de lesão periapical (sham e OVX) apresentaram resultados muito homogêneos. Em ambos os grupos, todos os espécimes avaliados evidenciaram espessura do ligamento periodontal normal, ausência de infiltrado inflamatório e ausência de processos reabsortivos dos tecidos mineralizados. Nossos resultados estão de acordo com Xiong et al. (2007) que evidenciaram que nos dentes sem indução de lesão a região periapical se apresenta com um padrão regular, sem sinais de inflamação e de reabsorção dos tecidos mineralizados, mesmo após ovariectomia. Além disso, os mesmos autores observaram que quando induzia-se lesões periapicais no grupo ovariectomizado sem 
tratamento, os espécimes apresentaram maior perda óssea periapical, em comparação às lesões no grupo sham, o mesmo observado no presente estudo e comprovado pela mensuração da área e do volume das lesões.

Outro estudo prévio (Gomes-Filho et al., 2015) também relatou lesões periapicais mais severas nos animais ovariectomizados, em comparação às lesões do grupo sham, com grande quantidade de infiltrado inflamatório crônico, após 30 dias da indução da lesão. A magnitude da reação inflamatória e da reabsorção óssea também foi maior no grupo ovariectomizado sem tratamento, em comparação ao grupo sham. Da mesma forma, Wayama et al. (2015) observaram lesões periapicais maiores no grupo ovariectomizado, em comparação ao sham, após 7 ou 30 dias.

No presente estudo, as lesões periapicais do grupo ovariectomizado e tratado com ALD apresentaram padrão de reabsorção óssea e de inflamação similar às lesões do grupo sham. Esse resultado está de acordo com Xiong et al. (2007) que observaram que as lesões periapicais no grupo ovariectomizado apresentaram maior perda óssea periapical em comparação às lesões no grupo sham e às lesões do grupo tratado com ALD. Após a administração diária de ALD, a presença de reabsorção óssea periapical foi reduzida (Xiong et al., 2007; Xiong et al., 2010). Assim, o tratamento com ALD fez com que as lesões periapicais, em condições de hipoestrogenicidade, apresentasse perdas ósseas semelhantes às lesões no grupo sham (animais normais).

Por outro lado, no presente estudo, as lesões periapicais dos animais ovariectomizados e tratados com ODN não apresentaram uniformidade na resposta tecidual no estudo histopatológico. 0 padrão das lesões periapicais observado foi similar ao grupo ovariectomizado e sem tratamento. Nossos resultados não concordaram com o que foi observado por Hao et al. (2015) que evidenciaram, após a administração de ODN em camundongos saudáveis, uma redução na reabsorção óssea por meio da inibição da função osteoclástica e da inflamação, considerando o medicamento como promissor na terapia endodôntica. No presente estudo, apesar da tentativa de mimetizar a dose utilizada por Hao et al. (2015), por extrapolação alométrica, não foi possível encontrar resultados semelhantes, o que pode ser explicado pela diferença no animal experimental utilizado. Não há na literatura 
estudos avaliando o efeito do ODN em lesões periapicais de animais ovariectomizados, impossibilitando a comparação dos achados do presente estudo.

Paralelamente, o presente estudo foi o primeiro a avaliar lesões periapicais em ratas ovariectomizadas de forma tridimensional, por meio de micro-CT, demonstrando que a deficiência de estrógeno em roedores leva à formação de lesões periapicais mais volumosas e que a realização da OVX não promoveu alterações volumétricas no ligamento periodontal de dentes saudáveis. Além disso, demonstramos que existe uma forte correlação positiva entre os valores bidimensionais histomorfométricos da área das lesões periapicais, obtidos pela técnica de imunofluorescência, e os valores tridimensionais do volume, obtidos pela micro-CT. Nossos resultados discordam do estudo prévio de De Oliveira et al. (2015) que evidenciou uma fraca correlação entre essas medidas obtidas a partir da avaliação de lesões periapicais, possivelmente pelas diferenças no modelo animal empregado (camundongos).

Com relação à análise microbiana esperava-se que, uma vez que a ovariectomia causa redução nos níveis de estrógeno e que as alterações hormonais podem apresentar repercussões na cavidade bucal, a deficiência estrogênica teria influência nos níveis de contaminação microbiana da cavidade bucal e, consequentemente, do canal radicular. Entretanto, no presente estudo não foram observadas diferenças entre os animais ovariectomizados ou não, com relação às quantidades e à diversidade microbiana, ou seja, a OVX não foi capaz de influenciar nos níveis de contaminação microbiana do canal radicular. A falta de trabalhos na literatura avaliando o perfil microbiano nas lesões periapicais de animais ovariectomizados impossibilita a comparação dos nossos resultados com achados prévios.

Ainda, sabe-se que os osteoclastos são as células reabsortivas mais importantes do corpo humano (Walsh et al., 2006). A destruição óssea observada em lesões periapicais é em grande parte realizada pelos osteoclastos e a inibição da atividade destas células pode permitir o controle da expansão da lesão diretamente (Suzuki et al., 2015). Com relação ao número de osteoclastos em contato direto com o osso alveolar ao redor da lesão periapical, no presente estudo não foi possível encontrar diferença significante no número dessas células entre os grupos onde a 
lesão periapical foi induzida. Nossos resultados estão de acordo com estudos prévios que não observaram diferença significante no número de osteoclastos ao redor das lesões de animais sham e ovariectomizados (Xiong et al., 2007; Liu et al., 2010). Por outro lado, nossos resultados discordam de estudos prévios que relataram que a região periapical nos animais ovariectomizados apresenta maior quantidade de células TRAP-positivas, em comparação aos animais sham (Gomes-Filho et al., 2015; Wayama et al., 2015) e que a administração de ALD reduziu o número de osteoclastos na região periapical, em comparação a animais ovariectomizados sem tratamento (Xiong et al., 2007). De acordo com a literatura específica, um dos mecanismos de ação dos bisfosfonatos é a indução da apoptose de osteoclastos. No entanto, esse mecanismo não é o único meio pelo qual o ALD pode inibir a reabsorção óssea. De acordo com Halasy-Nagy et al. (2001), o ALD inibe a reabsorção óssea afetando os mecanismos moleculares que regulam o citoesqueleto e a formação da borda em escova dos osteoclastos, sendo a apoptose um evento secundário. Portanto, esse conhecimento pode justificar a manutenção do número elevado de osteoclastos ao redor das lesões periapicais dos animais tratados com ALD no presente estudo, apesar deste medicamento ter reduzido o tamanho das lesões.

Sumarizando, em geral, os resultados do presente estudo demonstraram que lesões periapicais em ratas ovariectomizadas apresentaram expressão aumentada de marcadores da osteoclastogênese, de citocinas pró-inflamatórias e de metaloproteinases da matriz. Além disso, as lesões nesses animais foram maiores e não apresentaram uniformidade na resposta tecidual ao se avaliar o processo de reabsorção óssea e a reação inflamatória. Baseado nesses resultados, pôde-se especular que a condição hipoestrogênica agrava o processo de reabsorção, de inflamação e a degradação de componentes da matriz extracelular no microambiente periapical, ou seja, a infecção associada à deficiência de estrógeno desempenha um papel importante na regulação desses mediadores na lesão periapical. Este achado pode auxiliar na compreensão do mecanismo envolvido no desenvolvimento da lesão periapical, em pacientes pós-menopausa ou em pacientes (adultos ou crianças) com patologias ósseas. 
Além disso, observamos que a administração de ALD proporcionou uma melhora da resposta periapical, sendo que na maioria dos parâmetros avaliados o uso deste medicamento em animais ovariectomizados fez com que as lesões periapicais fossem similares às lesões no grupo sham, ou seja, permitiram a recuperação do fenótipo. Sugere-se que a sua ação tenha ocorrido principalmente via inibição de IL-6 e MMP-8. No entanto, o mesmo não ocorreu com o medicamento ODN, na dose e na frequência de administração utilizada neste estudo.

Tendo em vista a reduzida informação na literatura sobre o efeito da administração sistêmica de ALD e de ODN nos ossos maxilares e em lesões periapicais de roedores com deficiência estrogênica, a comparação dos achados do presente estudo com a literatura específica torna-se dificultada. Portanto, estudos adicionais avaliando o efeito destes medicamentos antirreabsortivos nos ossos maxilares e em lesões periapicais são necessários. 



\section{Conclusão}



Conclusão

Com base nas metodologias empregadas e nos resultados obtidos no presente estudo, pôde-se concluir que:

- A condição hipoestrogênica induzida pela ovariectomia foi capaz de diminuir a densidade mineral do fêmur e da maxila e alterar a microarquitetura apenas do fêmur. Ainda, agravou o processo de reabsorção, a inflamação e a expressão de marcadores da osteoclastogênese, de citocinas pró-inflamatórias e de metaloproteinases da matriz, provocando lesões periapicais maiores.

- O tratamento com Alendronato foi capaz de recuperar o fenótipo da densidade mineral óssea em fêmures e maxilas, ou seja, retorno aos níveis observados nos animais saudáveis. O Alendronato e o Odanacatib proporcionaram uma melhora da resposta periapical. Entretanto, apenas o tratamento com Alendronato recuperou o fenótipo, fazendo com que as lesões periapicais fossem similares às lesões dos animais saudáveis. 

Referências 



\section{REFERÊNCIAS}

1. Abtahi J, Agholme F, Sandberg O, Aspenberg P. Effect of local vs. systemic bisphosphonate delivery on dental implant fixation in a model of osteonecrosis of the jaw. J Dent Res. 2013;92(3):279-83.

2. Almeida M, Laurent MR, Dubois V, Claessens F, O'Brien CA, Bouillon R, et al. Estrogens and Androgens in Skeletal Physiology and Pathophysiology. Physiol Rev. 2017;97(1):135-87.

3. Anbinder AL, Prado Fde A, Prado Mde A, Balducci I, Rocha RF. The influence of ovariectomy, simvastatin and sodium alendronate on alveolar bone in rats. Braz Oral Res. 2007;21(3):247-52.

4. Arboleya L, Castaneda S. Osteoimmunology: the study of the relationship between the immune system and bone tissue. Reumatol Clin. 2013;9(5):303-15.

5. Ataoglu T, Ungor M, Serpek B, Haliloglu S, Ataoglu H, Ari $H$. Interleukin-1beta and tumour necrosis factor-alpha levels in periapical exudates. Int Endod $\mathrm{J}$. 2002;35(2):181-5.

6. Bahuguna R, Jain A, Khan SA, Arvind MS. Role of odanacatib in reducing bone loss due to endodontic disease: An overview. J Int Soc Prev Community Dent. 2016;6(Suppl 3):S175-s81.

7. Bezerra da Silva RA, Nelson-Filho P, Lucisano MP, De Rossi A, de Queiroz AM, Bezerra da Silva LA. MyD88 knockout mice develop initial enlarged periapical lesions with increased numbers of neutrophils. Int Endod J. 2014;47(7):675-86.

8. Black DM, Thompson DE, Bauer DC, Ensrud K, Musliner T, Hochberg MC, et al. Fracture risk reduction with alendronate in women with osteoporosis: the Fracture Intervention Trial. FIT Research Group. J Clin Endocrinol Metab. 2000;85(11):4118-24.

9. Bonnans C, Chou J, Werb Z. Remodelling the extracellular matrix in development and disease. Nat Rev Mol Cell Biol. 2014;15(12):786-801.

10. Bouxsein ML, Boyd SK, Christiansen BA, Guldberg RE, Jepsen KJ, Muller R. Guidelines for assessment of bone microstructure in rodents using micro-computed tomography. J Bone Miner Res. 2010;25(7):1468-86.

11. Boyce BF, Li P, Yao Z, Zhang Q, Badell IR, Schwarz EM, et al. TNF-alpha and pathologic bone resorption. Keio J Med. 2005;54(3):127-31.

12. Boyd SK, Davison P, Muller R, Gasser JA. Monitoring individual morphological changes over time in ovariectomized rats by in vivo micro-computed tomography. Bone. 2006;39(4):854-62.

13. Brixen $K$, Chapurlat $R$, Cheung AM, Keaveny TM, Fuerst $T$, Engelke $K$, et al. Bone density, turnover, and estimated strength in postmenopausal women treated with odanacatib: a randomized trial. J Clin Endocrinol Metab. 2013;98(2):571-80. 
14. Buduneli E, Vardar-Sengul S, Buduneli N, Atilla G, Wahlgren J, Sorsa T. Matrix metalloproteinases, tissue inhibitor of matrix metalloproteinase-1, and laminin-5 gamma2 chain immunolocalization in gingival tissue of endotoxin-induced periodontitis in rats: effects of low-dose doxycycline and alendronate. J Periodontol. 2007;78(1):127-34.

15. Chen B, Li Y, Yang X, Xie D. Comparable effects of alendronate and strontium ranelate on femur in ovariectomized rats. Calcif Tissue Int. 2013;93(5):481-6.

16. Chen GX, Zheng S, Qin S, Zhong ZM, Wu XH, Huang ZP, et al. Effect of low-magnitude whole-body vibration combined with alendronate in ovariectomized rats: a random controlled osteoporosis prevention study. PLoS One. 2014;9(5):e96181.

17. Chen K, Zhang N, Ding L, Zhang W, Hu J, Zhu S. Early intra-articular injection of alendronate reduces cartilage changes and subchondral bone loss in rat temporomandibular joints after ovariectomy. Int $\mathrm{J}$ Oral Maxillofac Surg. 2014;43(8):996-1004.

18. Cheung AM, Majumdar S, Brixen K, Chapurlat R, Fuerst T, Engelke $K$, et al. Effects of odanacatib on the radius and tibia of postmenopausal women: improvements in bone geometry, microarchitecture, and estimated bone strength. J Bone Miner Res. 2014;29(8):1786-94.

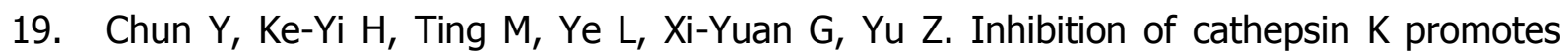
osseointegration of titanium implants in ovariectomised rats. Sci Rep [Internet]. 2017; 7.

20. Cline-Smith A, Gibbs J, Shashkova E, Buchwald ZS, Novack DV, Aurora R. Pulsed lowdose RANKL as a potential therapeutic for postmenopausal osteoporosis. JCI Insight. 2016;1(13).

21. Cochran DL. Inflammation and bone loss in periodontal disease. J Periodontol. 2008;79(8 Suppl):1569-76.

22. Cohenca N, Romualdo PC, da Silva LA, da Silva RA, de Queiroz AM, De Rossi A, et al. Tissue response to root canal irrigation systems in dogs' teeth with apical periodontitis. Clin Oral Investig. 2015;19(5):1147-56.

23. Consolaro A. The use of bisphosphonates does not contraindicate orthodontic and other types of treatment! Dental Press J Orthod. 2014;19(4):18-26.

24. Cui H, Zhu Y, Jiang D. The RIP1-RIP3 Complex Mediates Osteocyte Necroptosis after Ovariectomy in Rats. PLoS One. 2016;11(3):e0150805.

25. Dai J, Ma Y, Shi M, Cao Z, Zhang Y, Miron RJ. Initial changes in alveolar bone volume for sham-operated and ovariectomized rats in ligature-induced experimental periodontitis. Clin Oral Investig. 2016;20(3):581-8.

26. Dai QG, Zhang $P$, Wu YQ, Ma XH, Pang J, Jiang LY, et al. Ovariectomy induces osteoporosis in the maxillary alveolar bone: an in vivo micro-CT and histomorphometric analysis in rats. Oral Dis. 2014;20(5):514-20. 
27. Das S, Crockett JC. Osteoporosis - a current view of pharmacological prevention and treatment. Drug Des Devel Ther. 2013;7:435-48.

28. de Oliveira KM, da Silva RA, Kuchler EC, de Queiroz AM, Nelson Filho P, da Silva LA. Correlation Between Histomorphometric and Micro-computed Tomography Analysis of Periapical Lesions in Mice Model. Ultrastruct Pathol. 2015;39(3):187-91.

29. De Rossi A, De Rossi M, Rocha LB, da Silva LA, Rossi MA. Morphometric analysis of experimentally induced periapical lesions: radiographic vs histopathological findings. Dentomaxillofac Radiol. 2007;36(4):211-7.

30. Dempster DW, Lambing CL, Kostenuik PJ, Grauer A. Role of RANK ligand and denosumab, a targeted RANK ligand inhibitor, in bone health and osteoporosis: a review of preclinical and clinical data. Clin Ther. 2012;34(3):521-36.

31. Dennison EM, Harvey NC, Cooper C. Programming of osteoporosis and impact on osteoporosis risk. Clin Obstet Gynecol. 2013;56(3):549-55.

32. Dereci O, Orhan EO, Irmak O, Ay S. The effect of the duration of intravenous zolendronate medication on the success of non-surgical endodontic therapy: a retrospective study. BMC Oral Health. 2016;16:9.

33. Du Z, Steck R, Doan N, Woodruff MA, Ivanovski S, Xiao Y. Estrogen DeficiencyAssociated Bone Loss in the Maxilla: A Methodology to Quantify the Changes in the Maxillary Intra-radicular Alveolar Bone in an Ovariectomized Rat Osteoporosis Model. Tissue Eng Part C Methods. 2015;21(5):458-66.

34. Duarte PM, de Assis DR, Casati MZ, Sallum AW, Sallum EA, Nociti FH, Jr. Alendronate may protect against increased periodontitis-related bone loss in estrogen-deficient rats. J Periodontol. 2004;75(9):1196-202.

35. Eastell R, O'Neill TW, Hofbauer LC, Langdahl B, Reid IR, Gold DT, et al. Postmenopausal osteoporosis. Nat Rev Dis Primers. 2. England2016. p. 16069.

36. Eghbali-Fatourechi G, Khosla S, Sanyal A, Boyle WJ, Lacey DL, Riggs BL. Role of RANK ligand in mediating increased bone resorption in early postmenopausal women. J Clin Invest. 2003;111(8):1221-30.

37. Ejiri S, Tanaka M, Watanabe N, Anwar RB, Yamashita E, Yamada K, et al. Estrogen deficiency and its effect on the jaw bones. J Bone Miner Metab. 2008;26(5):409-15.

38. Falcai MJ, Zamarioli A, Leoni GB, de Sousa Neto MD, Volpon JB. Swimming Activity Prevents the Unloading Induced Loss of Bone Mass, Architecture, and Strength in Rats. Biomed Res Int. 2015;2015:507848.

39. Feldkamp LA, Goldstein SA, Parfitt AM, Jesion G, Kleerekoper M. The direct examination of three-dimensional bone architecture in vitro by computed tomography. J Bone Miner Res. 1989;4(1):3-11.

40. Fernandez-Gonzalez FJ, Lopez-Caballo JL, Canigral A, Menendez-Diaz I, Brizuela A, de Cos FJ, et al. Osteoprotegerin and zoledronate bone effects during orthodontic tooth movement. Orthod Craniofac Res. 2016;19(1):54-64. 
41. Frost HM, Jee WS. On the rat model of human osteopenias and osteoporoses. Bone Miner. 1992;18(3):227-36.

42. Fukada SY, Silva TA, Garlet GP, Rosa AL, da Silva JS, Cunha FQ. Factors involved in the T helper type 1 and type 2 cell commitment and osteoclast regulation in inflammatory apical diseases. Oral Microbiol Immunol. 2009;24(1):25-31.

43. Gao Y, Zou S, Liu X, Bao C, Hu J. The effect of surface immobilized bisphosphonates on the fixation of hydroxyapatite-coated titanium implants in ovariectomized rats. Biomaterials. 2009;30(9):1790-6.

44. Goes P, Melo IM, Silva LM, Benevides NM, Alencar NM, Ribeiro RA, et al. Low-dose combination of alendronate and atorvastatin reduces ligature-induced alveolar bone loss in rats. J Periodontal Res. 2014;49(1):45-54.

45. Gomes-Filho JE, Wayama MT, Dornelles RC, Ervolino E, Coclete GA, Duarte PC, et al. Effect of raloxifene on periapical lesions in ovariectomized rats. J Endod. 2015;41(5):671-5.

46. Gomes-Filho JE, Wayama MT, Dornelles RC, Ervolino E, Yamanari GH, Lodi CS, et al. Raloxifene modulates regulators of osteoclastogenesis and angiogenesis in an oestrogen deficiency periapical lesion model. Int Endod J. 2015;48(11):1059-68.

47. Gonzalez-Garcia R, Monje F. Is micro-computed tomography reliable to determine the microstructure of the maxillary alveolar bone? Clin Oral Implants Res. 2013;24(7):7307.

48. Graves DT, Oates T, Garlet GP. Review of osteoimmunology and the host response in endodontic and periodontal lesions. J Oral Microbiol. 2011;3.

49. Halasy-Nagy JM, Rodan GA, Reszka AA. Inhibition of bone resorption by alendronate and risedronate does not require osteoclast apoptosis. Bone. 2001;29(6):553-9.

50. Hao L, Chen W, McConnell M, Zhu Z, Li S, Reddy M, et al. A small molecule, odanacatib, inhibits inflammation and bone loss caused by endodontic disease. Infect Immun. 2015;83(4):1235-45.

51. Hao L, Li J, Tian $\mathrm{Y}, \mathrm{Wu}$ J. Changes in the MicroRNA Profile of the Mandible of Ovariectomized Mice. Cell Physiol Biochem. 2016;38(4):1267-87.

52. Hernandez-Vigueras S, Martinez-Garriga B, Sanchez MC, Sanz M, Estrugo-Devesa A, Vinuesa $T$, et al. Oral Microbiota, Periodontal Status, and Osteoporosis in Postmenopausal Females. J Periodontol. 2016;87(2):124-33.

53. Hernlund E, Svedbom A, Ivergard M, Compston J, Cooper C, Stenmark J, et al. Osteoporosis in the European Union: medical management, epidemiology and economic burden. A report prepared in collaboration with the International Osteoporosis Foundation (IOF) and the European Federation of Pharmaceutical Industry Associations (EFPIA). Arch Osteoporos. 2013;8:136.

54. Hofbauer LC, Heufelder AE. The role of osteoprotegerin and receptor activator of nuclear factor kappaB ligand in the pathogenesis and treatment of rheumatoid arthritis. Arthritis Rheum. 2001;44(2):253-9. 
55. Hsu JT, Fuh LJ, Tu MG, Li YF, Chen KT, Huang HL. The effects of cortical bone thickness and trabecular bone strength on noninvasive measures of the implant primary stability using synthetic bone models. Clin Implant Dent Relat Res. 2013;15(2):251-61.

56. Hsu PY, Tsai MT, Wang SP, Chen YJ, Wu J, Hsu JT. Cortical Bone Morphological and Trabecular Bone Microarchitectural Changes in the Mandible and Femoral Neck of Ovariectomized Rats. PLoS One. 2016;11(4):e0154367.

57. Ishihara A, Sasaki T, Debari K, Furuya R, Kawawa T, Ramamurthy NS, et al. Effects of ovariectomy on bone morphology in maxillae of mature rats. J Electron Microsc (Tokyo). 1999;48(4):465-9.

58. Jakovljevic A, Knezevic A, Karalic D, Soldatovic I, Popovic B, Milasin J, et al. Proinflammatory cytokine levels in human apical periodontitis: Correlation with clinical and histological findings. Aust Endod J. 2015;41(2):72-7.

59. Jee $\mathrm{JH}$, Lee $\mathrm{W}$, Lee $\mathrm{BD}$. The influence of alendronate on the healing of extraction sockets of ovariectomized rats assessed by in vivo micro-computed tomography. Oral Surg Oral Med Oral Pathol Oral Radiol Endod. 2010;110(2):e47-53.

60. Johnston $\mathrm{BD}$, Ward WE. The ovariectomized rat as a model for studying alveolar bone loss in postmenopausal women. Biomed Res Int. 2015;2015:635023.

61. Kakehashi S, Stanley HR, Fitzgerald RJ. The effects of surgical exposures of dental pulps in germ-free and conventional laboratory rats. Oral Surg Oral Med Oral Pathol. 1965;20:340-9.

62. Kalu DN. The ovariectomized rat model of postmenopausal bone loss. Bone Miner. 1991;15(3):175-91.

63. Kawashima N, Stashenko P. Expression of bone-resorptive and regulatory cytokines in murine periapical inflammation. Arch Oral Biol. 1999;44(1):55-66.

64. Kawashima N, Suzuki N, Yang G, Ohi C, Okuhara S, Nakano-Kawanishi H, et al. Kinetics of RANKL, RANK and OPG expressions in experimentally induced rat periapical lesions. Oral Surg Oral Med Oral Pathol Oral Radiol Endod. 2007;103(5):707-11.

65. Kearns $A E$, Khosla S, Kostenuik PJ. Receptor activator of nuclear factor kappaB ligand and osteoprotegerin regulation of bone remodeling in health and disease. Endocr Rev. 2008;29(2):155-92.

66. Kim JW, Tatad JC, Landayan ME, Kim SJ, Kim MR. Animal model for medication-related osteonecrosis of the jaw with precedent metabolic bone disease. Bone. 2015;81:442-8.

67. Kim MK, Kim HD, Park JH, Lim JI, Yang JS, Kwak WY, et al. An orally active cathepsin K inhibitor, furan-2-carboxylic acid, 1-\{1-[4-fluoro-2-(2-oxo-pyrrolidin-1-yl)-phenyl]-3oxo-piperidin-4-ylcarbamoyl\}-c yclohexyl)-amide (OST-4077), inhibits osteoclast activity in vitro and bone loss in ovariectomized rats. J Pharmacol Exp Ther. 2006;318(2):55562. 
68. Krum SA, Miranda-Carboni GA, Hauschka PV, Carroll JS, Lane TF, Freedman LP, et al. Estrogen protects bone by inducing Fas ligand in osteoblasts to regulate osteoclast survival. Embo j. 2008;27(3):535-45.

69. Lane N, Armitage GC, Loomer P, Hsieh S, Majumdar S, Wang HY, et al. Bisphosphonate therapy improves the outcome of conventional periodontal treatment: results of a 12-month, randomized, placebo-controlled study. J Periodontol. 2005;76(7):1113-22.

70. Li J, Liao EY, Dai RC, Wei QY, Luo XH. Effects of 17 beta-estradiol on the expression of interstitial collagenases-8 and -13 (MMP-8 and MMP-13) and tissue inhibitor of metalloproteinase-1 (TIMP-1) in ovariectomized rat osteoblastic cells. J Mol Histol. 2004;35(8-9):723-31.

71. Liu S, Cheng Y, Xu W, Bian Z. Protective effects of follicle-stimulating hormone inhibitor on alveolar bone loss resulting from experimental periapical lesions in ovariectomized rats. J Endod. 2010;36(4):658-63.

72. Liu XL, Li CL, Lu WW, Cai WX, Zheng LW. Skeletal site-specific response to ovariectomy in a rat model: change in bone density and microarchitecture. Clin Oral Implants Res. 2015;26(4):392-8.

73. Llavaneras A, Ramamurthy NS, Heikkila P, Teronen O, Salo T, Rifkin BR, et al. A combination of a chemically modified doxycycline and a bisphosphonate synergistically inhibits endotoxin-induced periodontal breakdown in rats. J Periodontol. 2001;72(8):1069-77.

74. Lopez-Lopez J, Castellanos-Cosano L, Estrugo-Devesa A, Gomez-Vaquero C, VelascoOrtega $\mathrm{E}$, Segura-Egea JJ. Radiolucent periapical lesions and bone mineral density in post-menopausal women. Gerodontology. 2015;32(3):195-201.

75. Lu Y, Jin L, Lei G, Fu Y, Wang Y, Yu J. Estrogen-mediated dental tissue regeneration. Histol Histopathol. 2016;31(12):1281-9.

76. Lucisano MP, Nelson-Filho P, Morse L, Battaglino R, Watanabe PC, Silva RA, et al. Radiodensitometric and DXA analyses for the measurement of bone mineral density after systemic alendronate therapy. Braz Oral Res. 2013;27(3):252-7.

77. Luo Y, Zhang L, Wang WY, Hu QF, Song HP, Su YL, et al. Alendronate retards the progression of lumbar intervertebral disc degeneration in ovariectomized rats. Bone. 2013;55(2):439-48.

78. Manolagas SC. Birth and death of bone cells: basic regulatory mechanisms and implications for the pathogenesis and treatment of osteoporosis. Endocr Rev. 2000;21(2):115-37.

79. Marrani E, Giani T, Simonini G, Cimaz R. Pediatric Osteoporosis: Diagnosis and Treatment Considerations. Drugs. 2017;77(6):679-95.

80. Martin-Millan M, Almeida M, Ambrogini E, Han L, Zhao H, Weinstein RS, et al. The estrogen receptor-alpha in osteoclasts mediates the protective effects of estrogens on cancellous but not cortical bone. Mol Endocrinol. 2010;24(2):323-34. 
81. Masarachia PJ, Pennypacker BL, Pickarski M, Scott KR, Wesolowski GA, Smith SY, et al. Odanacatib reduces bone turnover and increases bone mass in the lumbar spine of skeletally mature ovariectomized rhesus monkeys. J Bone Miner Res. 2012;27(3):50923.

82. Mathavan $\mathrm{N}$, Turunen $\mathrm{MJ}$, Tagil $\mathrm{M}$, Isaksson $\mathrm{H}$. Characterising bone material composition and structure in the ovariectomized (OVX) rat model of osteoporosis. Calcif Tissue Int. 2015;97(2):134-44.

83. Matsui H, Yamasaki M, Nakata K, Amano K, Nakamura H. Expression of MMP-8 and MMP-13 in the development of periradicular lesions. Int Endod J. 2011;44(8):739-45.

84. Michael $\mathrm{H}$, Harkonen $\mathrm{PL}$, Vaananen HK, Hentunen TA. Estrogen and testosterone use different cellular pathways to inhibit osteoclastogenesis and bone resorption. J Bone Miner Res. 2005;20(12):2224-32.

85. Muschitz C, Kocijan R, Fahrleitner-Pammer A, Pavo I, Haschka J, Schima W, et al. Overlapping and continued alendronate or raloxifene administration in patients on teriparatide: effects on areal and volumetric bone mineral density--the CONFORS Study. J Bone Miner Res. 2014;29(8):1777-85.

86. Nair PN. Pathogenesis of apical periodontitis and the causes of endodontic failures. Crit Rev Oral Biol Med. 2004;15(6):348-81.

87. Nelson-Filho P, Lucisano MP, Da Silva RA, Da Silva RS, Serra MC, Gerlach RF, et al. Systemically alendronate was incorporated into dental tissues but did not cause morphological or mechanical changes in rats teeth. Microsc Res Tech. 2012;75(9):1265-71.

88. Ochi Y, Yamada H, Mori H, Kawada N, Kayasuga R, Nakanishi Y, et al. ONO-5334, a cathepsin $\mathrm{K}$ inhibitor, improves bone strength by preferentially increasing cortical bone mass in ovariectomized rats. J Bone Miner Metab. 2014;32(6):645-52.

89. Orajarvi M, Hirvonen O, Yu SB, Liu X, Tiilikainen P, Wang M, et al. Effect of estrogen and altered diet hardness on the expression of estrogen receptor alpha and matrix metalloproteinase-8 in rat condylar cartilage. J Orofac Pain. 2011;25(3):261-8.

90. Orrico SR, Goncalves D, Galeazzi ST, Giro G, Takayama L, Pereira RM. The influence of loss of bone mass on induced periodontal disease: a radiographic and densitometric study of female rats. J Periodontol. 2005;76(9):1436-42.

91. Pacifici R. Estrogen, cytokines, and pathogenesis of postmenopausal osteoporosis. J Bone Miner Res. 1996;11(8):1043-51.

92. Patullo IM, Takayama L, Patullo RF, Jorgetti V, Pereira RM. Influence of ovariectomy and masticatory hypofunction on mandibular bone remodeling. Oral Dis. 2009;15(8):580-6.

93. Peng ZQ, Vaananen HK, Zhang HX, Tuukkanen J. Long-term effects of ovariectomy on the mechanical properties and chemical composition of rat bone. Bone. 1997;20(3):207-12. 
94. Reginster JY, Neuprez A, Beaudart C, Lecart MP, Sarlet N, Bernard D, et al. Antiresorptive drugs beyond bisphosphonates and selective oestrogen receptor modulators for the management of postmenopausal osteoporosis. Drugs Aging. 2014;31(6):413-24.

95. Riggs $B L$, Khosla $\mathrm{S}$, Melton $\mathrm{L}$, 3rd. A unitary model for involutional osteoporosis: estrogen deficiency causes both type I and type II osteoporosis in postmenopausal women and contributes to bone loss in aging men. J Bone Miner Res. 1998;13(5):76373.

96. Rogers MJ, Crockett JC, Coxon FP, Monkkonen J. Biochemical and molecular mechanisms of action of bisphosphonates. Bone. 2011;49(1):34-41.

97. Rogers NH, Perfield JW, 2nd, Strissel KJ, Obin MS, Greenberg AS. Reduced energy expenditure and increased inflammation are early events in the development of ovariectomy-induced obesity. Endocrinology. 2009;150(5):2161-8.

98. Russell RG. Bisphosphonates: mode of action and pharmacology. Pediatrics. 2007;119 Suppl 2:S150-62.

99. Santamaria M, Jr., Fracalossi AC, Consolaro MF, Consolaro A. Influence of bisphosphonates on alveolar bone density: a histomorphometric analysis. Braz Oral Res. 2010;24(3):309-15.

100. Saraff V, Hogler W. Endocrinology and adolescence: Osteoporosis in children: diagnosis and management. Eur J Endocrinol. 2015;173(6):R185-97.

101. Schett G. Effects of inflammatory and anti-inflammatory cytokines on the bone. Eur J Clin Invest. 2011;41(12):1361-6.

102. Seedor JG, Quartuccio HA, Thompson DD. The bisphosphonate alendronate (MK-217) inhibits bone loss due to ovariectomy in rats. J Bone Miner Res. 1991;6(4):339-46.

103. Seymour GJ, Gemmell E. Cytokines in periodontal disease: where to from here? Acta Odontol Scand. 2001;59(3):167-73.

104. Silva MJ, Kajiya M, AlShwaimi E, Sasaki H, Hong J, Ok P, et al. Bacteria-reactive immune response may induce RANKL-expressing $T$ cells in the mouse periapical bone loss lesion. J Endod. 2012;38(3):346-50.

105. Silva TA, Garlet GP, Fukada SY, Silva JS, Cunha FQ. Chemokines in oral inflammatory diseases: apical periodontitis and periodontal disease. J Dent Res. 2007;86(4):306-19.

106. Socransky SS, Smith C, Martin L, Paster BJ, Dewhirst FE, Levin AE. "Checkerboard" DNA-DNA hybridization. Biotechniques. 1994;17(4):788-92.

107. Song $H$, Luo $Y$, Wang W, Li S, Yang $K$, Dai M, et al. Effects of alendronate on lumbar intervertebral disc degeneration with bone loss in ovariectomized rats. Spine J. 2017.

108. Song M, Alshaikh A, Kim T, Kim S, Dang M, Mehrazarin S, et al. Preexisting Periapical Inflammatory Condition Exacerbates Tooth Extraction-induced Bisphosphonate-related Osteonecrosis of the Jaw Lesions in Mice. J Endod. 2016;42(11):1641-6. 
109. Stashenko P, Yu SM, Wang CY. Kinetics of immune cell and bone resorptive responses to endodontic infections. J Endod. 1992;18(9):422-6.

110. Sugimoto M, Futaki N, Harada M, Kaku S. Effects of combined treatment with eldecalcitol and alendronate on bone mass, mechanical properties, and bone histomorphometry in ovariectomized rats: a comparison with alfacalcidol and alendronate. Bone. 2013;52(1):181-8.

111. Suzuki N, Takimoto K, Kawashima N. Cathepsin K Inhibitor Regulates Inflammation and Bone Destruction in Experimentally Induced Rat Periapical Lesions. J Endod. 2015;41(9):1474-9.

112. Tabatabaei-Malazy $O$, Salari $P$, Khashayar $P$, Larijani B. New horizons in treatment of osteoporosis. Daru. 2017;25(1):2.

113. Tanaka M, Ejiri S, Toyooka E, Kohno S, Ozawa H. Effects of ovariectomy on trabecular structures of rat alveolar bone. J Periodontal Res. 2002;37(2):161-5.

114. Tanoue R, Koi K, Yamashita J. Effect of Alendronate on Bone Formation during Tooth Extraction Wound Healing. J Dent Res. 2015;94(9):1251-8.

115. Thompson DD, Simmons HA, Pirie CM, Ke HZ. FDA Guidelines and animal models for osteoporosis. Bone. 1995;17(4 Suppl):125s-33s.

116. Tian FM, Yang K, Wang WY, Luo Y, Li SY, Song HP, et al. Calcitonin suppresses intervertebral disk degeneration and preserves lumbar vertebral bone mineral density and bone strength in ovariectomized rats. Osteoporos Int. 2015;26(12):2853-61.

117. Turner AS. Animal models of osteoporosis--necessity and limitations. Eur Cell Mater. 2001;1:66-81.

118. Wajant H, Pfeffer K, Pfizenmaier K, Scheurich P. Tumor necrosis factors in 1998. Cytokine Growth Factor Rev. 1998;9(3-4):297-302.

119. Walsh MC, Kim N, Kadono Y, Rho J, Lee SY, Lorenzo J, et al. Osteoimmunology: interplay between the immune system and bone metabolism. Annu Rev Immunol. 2006;24:33-63.

120. Wayama MT, Yoshimura H, Ohba S, Yoshida H, Matsuda S, Kobayashi J, et al. Diminished Progression of Periapical Lesions with Zoledronic Acid in Ovariectomized Rats. J Endod. 2015;41(12):2002-7.

121. Wei S, Kawashima N, Suzuki N, Xu J, Takahashi S, Zhou M, et al. Kinetics of Th17related cytokine expression in experimentally induced rat periapical lesions. Aust Endod J. 2013;39(3):164-70.

122. Wei XX, Chu JP, Zou YZ, Ru N, Cui SX, Bai YX. Effect of odanacatib on root resorption and alveolar bone metabolism during orthodontic tooth movement. Genet Mol Res. 2015;14(4):17972-81.

123. Weitzmann MN, Pacifici R. Estrogen deficiency and bone loss: an inflammatory tale. J Clin Invest. 2006;116(5):1186-94. 
124. Xiong $H$, Peng B, Wei L, Zhang X, Wang L. Effect of an estrogen-deficient state and alendronate therapy on bone loss resulting from experimental periapical lesions in rats. J Endod. 2007;33(11):1304-8.

125. Xiong $\mathrm{H}$, Wei $\mathrm{L}$, Hu $\mathrm{Y}$, Zhang $\mathrm{C}$, Peng B. Effect of alendronate on alveolar bone resorption and angiogenesis in rats with experimental periapical lesions. Int Endod $\mathrm{J}$. 2010;43(6):485-91.

126. Yang $\mathrm{W}, \mathrm{Ko} \mathrm{H}, \mathrm{Kim} \mathrm{H}$, Kim M. The effect of cathepsin $\mathrm{K}$ inhibitor on osteoclastic activity compared to alendronate and enamel matrix protein. Dent Traumatol. 2015;31(3):2028.

127. Ying G, Bo L, Yanjun J, Lina W, Binquan W. Effect of a local, one time, low-dose injection of zoledronic acid on titanium implant osseointegration in ovariectomized rats. Arch Med Sci. 2016;12(5):941-9.

128. Zhang H, Bain JL, Caskey CP, Sandifer LC, Johnson RB. Effects of gender on serum biomarkers of systemic inflammation coincident to experimentally-induced periapical lesions. Arch Oral Biol. 2011;56(2):168-76.

129. Zhu L, Brown WC, Cai Q, Krust A, Chambon P, McGuinness OP, et al. Estrogen treatment after ovariectomy protects against fatty liver and may improve pathwayselective insulin resistance. Diabetes. 2013;62(2):424-34.

130. Zupan J, Jeras M, Marc J. Osteoimmunology and the influence of pro-inflammatory cytokines on osteoclasts. Biochem Med (Zagreb). 2013;23(1):43-63. 
Anexo 

Anexo A - Aprovação do Projeto pela Comissão de Ética no Uso de Animais

\begin{tabular}{|c|c|}
\hline 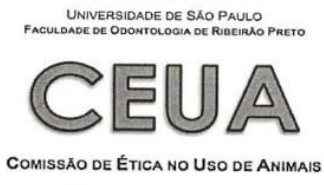 & 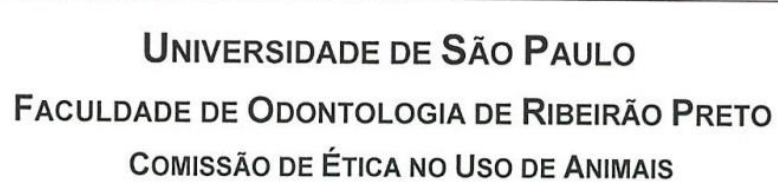 \\
\hline
\end{tabular}

\section{CeRTIFICAdo CEUA - FORP/USP}

Certificamos que o Protocolo $n^{\circ} 2013.1 .1404 .58 .4$ sobre a pesquisa intitulada “AVALIAÇÃO DE LESÕES PERIAPICAIS INDUZIDAS EM RATAS OSTEOPORÓTICAS SUBMETIDAS OU NÃO AO TRATAMENTO COM ALENDRONATO", sob a responsabilidade do Prof. Dr. Paulo Nelson Filho, está de acordo com os Princípios Éticos na Experimentação Animal adotados pela Comissão de Ética no Uso de Animais da Faculdade de Odontologia de Ribeirão Preto, USP, foi APROVADO em reunião da CEUA de 19/03/2014 (totalizando 48 animais).

We certify that the protocol $n^{\circ} 2013.1 .1404 .58 .4$ about the research entitled "EVALUATION OF INDUCED APLICAL PERIODONTITIS IN OSTEOPOROTIC RATS SUBMITTED OR NOT TO TREATMENT WITH ALENDRONATE", under responsibility of Prof. Dr. Paulo Nelson Filho, is in accordance with the Ethical principles in animal research adopted by the Animal Research Ethics Committee of the School of Dentistry of Ribeirão Preto, University of São Paulo, Brazil was approved in 19/03/2014 (totalizing 48 animals).

Ribeirão Preto, 19 de março de 2014.

Profa. Dra. Andiara De Rossi Daldegan

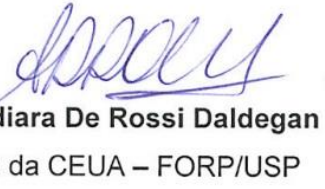

CEUA - FORP/US P 

Apêndice 



\section{Apêndice A - Principais Resultados Obtidos até o Presente Momento, REFERENTES À TESE DE DOUTORADO}

Apoio financeiro da Fundação de Amparo à Pesquisa do Estado de São Paulo

Processo FAPESP no 2013/18231-9 - Auxílio Regular.

Processo FAPESP no 2014/13238-8 - Bolsa de Doutorado.

\section{$\underline{\text { Trabalhos enviados para publicação em periódicos internacionais }}$}

Romualdo PC, Cunha NBFF, Leoni GB, Sousa-Neto MD, Silva RAB, Silva LAB, Nelson-Filho P. Microarchitecture and bone mineral density in long and maxillary bones of ovariectomized rats subjected or not to treatment with bisphosphonate or a cathepsin $\mathrm{K}$ inhibitor, trabalho enviado ao Clinical Oral Investigations.

Romualdo PC, Lucisano MP, Paula-Silva FWG, Leoni GB, Sousa-Neto MD, Silva RAB, Silva $L A B$, Nelson-Filho P. Ovariectomy exacerbates apical periodontitis in rats with increase in expression of proinflammatory cytokines and matrix metalloproteinases. Trabalho enviado ao Journal of Endodontics.

Apresentações de trabalho, com resumos publicados em anais de congresso

Romualdo PC, Lucisano MP, Paula-Silva FWG, Silva RAB, Silva LAB, Queiroz AM, Nelson-Filho $P$. Ovariectomy exacerbates expression of proinflamatory cytokines and matrix metalloproteinases in apical periodontitis in rats. In: World Congress on Osteoporosis, Osteoarthritis and Musculoskeletal Diseases, 2016, Málaga. Osteoporosis International, 2016. v. 27. p. S196-S197.

Romualdo PC, Cunha NBFF, Leoni GB, Sousa-Neto MD, Silva RAB, Silva LAB, Nelson-Filho P. Microarchitecture and bone mineral density in femurs and maxillae of ovariectomized rats subjected or not to treatment with bisphosphonate or a cathepsin k inhibitor. In: World Congress on Osteoporosis, Osteoarthritis and Musculoskeletal Diseases, 2017, Florence. Osteoporosis International, 2017. v. 28. p. 252.

Prêmios

2016 - ESCEO-Eli Lilly Scholarship, European Society for Clinical and Economic Aspects of Osteoporosis, Osteoarthritis and Musculoskeletal Diseases.

2017 - ESCEO-Eli Lilly Scholarship, European Society for Clinical and Economic Aspects of Osteoporosis, Osteoarthritis and Musculoskeletal Diseases. 